\title{
LAS DAGAS DEL EJÉRCITO ALTOIMPERIAL EN HISPANIA
}

\author{
DAGGERS OF THE HIGH ROMAN EMPIRE ARMY IN HISPANIA
}

POR

\author{
CARMElo Fernández IbÁÑEZ*
}

\section{Resumen - Abstract}

Este trabajo aborda el primer análisis diacrónico sobre las dagas en el ejército romano de ocupación en Hispania (España y Portugal) a través de las cincuenta y siete muestras hasta ahora conocidas, más un número inferior (ocho) de restos de sus fundas, desde el fin del siglo I a.C. al siglo III d.C., sin que posteriormente hayan sido encontrados por ahora más restos. Aunque sin desviarse demasiado de las corrientes que en cada momento imponía el gusto, tras las guerras de conquista las producciones del territorio peninsular sensiblemente no coincidieron con las de la vasta área del Limes, que estaría a la vanguardia. En lo que a dagas se refiere la primera centuria no tiene precedentes ni tendrá continuidad.

This paper is the first diachronic study of daggers in the Roman Army of occupation in Hispania (Spain and Portugal), dated between the $1^{\text {st }}$ century BC and the $3^{\text {rd }}$ century AD. The fifty seven specimens that are currently known are analysed, together with a smaller number (eight) of the remains of their sheaths, as no further examples have been found subsequently. After the wars of conquest, although they did not vary too far from the fashions that were in favour at any time, the products in the Iberian Peninsula were noticeably different from those in the vast area of the Limes, which was in the vanguard. The daggers of the first century had neither precedents nor continuity.

\section{Palabras Clave - Keywords}

Alto Imperio; daga; militaria; pugio.

Dagger; Early Roman Empire; Militaria; Pugio.

\section{INTRODUCCIÓN}

El estudio de las armas de la antigüedad es un tema verdaderamente apasionante. Los investigadores por múltiples razones siempre hemos tenido predilección por algunas en concreto, siendo las dagas de la cultura material romana una de las más populares y atractivas. Pese a lo cual es curioso constatar lo escaso en su conocimiento, que destaca de manera diferencial según las actuales zonas geográficas donde hacen acto de presencia. Generalmente, en aquellas regiones que estuvieron más militarizadas en función del número de tropas entonces presentes, del tiempo de su permanencia de la zona en conflicto, y del valor y símbolo que tuvieron en la antigüedad; y en la actualidad, a nivel de su conocimiento e identificación como tales. Y como no podría ser de otra manera, del contexto y las circunstancias en que se ha producido su hallazgo, así como del estado de conservación en que las materias constituyentes han permitido

\footnotetext{
* Museo de Palencia e Instituto «Sautuola» de Prehistoria y Arqueología (Santander) 〈carmelofdez@ono.com».
} 
su permanencia. De ahí se deriva por lo tanto el grado de información histórico-tecnológica que pudiera inferirse.

Esto último ha sido particularmente evidente en la Península Ibérica. La exigua dedicación hasta hace unos años por los estudios de arqueología militar, unidos al escaso interés (este de tipo más general) por la metalistería, hizo de la armamentaria ya no solamente un aspecto desconocido, sino particularmente equívoco en las evidencias que creían haberse identificado. Las dagas - para nuestro caso concreto - fueron buena prueba de ello. En el momento que procedimos a reunir los hallazgos, contrastar los datos e identificar nuevos objetos aproximadamente se habían publicado desde principios del siglo XX una quincena de ejemplares, de los cuales diez estaban defectuosamente clasificados; generalmente, como armas indígenas de la II Edad del Hierro. Para el estudio que aquí desarrollamos, y junto a aquellas, hemos conseguido reunir un total de 57 dagas y al menos 8 fundas o vainas, que se distribuyen a lo largo de aproximadamente unos 350 años. Estamos más que seguros que aún quedan muchos más restos en los almacenes de los museos peninsulares, a la espera de ser identificados y convenientemente publicados.

Visto así la proporción resulta exigua, máxime cuando el volumen de información aportado es muy desigual debido a las circunstancias en que se han producido los hallazgos, y también el volumen de materia implicada que ha llegado hasta nosotros. Pero no deja de ser una problemática idéntica a otro tipo de estudios que se encuentran todavía a la espera de que sean iniciados. Aún queda mucho por estudiar y por descubrir, pero el panorama que ahora nos proponemos desplegar acerca de las armas blancas del ejército de Roma, máxime en el territorio donde estas tuvieron su origen, se mostraba prácticamente yermo para la investigación. Una realidad que como se comprobará es bien diferente.

\section{CUESTIONES GENERALES SOBRE LAS DAGAS EN EL EJÉRCITO DE ROMA}

El puñal romano parece tener su origen a finales del siglo I a.C. a partir de las dagas dobleglobulares que utilizaban las tropas indígenas celtiberas en Hispania desde finales del siglo

IV a.C. Conocemos exiguos datos materiales sobre posibles tipos intermedios. Su presencia en el ejército de forma reglamentaria parece ser que tuvo lugar más o menos coincidiendo con el ascenso de Augusto al poder imperial, y más en concreto con la reforma que este personaje llevó a cabo en la estructura de su ejército. Siendo quizás ocasional su utilización y tal vez solo por soldados con cierto rango según nos muestra el centurión Minvcivs representado en la estela de Padova.

Los puñales del primer siglo d.C. en Europa eran armas muy vistosas con una longitud aproximada entre 180 y $360 \mathrm{~mm}$ por término medio. Poseían una hoja con delineación en forma de «S» más o menos acusada que finalizaba en una aguda punta, variando su longitud entre los 160 y los $265 \mathrm{~mm}$. Las caras podían presentar diferentes topografías: con un nervio central convexo más o menos marcado (a veces enmarcado mediante pequeñas acanaladuras a ambos lados de este), a veces hasta tres en paralelo, o bien, una o varias aristas conformadas por la disposición también paralela de varios surcos. La anchura oscilaba aproximadamente entre los 31 a $35 \mathrm{~mm}$ en los ejemplares más estrechos y los 45 a $60 \mathrm{~mm}$ en las hojas más anchas. La empuñadura resulta un elemento característico y distintivo, y cuya técnica de fabricación nuevamente fue heredada de los puñales indígenas doblegloburales celtibéricos de Hispania. $\mathrm{Su}$ longitud variaba entre los 80 y $100 \mathrm{~mm}$ con las cachas fabricadas en hierro y decoradas en superficie mediante nielados de plata que representaban figuras geométricas. Tenían forma de «T» invertida, cuya caña central adquiría sección en «V». El pomo característico de este siglo 
tenía forma de «D» invertida, mostrando dos remaches con cabezas decorativas en su frente y tres en el plano superior. Bajo las cachas se colocaban sendos elementos orgánicos de madera o hueso sobre cada lado de un espigo plano, por el cual se prolongaba la base de la hoja hasta el mismo pomo y sin llegar a él. En el centro de esta empuñadura un abultamiento circular (reminiscencia nuevamente de su origen) tenía posiblemente como finalidad su mejor prehensión, evitando deslizamientos y pérdidas involuntarias debido al sudor o en su caso la sangre, dejando inerme al soldado.

La superposición de estas dos materias formaba un «sándwich» de cinco partes que actuaba como firme elemento de sustentación y manejo, permaneciendo unido con remaches cilíndricos cuyo número oscilaba entre siete y nueve, según la cruceta hubiese sido unida por tres o cuatro de estos. Al exterior, buscando un efecto decorativo en el pomo y los extremos de las crucetas, las cabezas eran abultadas semiesferas, y en el resto eran pulidos y quedaban enrasados con la superficie disimulándolos. Estas empuñaduras deberían de ser muy proclives a las fracturas y los desarreglos, de ahí que quizás aparezcan tantas empuñaduras sueltas (completas o elementos sueltos - cachas-), o bien hojas de daga sin ellas.

Tal y como muestran las estelas funerarias de soldados del limes europeo, la daga la llevaba suspendida el soldado romano de un cinturón independiente en el costado izquierdo. La hoja estaba protegida en el interior de una funda o vaina, normalmente de hierro, aunque también en aleación de cobre, adaptándose las formas a la hoja de la daga. Su estructura va cambiando con el paso de los años. De tal manera que a los sencillos modelos lisos o bien con una estructura calada, les siguen los de una rica decoración esmaltada en colores y/o también embutida con nieles de plata o latón. De estas últimas las piezas más admirables son aquellas que han sido halladas en conjuntos fechados entre la mitad y el tercer cuarto del siglo I d.C. Estaban construidas de madera forrada de cuero y revestida por la estructura metálica, o bien recortadas en láminas de aleación de cobre con un revestimiento interior también de madera. También se conocen fundas de madera a cuya cara exterior se unía una placa metálica decorada con el mismo perfil. Los motivos decorativos estaban constituidos por temas religiosos, geométricos, simbólicos o civiles, distribuidos en cuatro registros verticales y a lo largo de la cara anterior que era la que quedaba a la vista del espectador. Remataba el extremo inferior un elemento plano y circular (buterola). Las fundas permanecían fijas al tahalí del cinturón por medio de tiras de cuero unidas a las dos anillas superiores, de las cuatro que permanecían suspendidas en los laterales; dos a cada lado.

La daga no desaparece al menos en las dos centurias siguientes, aunque sí se ven reducidas de forma ostensible entre el armamento militar hasta, quizás, llegar a desaparecer a partir del siglo III d.C., ya que los hallazgos de Künzing aún siguen siendo las dagas más modernas que conocemos. La desigual concentración de los hallazgos (buena parte procedentes de este último lugar), no demasiado numerosos, aportan reducidas características e impiden hacer sobradas consideraciones. Las dagas pierden esa «cierta uniformidad» que se percibía en el siglo precedente. Se aprecia un buen número de grandes hojas con nervio central que pueden llegar a medir más de $40 \mathrm{~cm}$ (más bien una espada corta), donde lo más particular suele ser la empuñadura, y en ella el pomo con la característica muesca en la parte superior, que despeja dos áreas lobulares que suelen apuntarse. Las vainas son de lámina calada al estilo de las vistas en los orígenes de esta arma que recubre un forro de materia orgánica. 


\section{CATÁLOGO DE DAGAS Y FUNDAS DE LA PENÍNSULA IBÉRICA}

Este catálogo descriptivo se ha organizado en primer lugar en dos grandes apartados: dagas y vainas. Dentro de cada uno de ellos, por países (comenzando por el que cuenta con un mayor número de ejemplares), distribuyéndose (y numerándose) los hallazgos por zonas geográficas.

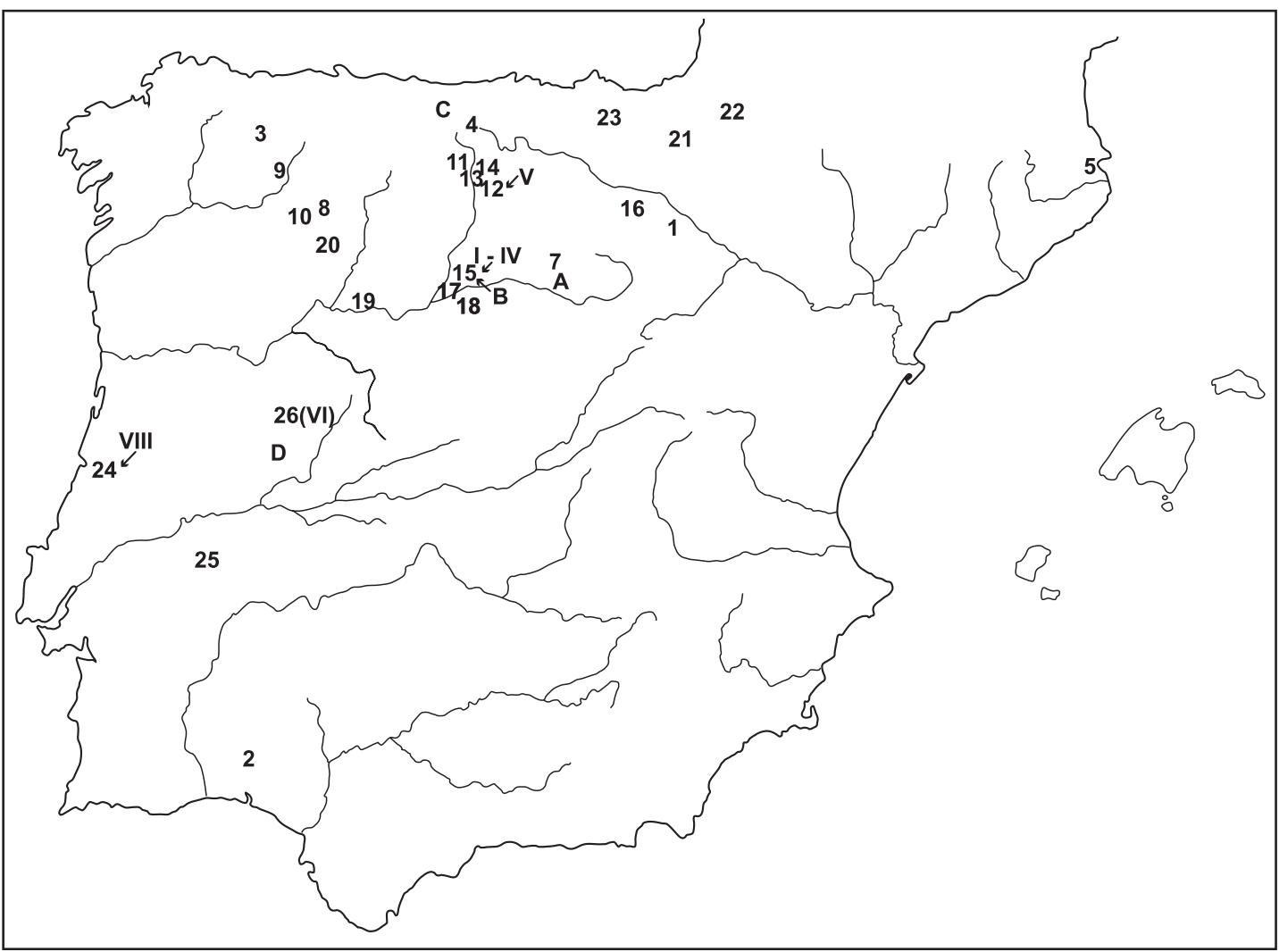

Figura 1. Situación geográfica de cada uno de los hallazgos de dagas y fundas imperiales romanas en la Península Ibérica citadas en el texto. Los números arábigos corresponden a las dagas, los romanos a las fundas, y las letras a otro tipo de materias y representaciones.

\section{DAGAS}

\section{ESPAÑA}

\section{Comunidad Autónoma de Aragón}

— Provincia de Zaragoza

- Arcobriga (Monreal de Ariza) (fig. 1.1)

1) Hoja de daga en hierro. Delineación pistiliforme debido a la estrechez de su cintura. Conserva restos de nervio central y carece de espigo, que debió ser plano. Se encuentra muy engrosada debido a su actual estado de alteración, muy oxidado y deformado (fig. 15.1). 
Dimensiones: $213 \mathrm{~mm}$ de longitud, 56,6 $\mathrm{mm}$ de anchura máxima (41 $\mathrm{mm}$ mínima en la cintura) y $39 \mathrm{~mm}$ de grosor. Se custodia en el Museo Arqueológico Nacional de Madrid.

Contexto: antiguas excavaciones de J. Cabré.

2) Fragmento de hoja de daga en hierro, carente de espigo (que debió ser plano) y punta. Los filos son rectos y ligeramente oblicuos hacia el extremo inferior, nervio central y en la cruceta restos de apéndices laterales (fig. 15.7).

Dimensiones: longitud $164 \mathrm{~mm}$, anchura 53,1 mm, grosor $11,2 \mathrm{~mm}$. Se custodia en el Museo Arqueológico Nacional.

Contexto: antiguas excavaciones de J. Cabré.

3) Fragmento central de hoja de daga en hierro con nervio central (fig. 15.3).

Dimensiones: longitud 96,7 mm, anchura 50,7 mm, grosor $7 \mathrm{~mm}$. Se custodia en el Museo Arqueológico Nacional.

Contexto: antiguas excavaciones de J. Cabré.

4) Tres extremos apuntados de daga en hierro. Sección aplanada (fig. 15.2, 4, 5).

Dimensiones: longitud 54,6 $\mathrm{mm}$, anchura $34,6 \mathrm{~mm}$, grosor $5,9 \mathrm{~mm}$; longitud $72,8 \mathrm{~mm}$, anchura $30 \mathrm{~mm}$, grosor 10,7 mm; Dimensiones: longitud 92,2 $\mathrm{mm}$, anchura $40 \mathrm{~mm}$, grosor 9,3 mm. Se custodian en el Museo Arqueológico Nacional.

Contexto: antiguas excavaciones de J. Cabré.

5) Dos fragmentos del tercio superior de hoja con el inicio de la espiga. Uno de ellos tiene sección biconvexa (fig. 15.6) y el otro nervio central convexo y dos perforaciones en los hombros (fig. 15.8).

Dimensiones: longitud 94,8 mm, anchura 49,8 mm, grosor 12,1 mm / Longitud 121,2 mm, anchura $59 \mathrm{~mm}$, grosor $11 \mathrm{~mm}$. Se custodian en el Museo Arqueológico Nacional.

Contexto: antiguas excavaciones de J. Cabré.

6) Hoja de puñal de sección biconvexa, carente del extremo apuntado. Los restos de la cruceta conservan el inicio de la empuñadura de estructura metálica tripartita (fig. 15.9).

Dimensiones: longitud $115 \mathrm{~mm}$, anchura $37,3 \mathrm{~mm}$, grosor $10,9 \mathrm{~mm}$. Se custodia en el Museo Arqueológico Nacional.

Contexto: antiguas excavaciones de J. Cabré.

\section{Comunidad Autónoma de Andalucía}

— Provincia de Huelva

- Aroche (fig. 1.2)

7) Presenta una larga hoja con nervio central, cuyos filos sinuosos en la primera mitad confluyen en una aguda apunta. El extremo opuesto se prolonga en un espigo plano, no sin antes crear a izquierda y derecha sendos apéndices. Este constituye el alma de la empuñadura. Esta se encuentra formada por cinco elementos unidos entre sí mediante al menos otros cinco remaches, dos de los cuales unen las crucetas: las cachas, de sección triangular con leve abultamiento central y pomo con depresión central forman un doble lóbulo, se sobreponen a sendas laminillas que actúan de elemento separador entre los anteriores elementos del apéndice central ya visto (fig. 32 ).

Dimensiones: $377 \mathrm{~mm}$ de longitud total, de los cuales $274 \mathrm{~mm}$ corresponden a la hoja (con $57,6 \mathrm{~mm}$ de anchura máxima) y $103 \mathrm{~mm}$ a la empuñadura. Se custodia en el Museo de Cádiz (Quesada, 2000: 101; 2008: 239). 
Contexto: se desconoce. Hallada en 1908 y donada por Pelayo Quintero Atauri al Museo de Cádiz (N. ${ }^{\circ}$ Inv. 5085) ${ }^{1}$.

\section{Comunidad Autónoma de Asturias}

- Monte Castrelo (Grandas de Salime) (fig. 1.3)

8) Daga de hierro. Arma recientemente descubierta y por el momento parcialmente publicada. Carece de los extremos de la cruceta y los hombros. Consta de una hoja estrecha de filos sinuosos y nervadura central. La empuñadura parece ser una estructura de triple componente: a la lámina o pedicelo de la hoja se superponen en anverso y reverso las cachas metálicas en forma de «T» invertida y sección en «V», con engrosamiento circular en el centro y pomo en forma de «D» invertida en el extremo. Todo ello queda unido por tres remaches (lám. III).

Dimensiones: longitud total $284 \mathrm{~mm}$, longitud de la hoja $177 \mathrm{~mm}$, anchura de la hoja $49 \mathrm{~mm}$. Se custodia en el Museo Monográfico del castro de Chao San Martín (Grandas de Salime, Asturias) (Fernández Ibáñez, 2006b: 288; 2007; Villa Valdés, 2003: 131-132; 2007: 42, lám. 12).

Contexto: pequeño castro minero cuyos orígenes se remontan al siglo IV a.C. En época romana la ocupación se establece en la segunda mitad de siglo I d.C., albergando una población cuya actividad principal se ha relacionado con el mantenimiento de la red hidráulica que abastecía a las minas de Valabilleiro. El hallazgo de un conjunto de armas entre las que se encuentra el puñal (fechado a finales del siglo I d.C.) pone a los excavadores sobre la pista de la presencia de un pequeño contingente militar, cuyas labores estarían relacionadas con el control, la vigilancia y el fisco a raíz del hallazgo de una tabula censitaria.

\section{Comunidad Autónoma de Cantabria}

- Llanura de Bolmir (fig. 1.4)

9) Daga de hierro. Estilizada hoja de sección biconvexa cuyos sinuosos bordes conforman un agudo extremo. Solo el anverso conserva hasta cinco nerviaciones (planta) o cúspides (sección). En la parte superior desarrolla una lámina plana (espigo) que es abrazada por anverso y reverso mediante un par de cachas en forma en «T» invertida y sección en «V», más dos láminas bajo ellas con la misma forma; con todo lo cual se organiza en la empuñadura esta estructura metálica quíntuple. Esta presenta un pomo en forma de «U», cuyo anverso conserva parte de una gráfila decorativa de semiesferas. En la parte media hay un engrosamiento triangular con motivo antideslizante, y finalmente la cruceta plana. Tanto en el engrosamiento central como a los extremos de la cruceta, la estructura de la empuñadura queda asegurada mediante remaches (fig. 34).

Dimensiones: longitud total $270 \mathrm{~mm}$, longitud de la hoja $172 \mathrm{~mm}$, longitud de la empuñadura $98 \mathrm{~mm}$, anchura de la hoja $34 \mathrm{~mm}$. Se custodia en el Museo Regional de Prehistoria y Arqueología de Cantabria en Santander (Fernández Ibáñez, 1999c; 2004: 210; 2006b: 294; 2007; e.p.; García y Bellido, 1963: 200-201).

Contexto: se desconoce.

\footnotetext{
1 Este ejemplar forma parte del Proyecto P.B.97/0057, dirigido por el profesor Fernando Quesada Sanz, miembro del Departamento de Arqueología de la Universidad Autónoma de Madrid.
} 


\section{Comunidad Autónoma de Cataluña}

— Provincia de Girona

- Tolegassos (Viladamat) (fig. 1.5)

10) Hoja de daga en hierro con una arista central que le confiere sección losángica. La base se amplía en dos cortos apéndices laterales a los que se superpone un guardapuños o cruceta con formas curvas en hueso o marfil, quedando unido al metal por dos pasadores remachados (fig. 37) (lám. VII).

Dimensiones: longitud $125 \mathrm{~mm}$. Se custodia en el Museo de Girona (Casas i Genover, 1989: 261 y fig. 62.2; Casas Genover y Soler Fusté, 2003: 253 y fig. 174.16).

Contexto: villa que forma parte de un conjunto de establecimientos con economía básica de autoabastecimiento y carácter eminentemente agropecuario, establecida en los alrededores de la ciudad de Ampurias. Erigida en la segunda mitad del siglo II a.C., tuvo cuatro fases de ocupación, basadas en ampliaciones y reacondicionamientos del edificio hasta mediados del siglo IV d.C. La daga fue hallada en el área sur, que se corresponde con la Segunda Fase, de cronología difícil de asignar, pero que pudo establecerse entre finales del siglo I d.C. y sobre todo a principios del siglo II d.C. Se trata claramente de un contexto civil.

\section{Comunidad Autónoma de Castilla y León}

- Provincia de Burgos

- La Cendrera (Sotopalacios) (fig. 1.6)

11) Daga de hierro. Ancha hoja que presenta sección plana de filos levemente sinuosos y cuyas caras muestran los restos de una aparentemente tosca decoración a buril, en un trabajo posterior a la forja. Sobre las tres nerviaciones/cuatro acanaladuras se desarrollan líneas de espigas en cada cara. La empuñadura tiene una estructura quíntuple. Sobre el elemento central, que se corresponde con el espigo plano que se prolonga desde la hoja, por anverso y reverso se superponen en primer lugar sendas piezas en forma de «T» invertida y sección en «V», con leve engrosamiento central. Al extremo se sitúa el pomo en forma de «U» cerrada con dos pequeños remaches en la parte inferior. Seguidamente, sendas láminas de 0,5 $\mathrm{mm}$ de espesor y con la misma forma. La cruceta es plana y ligeramente convexa. Todo el conjunto queda asegurado por cuatro remaches a lo largo de la caña y otros tantos en la cruceta; dos a cada lado (fig. 38).

Dimensiones: longitud total $295,7 \mathrm{~mm}$, longitud de la hoja $184,2 \mathrm{~mm}$, longitud de la empuñadura 111,5 mm, anchura de la hoja $50 \mathrm{~mm}$. Se custodia en el Museo de Burgos (Abásolo Álvarez y Ruiz Vélez, 1977: 46; Fernández Ibáñez, 2004: 211; 2006b: 294; 2007; Monteverde, 1975).

Contexto: se desconoce.

- Cuesta del Burro (Castrillo de la Reina) (fig. 1.7)

12) Daga de hierro. La hoja carece de una cuarta parte (el extremo apuntado), tiene filos levemente sinuosos, nervadura central y apéndice plano hacia la parte superior. La empuñadura está formada por estructura triple. Mediante remaches circulares dos cachas en forma de «T» y sección a dos aguas quedan unidas al apéndice superior de la hoja. El pomo es oblongo sin una forma demasiado definida; en el interior se conservan cuatro restos de remaches cuyas cabezas al exterior no se conservan, tal vez decorativos en la antigüedad. La parte central está 
poco desarrollada buscando una mejor prehensión, y las crucetas son planas cuyos extremos vuelven sobre sí hasta alcanzar la cara opuesta (fig. 23).

Dimensiones: longitud total $260 \mathrm{~mm}$, longitud de la empuñadura $116 \mathrm{~mm}$, anchura de la hoja $66 \mathrm{~mm}$. Se custodia en el Museo del Monasterio de Silos (Burgos) (Esparza Arroyo, 1988: 115-116; Fernández Ibáñez, 2002: 80-81; 2004: 209; 2006b: 286; 2007).

Contexto: al ser un hallazgo realizado en el año 1948, al parecer en superficie, los datos que se conservan no son claros ni definitorios. Parece ser que en el mismo asentamiento aparecieron además de objetos metálicos de la prehistoria reciente que se clasificaron como del Bronce Final, un hacha romana y una punta de lanza ambas en hierro y una fíbula de tipo torrecilla en bronce, sigillata, etc.

— Provincia de León

- León (fig. 1.8)

13) Fragmento de daga en hierro en pésimo estado de conservación, del que se conservan unos $170 \mathrm{~mm}, 70$ de los cuales corresponden aproximadamente a la parte inferior de una hoja fragmentada, aparentemente de filos casi paralelos y, quizás, nervio central. Tras una cruceta muy alterada, la mitad de la empuñadura se conserva hasta el ensanchamiento central.

Contexto: procede de las excavaciones practicadas por la empresa Talactor S.L. en la calle San Pedro de la capital leonesa. Se trata de un vertedero en uso entre los siglos I-III d.C. y que se localizaba cercano a la Porta Principalis Sinistra del recinto campamental de la Legio VII Gemina, encontrándose contextualizado nuestro hallazgo entre finales del siglo I d.C. e inicios de la centuria siguiente. Se custodia en el Museo de León.

- La Edrada (Cacabelos) (fig. 1.9)

14) Fragmento de daga inédita en muy deficiente estado de conservación. Lo conservado está compuesto por la parte más inferior de la empuñadura con espigo plano (cachas y estructura interna de láminas) incluida la cruceta, junto a la parte superior de la hoja con filos de delineación cóncava.

Contexto: en un ambiente claramente civil con estructuras que se extienden fundamentalmente entre los siglos I-IV d.C. El material se encuentra en estudio. Se custodia en el Museo Arqueológico de Cacabelos (León).

- Castro de Corporales (Truchas) (fig. 1.10)

15) Daga en hierro. Empuñadura compuesta por los tres elementos metálicos característicos (el espigo plano no llega al pomo) unidos por tres remaches, cachas de sección en «V», engrosamiento central y restos de hueso como estructura orgánica. El pomo es oval en la actualidad con restos de dos remaches en el frente. La cruceta en una de las caras tiene como característica los restos de un elemento transversal desconocido. La hoja, carente de extremo puntiagudo, es estrecha, lisa y por lo tanto de sección biconvexa, tiene hombros oblicuos y la delineación de los filos es levemente sinuosa (fig. 17).

Dimensiones: longitud total: $289 \mathrm{~mm}$, longitud de la empuñadura: $107 \mathrm{~mm}$. Se custodia en el Museo de León (Sánchez Palencia y Fernández-Posse, 1985: 227, fig. 107, lám. XLIV).

Contexto: poblado minero cuya excavación determinó que su ocupación estuvo constituida por dos momentos, la denominada Fase I: 45/50-60/70 d.C. y la Fase II: 70/75-100/120 d.C. Fue en uno de los pequeños sondeos periféricos al área principal de excavación (más concretamente el Sondeo IIIB) y dentro de una de las estructuras de habitación donde hizo su aparición esta daga. El poco relevante material arqueológico que le acompañaba en cuanto a 
cronología se refiere, no hizo posible el poder adscribirla a ninguna de las dos fases ocupacionales establecidas.

— Provincia de Palencia

- Campamento de la Loma (Santibáñez de la Peña) (fig. 1.11)

16) Parte superior correspondiente a la zona del pomo de una daga de hierro con empuñadura de tipo biglobular. Es circular en planta y convexa en sección, con restos de reborde oblicuo hacia el interior y perforación circular en el centro. Conserva el arranque del vástago de la empuñadura a doble vertiente, con restos de la perforación para un roblón. En el punto de unión de ambas partes, muestra una característica figura triangular en relieve (fig. 4) (lám. II).

Dimensiones: longitud 41,6 mm, Ø 30,8 mm, grosor 1,5 mm. Se custodia en el Museo de Palencia (Peralta Labrador, 2007).

Contexto: según E. Peralta, director de las excavaciones, procede de una recogida superficial de objetos en el que ha sido identificado como campamento principal del asedio al castro de La Loma. Más en concreto en su ladera NW y en torno a un conjunto numismático fechable entre el 28-27 a.C.

- Herrera de Pisuerga (fig. 1.12)

\section{La Chorquilla:}

17) Empuñadura biglobular en hierro. Estructura metálica tripartita, compuesta por una lámina central plana que constituye el apéndice de la hoja, y al exterior las cachas que la cubren por ambas caras. Entre ellas sendas láminas de hueso. El conjunto queda unido como ya es conocido mediante roblones (fig. 6).

Dimensiones: longitud 100,9 mm, Ø del pomo $\pm 36 \mathrm{~mm}$. Se custodia en el Museo de Palencia (Fernández Ibáñez, 1999a: fig. 1-B; 2004: 209; Fernández Ibáñez y Cavada Nieto, 2005; Fernández Ibáñez, 2006a: 189 y 197; 2006b: fig. 3.2; 2007; García y Bellido, Fernández de Avilés y García Guinea, 1970: 19).

Contexto: La Chorquilla es una extensa y muy potente área de vertido (hasta cuatro metros de profundidad), cuyos materiales han sido allí arrojados en dos momentos diferentes. Por un lado, en el periodo comprendido entre los reinados de los emperadores Augusto y Tiberio, cuando el emplazamiento era un campamento donde se asentaba la legio IIII Macedonica. Y posteriormente, en la segunda mitad del siglo I, cuando el lugar fue transformado en castelum como acantonamiento de tropas auxiliares.

18) Empuñadura de daga en hierro. Su estado de conservación responde no solo a la oxidación, sino que supone un desecho abandonado en época romana, puesto que aparece deformada. Está compuesto por los elementos exteriores de sección en « $\mathrm{V}$ » con engrosamiento circular central y clásico pomo en forma de «D» invertida, donde tan solo queda uno de los dos remaches decorativos del anverso. En el extremo opuesto se encuentra la cruceta de sección triangular (fig. 16).

Dimensiones: longitud $105 \mathrm{~mm}$. Se custodia en el Museo de Palencia (Fernández Ibáñez, 2004: 209; 2006a: 189 y 197; 2006b: fig. 3.1; 2007; García Bellido, Fernández de Avilés y García Guinea, 1970: 19 y fig. 22).

Contexto: igual al anterior. 


\section{La Ribera:}

19) Fragmento de empuñadura de daga en hierro. Conserva completa la característica estructura en forma de «sándwich» de esta parte del arma. Describiéndola desde el exterior, en primer lugar hay dos piezas (anverso y reverso) que presentan un vástago de sección en «V» (47 mm de altura cada una) con engrosamiento circular en el centro ( $\pm 25 \mathrm{~mm} \varnothing)$. En el extremo superior se sitúa el pomo en forma de «D» con la parte convexa hacia abajo; está decorado con tres remaches en la parte superior y dos en el frente. Contenían sendas láminas de hueso (4 $\mathrm{mm}$ de grosor cada una) que abrazan al elemento central constituido por una lámina o espigo plano (3,8 $\mathrm{mm}$ de grosor) que llega desde la base de la hoja. Estas tres últimas piezas no se alargan hasta el pomo. Todo el conjunto queda asegurado con remaches. Dimensiones: longitud 91,6 mm y grosor total 21,2 mm (fig. 18).

Contexto: el yacimiento tiene carácter de vertedero, o más en concreto se trata del extremo Sur de una extensa y bien conocida área como es La Chorquilla de la que ya hablamos antes. Cronológicamente abarca la segunda mitad del siglo I d.C.

\section{Sin procedencia:}

20) Dos láminas en aleación de cobre correspondientes a la estructura de la empuñadura de dagas posiblemente dobleglobulares (fig. 3-G). Dichas láminas son rectangulares, con un engrosamiento central circular y dos perforaciones circulares para sendos roblones. Los extremos ligeramente se ensanchan cerrándose en arcos de círculo.

Dimensiones: longitud $85 \mathrm{~mm}$ y $13 \mathrm{~mm}$ de anchura.

Contexto: se trata de hallazgos realizados hace muchos años, casuales y sin contexto alguno, producto de excavaciones de acondicionamiento como pozos, cimentaciones, etc.

\section{- Los Majuelos (Olmos de Ojeda) (fig. 1.13)}

21) Fragmento de hoja en hierro que se nos muestra hoy en un estado de conservación deficiente. Se trata de buena parte del extremo cortante de esta arma. Presenta filos rectos y convergentes hacia el extremo punzante, y nervadura central (fig. 24).

Dimensiones: longitud $69 \mathrm{~mm}$, anchura 42,5 mm, grosor 3,1/4,1 $\mathrm{mm}$. Se custodia en el Museo de Palencia (Fernández Ibáñez, 2006b: 267-269; 2007).

Contexto: no se ha realizado intervención arqueológica alguna en este yacimiento. El conocimiento parcial que tenemos proviene de los hallazgos recogidos en prospección superficial, algunos de los cuales se conservan en colecciones particulares. Se trata de un lugar muy castigado por las actividades del furtivismo. A sigillata aretina y galica se suman objetos metálicos variados, numismática imperial —alguna con resellos militares - y tardía, etc. Parece que en algún momento, quizás en su mismo origen como asentamiento, tuvo un carácter militar junto a la vía que unía Castum Legionis IIII Macedonicae, Pisoraca y quizás Camarica (?).

\section{- Monte Cildá (Olleros de Pisuerga) (fig. 1.14)}

22) Daga de hierro. Conserva la estructura completa de su empuñadura a doble vertiente en su configuración dobleglobular. La empuñadura se encuentra formada por siete elementos: el espigo y las cachas son de hierro, mientras que sobre aquel se superponen dos láminas de aleación de cobre, y a su vez sobre estas dos de hueso. El pomo lleva un refuerzo interior de hierro, y perimetrándolo una cinta de plata con una simple decoración en relieve de dientes de sierra. La hoja, muy alterada y con arista central redondeada hoy se presenta doblada en ángulo, careciendo tanto de filos como de extremo punzante (fig. 5).

Dimensiones: $217 \mathrm{~mm}$ de longitud, correspondiendo $107 \mathrm{~mm}$ a la empuñadura (Alonso Gregorio, 2004). 
Contexto: hallazgo sin contexto recogido en una de las plataformas del lado norte, bajo las primitivas estructuras de acceso al poblado excavadas en 1969. Objeto que junto a otros hallazgos fue depositado en superficie debido a las labores agrícolas llevadas a efecto mediante arado.

- Palencia capital (fig. 1.15)

23) Daga de hierro. Se trata de un ejemplar completo de tipo biglobular. La hoja es larga presentando filos escasamente sinuosos. A lo largo de ambas caras y a los lados del nervio central, se desarrolla una decoración grabada de líneas paralelas y ondulantes. La empuñadura en forma de «T invertida posee el pomo circular y engrosamiento central. Está compuesta por las cachas de sección en «V» sobre dos láminas de aleación de cobre que soportan el disco de hierro que refuerza al pomo, decorado exteriormente con una lámina de aleación de cobre con decoración en relieve de dientes de sierra y puntos. En el centro la espiga plana que asciende desde la base de la hoja. Seis remaches circulares (dos de ellos a los extremos de la cruceta) mantienen unido todo este conjunto (Figs. 2-3).

Dimensiones: longitud de la daga $339 \mathrm{~mm}$, longitud de la empunadura $116,3 \mathrm{~mm}$, longitud x anchura x espesor de hoja: 234 x 45,8 x $22 \mathrm{~mm}$. Se custodia en la Colección Eugenio Fontaneda del castillo de Ampudia (Palencia) (Cabré, 1931: lám. XX.4).

Contexto: necrópolis de Eras del Bosque.

24) Daga enfundada en la vaina (n. ${ }^{\circ}$ II) y que se encuentran firmemente unidas por los productos de oxidación. El arma es de hierro y carece de empuñadura, aunque la tuvo hace años (fig. 20). Con pomo en «D» su estructura metálica es tripartita con el espigo plano en su interior. La hoja tiene los filos con delineación en «S» según evidencia el perfil de la vaina, y arista semicircular a lo largo de las caras (fig. 19).

Dimensiones: longitud total en la actualidad $246 \mathrm{~mm}$, anchura de la hoja $47 \mathrm{~mm}$ y espesor (en el extremo puntiagudo) $3 \mathrm{~mm}$. Se custodia en la Colección Eugenio Fontaneda del castillo de Ampudia (Palencia) (Cabré, 1931: 241, lám. XX.4).

Contexto: necrópolis de Eras del Bosque.

25) Daga enfundada en su vaina (n. ${ }^{\circ}$ I) (fig. 10). Ambos objetos de hierro permanecen íntimamente unidos por la oxidación.

La daga (fig. 9) tiene una hoja con hombros oblicuos, filos delineados en «S zada por un grueso nervio central. El extremo opuesto a la punta primero se ensancha hacia ambos lados en cortos apéndices para servir de sustentación a los extremos de la cruceta. Prolongándose en un apéndice plano o lengüeta, la cual es cubierta por anverso y reverso mediante una estructura metálica en forma de «T» invertida, permaneciendo todas sus partes unidas mediante remaches. El pomo presenta forma en «D» invertida, asomando en el frente dos cabezas circulares y en la parte superior una cabeza más (de las tres que en origen tenía), esta última con una función decorativa, pues lo que realmente une aquel extremo es un roblón de $5,5 \mathrm{~mm} \varnothing$, cuyos extremos fueron disimulados mediante pulido. La caña tiene sección triangular hueca con engrosamiento circular antideslizante en su centro, donde el remache que las unía fue disimulado por pulimento y hoy está ausente. Finalmente las crucetas planas vuelven sobre sí en los extremos para enlazar con la opuesta de forma curva. Presenta sendos remaches circulares en sus extremos - careciendo de unos de ellos- con cabezas semiesféricas, que los aseguran a las prolongaciones del extremo de la hoja (fig. 8).

Dimensiones: longitud de la daga $315 \mathrm{~mm}$ ( $\pm 333 \mathrm{~mm}$ en origen), longitud de la empuñadura $104 \mathrm{~mm}$, longitud x anchura x espesor de hoja: 211 x $50 \times 23 \mathrm{~mm}$. Se custodia en el Museo de Palencia (Fernández Ibáñez, 1999b; 2004: 209; 2006b: 285-286; 2007).

Contexto: necrópolis de Eras del Bosque. 
26) Daga de hierro. La hoja presenta nervadura central y filos que delinean una «S» suave, hacia un extremo apuntado inexistente por rotura. El extremo opuesto se ensancha levemente hacia ambos lados formando lengüetas, hasta conseguir la longitud de la cruceta. La empuñadura, fracturada aproximadamente a la mitad de su longitud, se encuentra formada por los tres elementos que ya son conocidos. Las cachas tienen la forma de una «T» invertida y sección en $\langle\mathrm{V} »$ con engrosamiento central. Este conjunto permanecía unido por medio de remaches circulares de los cuales tan solo uno se conserva $(4,4 \mathrm{~mm} \varnothing)$. Los huecos que hoy son visibles entre ellos eran los espacios que ocupaban sendos rellenos de materia orgánica (fig. 11).

Dimensiones: $203 \mathrm{~mm}$ de longitud total, correspondiendo $70 \mathrm{~mm}$ a la hoja, que además tiene una anchura máxima de 37,4 mm. Se custodia en el Museo de Palencia (Fernández Ibáñez, 2004: 209; 2006b: 285-286; 2007).

Contexto: necrópolis de Eras del Bosque. Se desconoce cualquier otro dato.

27) Daga forjada en hierro. La empuñadura es de triple estructura metálica: las cachas de sección plano-convexa se sobreponen a la lengüeta de la hoja que, además de ser plana, solo alcanza hasta el mismo inicio del pomo. Este presenta una forma en «D» invertida, con dos remaches decorativos en su frente (de los que solo resta uno), y tres en la parte superior de los que se conservan dos. Otro de estos remaches atraviesa el engrosamiento circular central. Hoja de filos con delineación en «S» suave y nervadura central (fig. 12).

Dimensiones: longitud total: $277 \mathrm{~mm}$, longitud $\mathrm{x}$ anchura máxima $\mathrm{x}$ espesor de la hoja: 167 x 39,5 x 7,4 mm. Se custodia en el Museo Arqueológico Nacional de Madrid.

Contexto: se desconoce.

28) Fragmento de la parte superior de una hoja conservada en el interior de una vaina de aleación de cobre (n. ${ }^{\circ}$ III) (fig. 25). Se encuentra forjada en hierro en mal estado de conservación, y hoy se nos muestra aproximadamente a la mitad de su longitud. Presenta hombros oblicuos, nervio central y buena parte de la cruceta (fig. 21).

Dimensiones: $147 \mathrm{~mm}$ de longitud y $68 \mathrm{~mm}$ de anchura máxima de la base de la hoja. Se custodia en la Hispanic Society of America de Nueva York (Fernández Ibáñez, 2004: 209; 2006b: 285; 2007; García y Bellido, 1993: 214, lám. 350-3; VV. AA., 1938: 213-214).

\section{— Provincia de Soria}

- Numancia (Garray) (fig. 1.16)

29) Daga de hierro con una conservación deficiente, aunque diferencial, entre hoja y empuñadura. Esta última es de tipología dobleglobular con estructura metálica triple, de la cual no parece haberse conservado la parte orgánica; son apreciables dos remaches en el centro de cada disco. La hoja de apéndice plano (que reproduce la forma íntegra de la empuñadura), apenas conserva características de su primitiva estructura, de la cual solo es apreciable el leve resto de un nervio central (fig. 7).

Dimensiones: longitud total actual $\pm 242 \mathrm{~mm}$, de los cuales $115,2 \mathrm{~mm}$ corresponden a la empuñadura; el disco del pomo tiene un $\varnothing$ de 28,6 mm. Se custodia en el Museo Numantino de Soria (Lorrio, 1997: fig. 78.3; Luik, 2002: Abb. 53.3; Schüle, 1969-II: lám. 166.3).

Contexto: excavaciones de A. Schulten.

30) Empuñadura de hierro. Triple estructura metálica entre la cual se observan concrecionadas las dos partes orgánicas aparentemente de hueso, todo ello envuelto por los productos de oxidación y formando un conjunto compacto. Sobre una espiga plana que no llega hasta el pomo, se sobreponen las cachas metálicas de sección en «V》 y el glóbulo central, con también el pomo en forma de «D» en el que se aprecian las cabezas de tres remaches en la parte superior y dos más en el frente. Restos de otros cuatro remaches disimulados se detectan en 
el punto de unión entre empuñadura y pomo, otro en el centro del glóbulo inferior y dos en la cruceta de la apenas quedan restos (fig. 13.8).

Dimensiones: longitud total 105,7 mm, grosor de la espiga 3,4 $\mathrm{mm}$. Se custodia en el Museo Numantino de Soria (Luik, 2002: Abb. 53.4; Schüle, 1969-II: lám. 166.5).

Contexto: excavaciones de J. R. Mélida y B. Taracena.

31) Empuñadura de hierro. Triple estructura metálica entre la cual se observan duras concreciones blanquecinas, todo ello alterado por la oxidación conformando un conjunto compacto. Sobre un espigo plano que no llega hasta el pomo - hoy deformado-, se sobreponen las cachas metálicas de sección en «V». Se observan restos de tres remaches: uno estructural y disimulado que une las dos partes del pomo, al exterior de este último una cabeza decorativa deformada, y finalmente otro en el centro del glóbulo (fig. 13.1).

Dimensiones: longitud total 109,8 mm, grosor de la espiga $3 \mathrm{~mm}$. Se custodia en el Museo Numantino de Soria (Lorrio, 1997: fig. 78.7; Schüle, 1969-II: lám. 166.7).

Contexto: excavaciones de A. Schulten.

32) Empuñadura de hierro. Triple estructura metálica entre la cual se observan duras concreciones blanquecinas, todo ello alterado por la oxidación conformando un conjunto compacto. Sobre un espigo plano que no llega hasta el pomo - hoy transformado en un óvalo-, se sobreponen las cachas metálicas de sección en «V». Apenas de conserva algo de la cruceta (fig. 13.4).

Dimensiones: longitud total 111,3 mm. Se custodia en el Museo Numantino de Soria (Lorrio, 1997: fig. 78.8; Schüle, 1969-II: lám. 166.8).

Contexto: excavaciones de A. Schulten.

33) Cacha de empuñadura. Hierro. En ella los productos de oxidación han mineralizado y compactado en una muy dura masa la clásica estructura metálica tripartita tantas veces vista. El pomo oval precede a la empuñadura en sí (con remache disimulado en la parte superior) de sección losángica con abultamiento central. No conserva la cruceta (fig. 13.5).

Dimensiones: longitud total $114 \mathrm{~mm}$. Se custodia en el Museo Numantino de Soria.

Contexto: excavaciones de A. Schulten.

34) Fragmento de empuñadura que se corresponde con la parte superior de esta. El pomo es oval con un remache disimulado en su centro. El fragmento de caña con cachas de sección en «V» conserva el glóbulo central, y entre este y el pomo otro remache disimulado. Los productos de corrosión generados por la estructura metálica triple han compactado el conjunto haciéndolo inobservable (fig. 13.7).

Dimensiones: longitud total 75,7 mm. Se custodia en el Museo Numantino de Soria.

Contexto: excavaciones de A. Schulten.

35) Cacha de empuñadura. Pomo oval, engrosamiento central y cruceta deformada. Sección triangular. Son perceptibles hasta tres remaches. En la cara posterior la corrosión ha conservado restos de madera en toda su longitud, correspondiendo con la materia que fue interpuesta entre esta pieza y el apéndice de la hoja (fig. 13.2).

Dimensiones: longitud total $165 \mathrm{~mm}$. Se custodia en el Museo Numantino de Soria.

Contexto: excavaciones de A. Schulten.

36) Fragmento de pomo de empuñadura en forma de «D» con arranque del vástago (fig. 13.6).

Dimensiones: longitud 39,3 mm. Se custodia en el Museo Numantino de Soria.

Contexto: excavaciones de A. Schulten.

37) Hoja de hierro. Lámina de filos sinuosos con los restos del nervio central convexo que la recorre a todo lo largo. En la parte opuesta a la punta conserva el inicio de la espiga plana. 
A la altura de la cruceta dos remaches sujetan una lámina estrecha de aleación de cobre que la recorre a todo lo largo y ancho, tratándose quizás de los restos de una reparación (fig. 13.3).

Dimensiones: longitud total 224,6 mm. Se custodia en el Museo Numantino de Soria (Schulten, 1931: Taf. 58).

Contexto: excavaciones de A. Schulten.

38) Hoja de hierro. Lámina de filos rectos con restos del nervio central. Conserva adheridos por la corrosión y un remache los restos de la cruceta trapezoidal. Se encuentra en muy precario estado de conservación (fig.13.10).

Dimensiones: longitud total $195 \mathrm{~mm}$. Se custodia en el Museo Numantino de Soria (Lorrio, 1997: fig. 78.5; Luik, 2002: Abb. 53.6; Schüle, 1969-II: lám. 166.15).

Contexto: excavaciones de A. Schulten.

39) Hoja de hierro. Lámina de filos levemente sinuosos con restos del nervio central. Conserva restos de la cruceta trapezoidal. Se encuentra en muy precario estado de conservación (fig. 13.9).

Dimensiones: longitud total $190 \mathrm{~mm}$. Se custodia en el Museo Numantino de Soria.

Contexto: excavaciones de A. Schulten.

- Cerco de Numancia. Campamento de Castillejo (Garray) (fig. 1.16)

40) Hoja de daga en hierro con arista central convexa en ambas caras, espigo plano y filos sinuosos. Muestra una ancha base de hombros oblicuos donde conserva en ambas caras la cruceta hexagonal que abraza por ambos extremos, permaneciendo unida por tres roblones (fig. 14.1).

Dimensiones: longitud total $210 \mathrm{~mm}$. Se custodia en el Römisch-Germanischen Zentralmuseum de Mainz - N. ${ }^{\circ}$ Inv. O.18225- (Luik, 2002: 196, Abb. 91.204, Taf. 14.2; Schulten, 1927: Taf. 34.2, 49.2).

Contexto: excavaciones de A. Schulten.

- Cerco de Numancia. Campamento del Molino (Garray) (fig. 1.16)

41) Hoja de daga en hierro con nervio de arista que lo realzan dos grandes concavidades a cada lado a lo largo del centro de ambas caras y cintura estrecha, lo que delinea unos filos muy sinuosos. El fragmento de espigo es estrecho y los hombros rectos (fig. 14.3).

Dimensiones: longitud total $175 \mathrm{~mm}$. Se custodia en el Römisch-Germanischen Zentralmuseum de Mainz -N. ${ }^{\circ}$ Inv. O.18514- (Luik, 2002: 196, Abb. 91.202, Taf. 14.2; Schulten, 1927: Taf. 34.7).

Contexto: Excavaciones de A. Schulten.

- Cerco de Numancia. Campamento indeterminado

42) Estrecha hoja de hierro con nervio de refuerzo en cada cara, filos sinuosos, hombros rectos y estrecho pedicelo fracturado (fig. 14.2).

Dimensiones: longitud total $210 \mathrm{~mm}$., anchura $45 \mathrm{~mm}$. Se custodia en el Römisch-Germanischen Zentralmuseum de Maniz - N. ${ }^{\circ}$ Inv. O.18224- (Luik, 2002: 196, Abb. 91.205, Taf. 14.1; Schulten, 1927: Taf. 34.1, 49.1).

Contexto: excavaciones de A. Schulten.

43) Hoja de daga en hierro de filos rectos y oblicuos hasta confluir en el extremo agudo, base cóncava y sección biconvexa, aunque en origen pudo haber tenido nervio central (fig. 14.4). 
Dimensiones: longitud total $175 \mathrm{~mm}$. Se custodia en el Römisch-Germanischen Zentralmuseum de Mainz —N. ${ }^{\circ}$ Inv. O.18226 - (Luik, 2002: 196, Abb. 91.203; Schulten, 1927: Taf. 49.3).

Contexto: excavaciones de A. Schulten.

— Provincia de Valladolid

- Santa Cruz (Cabezón de Pisuerga) (fig. 1.17)

44) Hoja de daga en hierro. Ancha estructura con filos contorneados en forma de «S» con el centro reforzado por medio de un nervio longitudinal. En la base se conservan los restos de la base de la empuñadura, formados por la cruceta lisa (de longitud igual al de la base de la hoja) que vuelve sobre sí en los extremos hasta alcanzar la opuesta. A continuación el inicio de la caña, la ya conocida disposición tripartita metálica formada por las dos cachas de sección triangular, que se acoplan a ambos lados de un apéndice central plano (fig. 21).

Dimensiones: longitud $223 \mathrm{~mm}$, anchura 82 (en la cruceta) y 70 (en el centro) $\mathrm{mm}$. Se custodia en el Museo de Valladolid (Fernández Ibáñez, 2002: 80; 2004: 209; 2006b: 286; 2007; Mañanes, Gutiérrez y Agundez, 1987: 57).

Contexto: Objeto recogido en superficie junto a una punta de pilum y un regatón. El lugar del hallazgo es un extenso paraje rico en material arqueológico debido a las labores agrícolas. El abanico cronológico del lugar en que fue hallada la daga en función del material arqueológico que las labores agrícolas depositan en superficie, y fundamentalmente por la terra sigillata hispánica en formas lisas y decoradas, abarca un arco cronológico bastante coherente desde el último cuarto del siglo I d.C. y la centuria siguiente.

- La Armedilla (Cogeces del Monte, Valladolid) (fig. 1.18)

45) Empuñadura de daga en hierro. Objeto recogido en superficie y que por el momento podemos considerarlo como en paradero desconocido. Tan solo dan fe de su existencia las fotografías que hacemos acompañar a esta descripción. Se encuentra compuesta por las ya conocidas láminas exteriores que forman las cachas y que son de sección en «V les solo una se encuentra completa. Pomo más bien tendente al óvalo en su forma con restos de una fila de tres remaches en el frente, engrosamiento central circular remachado y cruceta triangular de amplia base. Abrazan mediante remaches en número indeterminado a sendas láminas y a una lengüeta plana que es la prolongación de la hoja, de la cual tan solo queda la parte superior permitiendo apreciar que tenía nervio central. Entre las cachas, laminillas y la lengüeta se insertan otras dos láminas posiblemente en hueso, aunque no es posible asegurarlo (Láms. IV y V).

Contexto: se desconoce.

- Provincia de Zamora

- Las Minas (Pinilla de Toro) (fig. 1.19)

46) Daga de hierro. Se encuentra constituida por una hoja quasi-triangular de base tan ancha como la cruceta, que delinea unos filos con muy escasa sinuosidad hacia el extremo apuntado. El centro está reforzado longitudinalmente por un leve nervio semicircular. Desarrolla una lengüeta o apéndice plano hacia la parte superior. La empuñadura, de triple estructura metálica como ya nos es conocida, está compuesta por las dos cachas de sección en «V» que abrazan mediante remaches el apéndice de la hoja. El pomo es bilobulado por la escotadura o concavidad superior. En la parte media hay un pequeño ensanchamiento con finalidad antides- 
lizante de forma triangular. La cruceta es plana y sus extremos vuelven sobre sí, hasta fundirse con la de la cara opuesta (fig. 33).

Dimensiones: longitud total $289 \mathrm{~mm}$, longitud empuñadura $104 \mathrm{~mm}$, longitud hoja 185 mm, anchura hoja 64 mm (Fernández Ibáñez, 2004: 211; 2006b: 295-296; 2007; Martín Valls y Delibes de Castro, 1975: 461-463).

Contexto: objeto, que junto a otros de materias diversas fueron recogidos superficialmente en el yacimiento. Las valoraciones cultural y cronológica de todos ellos llevaron a considerar de forma provisional que se trataba de un núcleo poblacional de tipo villa.

- Petavonium (Rosinos de Vidriales) (fig. 1.20)

47) Hoja de daga en hierro de filos convexos y sección muy aplanada. La base o extremo opuesto a la punta es triangular, con un pedicelo estrecho de sección rectangular que se inicia en su centro (fig. 30).

Dimensiones: longitud total $199 \mathrm{~mm}$, lontitud de hoja $169 \mathrm{~mm}$, anchura de hoja $38 \mathrm{~mm}$, longitud, anchura y espesor de pedicelo 30 x 11 x 4,7 mm. Se custodia en el Museo de Zamora.

Contexto: fue exhumado durante las excavaciones arqueológicas llevadas a cabo en el yacimiento de Rosinos de Vidriales entre los años 1989 y 1991. Hizo su aparición dentro de la habitación G (cuadrícula F-50) U.E.2709 que se corresponde con el estrato más inferior de la Fase IV del yacimiento o «de destrucción de los edificios», coincidiendo con la ocupación del campamento por parte de la tropa auxiliar conocida como Ala II Flavia Hispanorum civium Romanorum. Esta unidad de caballería ocupó el castellum entre el último tercio del siglo I d.C. y toda la centuria siguiente. La cronología del contexto arqueológico dentro de cual apareció el hallazgo es difícil de establecer según sus excavadores, y que según los estudios llevados a cabo a través de la cerámica y las monedas podría situarse entorno a los últimos decenios del siglo II d.C.

\section{Comunidad Autónoma de Navarra}

- Santacara (fig. 1.21)

48) Daga en hierro. La parte mejor conservada es la hoja con filos ligeramente convexos lo que le da un aspecto oval, con sección biconvexa. De la empuñadura apenas se han conservado algunos fragmentos que permiten adivinar que se encontraba formada por una lámina central o apéndice de la hoja recubierta de madera (hoy mineralizada), rematando en el pomo en forma de «D» invertida (fig. 36).

Dimensiones: longitud $310 \mathrm{~mm}$. Se custodia en el Museo de Navarra (Pamplona) (Mezquíriz Irujo, 2006: 254).

Contexto: claramente civil al tratarse de un núcleo urbano sin otros indicios armamentísticos sino esta pieza y la siguiente. La cronología dada es la genérica para el resto de la parte romana del yacimiento, masivamente entre los siglos I-II d.C.

49) Hoja de daga en hierro casi completa, de filos rectos y oblicuos hacia una punta inexistente. La contera es redondeada.

Dimensiones: longitud total $145 \mathrm{~mm}$. Se custodia en el Museo de Navarra (Pamplona) (Mezquíriz Irujo, 2006: 255).

Contexto: ídem a al anterior.

- Ateabalsa (Espinar) (fig. 1.22)

50) Daga en hierro. Se conserva la hoja de base plana, filos en «S»y nervio central, así como el espigo estrecho de sección rectangular (fig. 31). 
Dimensiones: longitud total $320 \mathrm{~mm}$, anchura máxima de la hoja $52 \mathrm{~mm}$. Se custodia en el Museo de Navarra (Pamplona) (Peréx Agorreta y Unzu Urmeneta, 1997-98: 94-95; 2008: 158; Fernández Ibáñez, 2004: 209; 2006b: 277-279; 2007).

Contexto: Ateabalsa es una necrópolis de incineración que mantuvo en uso la mayor parte de los dos primeros siglos d.C., y que parece evidenciar la presencia próxima de un asentamiento militar donde quizás estuviese acantonada una unidad de auxiliares. Es frecuente que en el medio centenar de tumbas excavadas aparezcan moharras. De la tumba $n .^{\circ} 41$ procede esta daga junto a una punta de lanza, y entre otros objetos de ajuar una moneda de Antonino Pío (140-144) que da cronología precisa a este objeto al que nos referimos.

\section{Comunidad Autónoma del País Vasco}

— Provincia de Álava

- Iruña (fig. 1.23)

51) Hoja de daga en hierro. Es ancha y presenta pedicelo fracturado de sección cuadrada/ rectangular (inédita). Se custodia en el Museo de Álava.

Contexto: hallada durante las últimas excavaciones llevadas a cabo en la ciudad romana de Iruña (Trespuentes) - antigua Veleia —, en contexto civil-doméstico y en el interior de una vivienda. Se fecha en torno al siglo II d.C.

\section{Portugal}

- Conimbriga (Condeixa, Coimbra) (fig. 1.24)

52) Hoja de puñal en hierro. Lámina de base redondeada, de sección biconvexa, filos rectos y levemente oblicuos hacia el extremo opuesto para conformar una punta ausente (fig. 27.1).

Dimensiones: longitud $200 \mathrm{~mm}$, anchura $94 \mathrm{~mm}$, espesor $17 \mathrm{~mm}$. Se custodia en el Museo Monográfico de Conímbriga (Condeixa).

Contexto: exhumado durante las campañas de excavación franco-lusas. Procede del nivel de construcción del foro de la ciudad fechado en época flavia (Alarcão et al., 1979: 91 y 95, lám. XX.52).

- Torre de Palma (Monfornte, Portalegre) (fig. 1.25)

53) Daga prácticamente completa. La empuñadura consta de un pomo oblongo, del cual solo se conserva la mitad. El vástago central tiene cachas de sección en «V», como también la planta y la sección de los dos cortos apéndices centrales. La hoja se conserva lisa con sección biconvexa y filos ligeramente oblicuos hacia la punta.

Dimensiones: $280 \mathrm{~mm}$ de longitud. Se custodia en el Museo Nacional de Arqueología (Lisboa), N. ${ }^{\circ}$ Inv. 2001.5.9. Referencia en Internet: 〈http:/www.mnarqueologia-ipmuseus. $\mathrm{pt} / ? \mathrm{a}=3 \& \mathrm{x}=3 \& \mathrm{i}=321$ > (fecha de consulta, 15 de septiembre de 2008).

Contexto: villa excavada en varias ocasiones (Heleno, 1962; Maloney y Hale, 1996). Debido a los especiales requerimientos del Museo de Lisboa nos ha sido imposible acceder a la documentación de origen. Por lo que no contamos con la posibilidad de adscribirla a una de las tres fases romanas (de las VII detectadas) en las últimas excavaciones (1987-1995) por la Universidad de Louisville: I) Mediados del siglo I d.C., II) finales del siglo I d.C. y III) segunda mitad del siglo III/inicios del IV d.C. 


\section{- Procedencia desconocida}

54) Daga en hierro. Empuñadura con cachas a doble vertiente decoradas por damasquinado en base a un reticulado de hilos de plata. Pomo en forma de media luna con botón decorativo central (fig. 35).

Esta breve descripción ha podido ser realizada a partir de un apunte tomado en Madrid, sobre esta antigua arma que procedía del mercado de antigüedades. Este objeto puede darse por desaparecido (Cabré Herreros y Morán Cabré, 1991: 344, fig. 2.C).

Contexto: se desconoce.

\section{VAINAS O FUNDAS}

\section{ESPAÑA}

\section{Provincia de Palencia}

- Palencia capital (fig. 1.15)

I) La vaina tiene forma de ojiva. Está compuesta por dos cantoneras de sección en «U» por donde se deslizaba la hoja (n. ${ }^{\circ}$ 24) (fig. 19). Estas quedan unidas en la parte media y superior (junto al brocal o embocadura) de anverso y reverso por dos láminas rectangulares, una de las cuales conserva un pequeño resto decorativo en forma de espiga. Los lados menores de estos rectángulos aún conservan parte del sistema de suspensión al tahalí del cinturón. Son pequeñas láminas o bridas dobladas en «U» que por medio de remaches unen a la vez cañas y laminas transversales. Esta vaina queda rematada en la parte inferior por un círculo decorativo - hoy deformado - en una de cuyas caras lleva grabada una cruz de brazos iguales (fig. 10).

Dimensiones: longitud $240 \mathrm{~mm}$, anchura $72,2 \mathrm{~mm}$, espesor $15,5 \mathrm{~mm}$. Se custodia junto al puñal en el Museo de Palencia (Fernández Ibáñez, 1999b; 2004: 209; 2006b: 285-286; 2007).

Contexto: necrópolis de Eras del Bosque.

II) Vaina con la daga $n .^{\circ} 24$ enfundada y unida en su interior por los productos de oxidación. Está formada por dos tipos de metales. Mientras la trasera es lisa y de hierro, la placa delantera es de aleación de cobre y se presenta decorada mediante una alternancia de superficies lisas con grupos de líneas grabadas, y dos calados. Bajo el calado superior se deja ver otra lámina decorativa infrapuesta, cuya superficie se encuentra completamente recubierta de pequeños puntos en relieve. Está fracturada y ha perdido el tercio inferior. En los bordes de las zonas superior y media había cuatro presillas (de las que solo se conservan tres, una de ellas diferente, quizás producto de una reparación) sustentadas por clavillos de gran cabeza, que sustentaban las argollas (solo se conserva parte de una) mediante las cuales quedaba suspendida el arma. Según consta en un dibujo antiguo primitivamente estaba rematada por un disco (fig. 20).

Dimensiones: longitud total $202,2 \mathrm{~mm}$, anchura en la embocadura $650 \mathrm{~mm}$ y espesor de la hoja del anverso 1,1 mm. Se custodia en la Colección Eugenio Fontaneda del castillo de Ampudia (Palencia) (Cabré, 1931: 241, lám. XX.5).

Contexto: necrópolis de Eras del Bosque.

III) Vaina que conserva en su interior el fragmento de daga (n. $\left.{ }^{\circ} 28\right)$ (fig. 22). Esta vaina se encuentra fabricada en aleación de cobre, presentando una ya clásica forma alargada que remata en disco. En el extremo de la embocadura y en el centro del objeto la superficie queda ensanchada hasta alcanzar sendas formas rectangulares, cuyos ángulos se decoran mediante grandes cabezas de remaches decorativos. Ambas caras muestran una decoración complemen- 
taria grabada, distinta en cada una, habiéndose creado formas geométricas mediante paquetes de líneas paralelas (en número desigual) que se cruzan entre sí, oblicuamente confluyen, etc. (fig. 25).

Dimensiones: $240 \mathrm{~mm}$ de longitud, $73 \mathrm{~mm}$ de anchura en la embocadura y 26/28 $\mathrm{mm} \emptyset$ el disco. Se custodia en la Hispanic Society of America de Nueva York (Fernández Ibáñez, 2004: 209; 2006b: 285; 2007; García y Bellido, 1993: 214, lám. 350-3; VV. AA., 1938: 213-214).

Contexto: necrópolis de Eras del Bosque.

IV) Placa frontal de vaina. Se encuentra recortada en una lámina de aleación de cobre. En las partes superior (embocadura) y media se ensancha en apéndices laterales que vuelven sobre sí (carece de uno de ellos), y tras un refuerzo metálico, abrazaban a la lámina posterior de la vaina que era de hierro y de la cual solo quedan muy leves restos puntuales. Ambas láminas que conformaban el cuerpo de la vaina quedaban unidas mediante remaches (tres en cada apéndice) de cabeza globular-decorativa, que a la vez sujetaban en los apéndices superiores de la cara anterior, laminillas bífidas que abrazan las anillas de suspensión. Se encuentra decorada por bandas paralelas, transversales entre sí - y convergentes-, de apretados grupos de seis finas líneas (fig. 26).

Dimensiones: longitud total $186 \mathrm{~mm}$, anchura máxima en la embocadura 66,6 mm y espesor de la lámina 0,6 mm. Se custodia en el Museo Arqueológico Nacional de Madrid.

Contexto: se desconoce.

- Herrera de Pisuerga (fig. 1.12)

Asilo, La Ribera, San Millán:

V) Varios han sido los hallazgos (siempre de pequeña dimensión y en aleación de cobre) que se han recuperado en este yacimiento, procedentes de tres áreas de excavación.

1. Del área excavada en el solar que posteriormente fue Asilo o Geriátrico, de donde deriva el apelativo, procede el resto de una brida que abrazaba la anilla mediante la cual colgaba una funda de su tahalí. Está formada por una lámina que se ancha en uno de los extremos con la perforación que acogía el remache.

Dimensiones: longitud 25,3 mm, anchura 7,2 mm, grosor 0,9 mm (fig. 29.1).

2. En La Ribera un disco que se corresponde con una placa trasera del remate inferior de una vaina. Muestra dos conjuntos de cuatro líneas grabadas cada uno, cruzadas entre sí. En tres de los cuatro espacios lisos que esta sencilla decoración crea, se encuentran reducidas perforaciones para pequeños roblones de sujeción junto al límite periférico.

Dimensiones: $25,5 \mathrm{~mm} \varnothing$ y $0,8 \mathrm{~mm}$ de espesor.

3. De la fecunda área de San Millán proceden varios pequeños objetos:

A) Nivel II. Posible fragmento de una brida que abrazaba la anilla mediante la cual colgaba una funda del tahalí.

Dimensiones: 17,3 mm (fig. 29.2).

$B$ ) Nivel V. Soporte de anilla de suspensión de funda, realizado en una laminita de sección gallonada. Se aplana y ancha en los extremos perforados.

Dimensiones: 216,8 mm (fig. 29.3).

C) Nivel V. Anilla de suspensión formada a partir de una barrita doblada círculo.

Dimensiones: Ø 22 mm, Ø de la sección 2,5 mm (fig. 29.4).

D) Nivel V. Anilla circular de suspensión con sección oval.

Dimensiones: Ø 19,5 mm, anchura y espesor de la sección 1,5 x 3 mm (fig. 29.5).

E) Nivel V. Anilla circular de suspensión con sección semi-oval.

Dimensiones: Ø $2 \mathrm{~mm}$, anchura y espesor de la sección 2,5 x 3 mm (fig. 29.6). 
Contexto: Asilo es un basurero con varias fases de vertido cuya cronología se sitúa en el siglo I d.C., más en concreto entre los años 60-100 d.C. La Ribera proporcionó un único nivel cuyos materiales se fecharon entre los años 60 y 150 d.C. y los objetos de carácter militar como este fueron hallados en la base del relleno sedimentario. San Millán es un importante yacimiento con cinco niveles, correspondiendo el II a mediados del siglo I d.C. (40-60), y el V entre el 15/20 a.C. hasta el 39 d.C.

\section{Provincia de Salamanca}

- Fuente de la Mora (El Cabaco) (fig. 1.26)

VI) Vaina de daga en hierro. Se encuentra en un estado muy precario de conservación. Tiene forma de ojiva con lados paralelos, que son las cañas o rieles de sección en «U» por donde se deslizaría el filo del arma. A la altura de la embocadura y también a la mitad de este objeto quedan unidos dichos rieles por sendas láminas rectangulares (las cuales tal vez no se conservan en el reverso), cuya superficie conserva restos de cobre embutidos (también en el extremo apuntado) en lo que otrora fueron decoraciones hoy irreconstruibles. Tres cabezas de remaches y otras tantas pequeñas perforaciones en aquellas láminas es probable tengan relación con los estribos de suspensión de este objeto al tahalí del cinturón (fig. 28).

Dimensiones: longitud total $\pm 277 \mathrm{~mm}$, anchura en la embocadura o brocal $74 \mathrm{~mm}$. Se custodia en el Museo de Salamanca (Sánchez Palencia, Ruiz del Árbol y López Jiménez, 2003: 76).

Contexto: núcleo poblacional romano de tipo rural relacionado con la actividad artesanal y las explotaciones de tipo minero y agrícola. La vaina se encuentra cronológicamente relacionada con la ocupación de finales del siglo I d.C.

- Sin procedencia

VII) Vaina sin lugar exacto de hallazgo en España. Presenta perfiles sinuosos y está formada por dos láminas de diferente metal, siendo de bronce el anverso y hierro la del reverso, habiendo sido decorada tan solo la primera de ellas mediante un abigarrado esquema que está grabado, compuesto por «paquetes» o conjuntos de líneas paralelas. Dos franjas con desarrollo horizontal emplazadas en la embocadura y en el centro o parte más ancha de la pieza, con ocho remaches decorativos de cabeza esférica; dos junto a cada costado. De la primera y hasta la parte inferior de la vaina se desarrolla un motivo geométrico semejante al descrito pero con desarrollo ojival. Finalmente remata en un disco decorado con semicírculos, un remache central de cabeza esférica y una gráfila perimetral en relieve (lám. VI).

Dimensiones: longitud total $209 \mathrm{~mm}$.

Se custodia en Alemania en el Romisches Germanischen Zentralmuseum de la ciudad de Mainz (Inv. N. ${ }^{\circ}$ O.40559) (Egg, 1986; Obmann, 2000: Taf. 46.2).

Contexto: se desconoce.

\section{Portugal}

- Conimbriga (Condeixa, Portugal) (fig. 1.24)

VIII) Vaina de daga en hierro y aleación de cobre. Se encuentra constituida por dos láminas, la posterior lisa es de hierro y la superior en bronce dorado y de menor grosor, decorada con cuatro frisos o metopas (la parte que se conserva) enmarcados por líneas grabadas, lisos o calados de forma alterna. Su forma en planta se encuentra delineada por bordes en «S» suave. En dichos bordes y sujetos por tres clavillos cada uno (que aseguran a la vez la unión de ambas placas), se emplazan a cada extremo del brocal y parte media de esta vaina, cuatro diferentes tipos de bridas (de las cuales 
se conservan tres) para la inserción de las correspondientes anillas de suspensión del arma al tahalí del cinturón; los diferentes modelos responden a reparaciones. Carece de extremo inferior en lo que esta pieza se podría considerar hoy como 1/3 del primitivo objeto (fig. 27.2).

Dimensiones: longitud $136 \mathrm{~mm}$, anchura $105 \mathrm{~mm}$ en la embocadura. Se custodia en el Museo Monográfico de Conímbriga (Condeixa) (Alarcão et al., 1979: 91 y 95, lám. XX, 53; Obmann, 2000: Taf. 46.3).

Contexto: exhumada durante las campañas de excavación franco-lusas en la llamada «Insula del vaso fálico», formando parte de los desmontes de rellenos antiguos efectuados en el siglo IV d.C. para llevar a cabo una transformación del lugar.

\section{ORÍGENES Y PRIMERAS DAGAS EN EL EJÉRCITO DE ROMA: SIGLOS I A.C.-I D.C.}

En los orígenes de la daga como arma reglamentaria del ejército romano a finales del siglo I a.C., confluyeron un par de modelos claramente diferenciables por las formas que adoptaron las cachas que formaban parte de sus empuñaduras. Debido a que presentan estructuras diferentes como también fueron dispares sus destinos, nos proponemos analizarlas por separado.

\section{IV.1. LAS EMPUÑADURAS DOBLEGLOBULARES}

La investigación hoy, aunque con escasos datos arqueológicos y ninguno de tipo textual, acepta que la daga militar romana formal y culturalmente deriva del arma celtíbera hispana de tipo dobleglobular. Hasta la fecha de hoy armas morfológicamente intermedias parece ser que no han sido halladas, solo Oberaden había proporcionado un modelo claro de aquel aserto, habiendo sido fechado en un momento cercano al cambio de era.

Para intentar aportar luz a esta situación en el conocimiento, en la Península Ibérica hemos podido recoger seis ejemplares $\left(n{ }^{\text {os }} 16,17,20,22,23,29\right)^{2}$, paradójicamente cuatro de los cuales han sido hallados dentro del territorio de la actual provincia de Palencia (figs. 2, 4-6) y uno en la ciudad de Numancia (fig. 7) que tradicionalmente se ha venido considerando como de tipo indígena celtibérico. De particular interés entre los puñales palentinos resulta el que proviene de la capital, más concretamente de la necrópolis de Eras del Bosque y hoy en la colección Eugenio Fontaneda del castillo de Ampudia (Palencia). Su pormenorizada descripción se nos hace aquí necesaria por la complicada y desconocida estructura de este singular y primigenio tipo dobleglobular. Se trata de un ejemplar completo (339 mm de longitud) (fig. 2) y en excelente estado de conservación, algo inusual en cualquier tipo de objeto forjado en hierro que nos haya llegado de la antigüedad, lo que ha permitido preservar prácticamente inalteradas buena parte de sus características originales, tanto formales como dimensionales. Para que la descripción pormenorizada de las trece partes de las que está compuesta no resulte engorrosa y confusa (fig. 3), la realizaremos en dos fracciones: hoja y empuñadura.

\section{IV.1.1. El prototipo}

La hoja (fig. 3.A) (medidas máximas: longitud $234 \mathrm{x}$ anchura 45,8 x grosor $2,2 \mathrm{~mm}$ ) presenta delineación ligeramente pistiliforme. El extremo inferior remata en una aguda punta

\footnotetext{
2 Desde ahora y en adelante durante el resto del trabajo, los números entre paréntesis harán referencia al número de daga que corresponda, ya descrita en el catálogo precedente (Apartado III).
} 
cuyos costados o filos conservan huellas de afilado. En el extremo opuesto y a la altura de la cruceta (de 58,7 mm de longitud) se encuentran los hombros con delineación oblicua, sobresaliendo ligeramente estos en forma de cortos apéndices sobre el ancho general de la propia hoja, a las que abrazan los extremos de la cruceta; las dos perforaciones eran destinadas a remaches. En el centro de este lugar se prolonga un corto espigo $(67 \times 9,4 \times 2,1 \mathrm{~mm})$ que forma el alma de la empuñadura, con triple perforación para acoger roblones cilíndricos. Los filos de la hoja son agudos y levemente sinuosos. El centro de ambas caras y desde la cruceta hasta la punta está recorrido por un agudo nervio de refuerzo con sección en «V» $(3,5$ de anchura x 1,2 mm de espesor). Sobre las caras y a ambos lados de este nervio central y desarrollándose a lo largo de casi la totalidad de la longitud de cada una de ellas, se muestra una decoración compuesta por tres líneas grabadas en paralelo y ligeramente ondulantes. Es la primera vez que se documenta algo similar debido a la excelente conservación de esta arma.

La empuñadura (116,3 mm de longitud) es una estructura múltiple compuesta por catorce piezas ensambladas. Su descripción la haremos aproximadamente en orden a su montaje. En el centro del conjunto, una lámina central con engrosamiento aproximadamente circular a la mitad de su longitud y triple perforación, que supone la prolongación de la hoja. Sobre ambas caras de esta se superponen sendas láminas de aleación de cobre (D) $(78,3$ x 13,1 x 0,5) que al igual que la anterior tienen engrosamiento en su centro, extremos convexos (de anchura algo mayor que la propia lámina y rematados sus costados de forma aguda) y triple perforación. Finalmente las cachas (E) o elementos exteriores en forma de una aproximada «T» invertida. $\mathrm{Al}$ extremo de un cuerpo central macizo y engrosado nuevamente en su centro (más bien con forma oval: $27 \times 18 \mathrm{~mm}$ ) a doble vertiente y triple perforación con pequeños relieves triangulares adiamantados en sus extremos, se sitúa el pomo en forma de un gran disco $(37,2 \mathrm{~mm}$ $\varnothing)$ de superficie convexa, rebordes oblicuos hacia el interior y perforación central atravesada por un roblón. En la parte opuesta un elemento transversal al eje de la pieza forma la cruceta (61,3 mm de longitud), siendo triangular en su forma y perforado cerca de cada extremo. Todo este conjunto permanece firmemente unido por seis roblones cilíndricos (F) (de $\pm 2,4 \mathrm{~mm}$ de $\varnothing)$ de diferente longitud, remachados en sus extremos. Entre las cachas y las láminas de cobre se colocaban sendos estratos de materia orgánica.

De la empuñadura no nos resta sino comentar la sub-estructura del pomo, desconocida a día de hoy. Esta se nos muestra muy poco accesible debido a su estado de conservación. Contradictorio para este caso concreto, ya que por otra parte ha preservado casi todos los elementos más o menos transformados, aunque cierto grado de oxidación en esta parte del hierro ha llegado a soldarlos. El pomo circular aprisiona en su interior un disco de hierro (B) ( $\pm 33 \mathrm{~mm}$ de $\varnothing \times 2,5$ de grosor) aparentemente macizo y en cuyas caras se encuentran círculos concéntricos grabados. En la periferia de este disco se muestra una escotadura para alojar y hacer de tope a los extremos superiores de las láminas de aleación de cobre (G) (lám. I). Este agregado triple se mantiene firmemente unido en su centro mediante un roblón remachado por ambos extremos, de tal manera que forma un sólido conjunto de características adecuadas para la función que requiere este extremo. Exteriormente el glóbulo del pomo se encuentra perimetrado por una cinta de aleación de cobre (C) $(86,6 \times 4,2 \times 1,3 \mathrm{~mm})$ decorada en relieve mediante dientes de sierra, que oculta la estructura y adorna este extremo. El conocimiento de la presencia y función de aquellas láminas de aleación de cobre en la estructura de la empuñadura ha sido tan desconocida a los investigadores como interesante en nuestra observación. Como vimos, ambos extremos de estas láminas se prolongan brevemente de forma convexa, sobresaliendo de la anchura de la propia lámina mediante agudos ángulos. En uno de dichos extremos - el superior- dichos ángulos han sido doblados en forma de «Z», de tal manera que el «sándwich» formado entre ambas láminas unidas al pedicelo de hierro que proviene de 
la hoja forma un «cajetín» cuya cavidad alcanza la base del disco del pomo. Dicho «cajetín» dimensionalmente es algo superior al espesor del susodicho disco, de tal manera que descansa en el interior a la altura de la escotadura. Vistos ya todos los elementos debidamente ensamblados, forman una necesariamente sólida estructura con características imprescindibles para este tipo de arma.

\section{IV.1.2. Estudio de conjunto}

A partir de la descripción anterior realizaremos un primer acercamiento al análisis de estas antiguas armas romanas tan desconocidas hasta hoy, junto a cuatro ejemplares más que conocemos en la Península Ibérica; todos ellos localizados en la Meseta Norte española (n.os 16, 17, 22 y 29). A estos debemos añadir el de Oberaden (Bishop y Coluston, 1993: 75.1; Obmann, 2000: Taf. 32.1) y quizás el de Chalonnais (Bailly, 1977: fig. 4.25). De especial interés para nosotros es la daga del castro del Raso de Candelada (Ávila) (Fernández Gómez, 1986-I: fig. 166).

En primer lugar la empuñadura. Los ejemplares de dagas romanas presentanban como pomo un gran disco circular-convexo remachado en su centro, si bien esta característica ya estaba presente en algunas dagas dobleglobulares indígenas como las aparecidas en las necrópolis de Carratiermes (Argente, Díaz y Bescós, 2001: 59), Quintanas de Gormáz y Ciruelos (Schüle, 1969-II: Taf. 38.2, 43.1, 56.9, 58.2); también en la empuñadura del campamento sertoriano de Cáceres el Viejo (Ulbert, 1994; Taf. 25.196, 62.196). No obstante y aunque contamos con algún ejemplo aislado, resulta exclusivo el refuerzo interior metálico ${ }^{3}$ y sobre todo la lámina decorativa ${ }^{4}$ que envuelve al pomo en dos de los hallazgos palentinos; de plata en Monte Cildá (n. $\left.{ }^{\circ} 22\right)$ y cobre en Palencia capital (n. $\left.{ }^{\circ} 23\right)$. Muestran una decoración a base de «dientes de sierra» cuyos triángulos se rellenan de pequeños puntos. Resulta una decoración de temática geométrica netamente indígena, muy reiterada en recipientes cerámicos, joyas, etc. Un motivo zigzagueante enmarcado entre dos líneas paralelas, solo a veces con un punto que rellena los espacios libres, ha sido repetidamente utilizado como nielado decorativo en fundas de dagas del siglo I d.C. halladas en el Limes septentrional, así: Lincoln (Inglaterra), Vechten (Holanda), Kempten, Rißtisen, Oberamergau y Magdalensberg (Alemania) (Obmann, 2000: Taf. 3.16, 6.4, 8.7, 15.26, 31.4 y 6).

La caña es de sección a doble vertiente en cuyo centro en encuentra el ya clásico engrosamiento remachado también en el centro. Este es visualmente circular, aunque presenta una leve tendencia dimensional hacia el óvalo. La estructura parece ser estar constituida por tres piezas de metal y dos de materia orgánica, a excepción del ejemplar de Palencia capital que acabamos de describir con cinco de metal; tres de hierro y dos de aleación de cobre. No obstante este último ejemplar no parece ser exclusivo, a tenor del hallazgo de dos láminas características de esta aleación halladas en Herrera de Pisuerga (n. $\left.{ }^{\circ} 20\right)$.

Quizás una característica de cierta singularidad sean los resaltes decorativos poliédricotriangulares de forma adiamantada que se muestran en las uniones entre la caña, y tanto el pomo como la cruceta en este ejemplar de Palencia capital. También observamos algo semejante tanto en el fragmento de La Loma (n. ${ }^{\circ}$ 16) (fig. 4) (lám. I) como en Monte Cildá (n. ${ }^{\circ} 22$ ) (fig. 5). Quizás pudiera tratarse de una característica de taller al encontrase todos en un área geográfica cercana. Algo levemente parecido vemos insinuado en la cruceta del dobleglobular

3 Un refuerzo metálico mediante un disco en el pomo de un puñal biglobular indígena es raro de encontrar. Lo hemos apreciado en una daga de hierro de la necrópolis de Quintanas de Gormaz (Soria) (Schüle, 1969-II: Taf. 38.2).

4 Así parece tener una cinta de cobre que envolvía perimetralmente al pomo, una daga de hierro enfundada procedente de la necrópolis de Osma (Soria) (Schüle, 1969-II: Taf. 57.1), y tres ejemplares de Quintanas de Gormaz (Soria) también la muestran (Schüle, 1969-II: Taf. 33.7, 37.2, 38.2). 
indígena de la Hispanic Society de Nueva York (García y Bellido, 1993: 276, lám. 350.3; VV. AA., 1938: 213-214), y también en una daga que formalmente tiene mucho parecido como es la del castro del Raso de Candelada citada antes. Otras decoraciones parecidas de la daga palentina las vemos en el engrosamiento central, lo que con formas mucho más simples tiene la daga de Titelberg. Vanden y Simkins (2001-02: 77) ya apuntaron el parecido que observaron entre sendos triángulos en forma de flecha a los extremos de la empuñadura nuevamente en la daga de Titelberg con respecto a la indígena de la tumba 512 de Carratiermes.

El excelente estado de conservación de esta daga nos ha permitido saber que las hojas tenían un fino nervio central de refuerzo de sección triangular sin acanaladuras laterales. Estaban decoradas, de tal manera que esta y la de Oberaden presentan el mismo motivo de líneas sinuosas y paralelas; no conocemos otros casos parecidos ${ }^{5}$. Ambos filos también presentan una delineación escasamente sinuosa. Los espigos en esta época son siempre planos, nunca llegarán ya hasta el pomo, con tres o cuatro remaches (según modelo) de sujeción para las cachas. Las dagas antiguas (de este tipo dobleglobular o algunos de los primeros modelos con el pomo en «D» que veremos en el apartado siguiente) presentan como característica significativa los hombros oblicuos ${ }^{6}$ que continuarán durante todo el siglo I d.C. Y a los extremos de estos, sendos apéndices cortos (que desaparecerán) ${ }^{7}$ alrededor de los cuales giran sobre él los extremos de unas crucetas hexagonales que los abrazan, quizás actuando como dos puntos adicionales de refuerzo siempre junto a un par de remaches. Una de las dagas de Dangstetten (15-9 a.C.) - sin empuñadura - presenta una hoja más semejante a Oberaden que a Palencia (sin apéndices y con cuatro remaches en la cruceta), sin decoración y con nervio central convexo (Bishop y Coulston, 1993: fig. 39.2). Finalmente no contamos con dato alguno por el momento sobre el tipo de fundas donde eran guardadas estas dagas de empuñadura dobleglobular. Suponemos que fuesen de un tipo muy similar, si no idéntico, a sus contemporáneos que veremos a continuación.

Importantes cuestiones a plantearse son el tiempo que estuvieron en uso y cuándo el ejército romano las adaptó como primer arma blanca «reglamentaria», variando los aspectos formales que las identifican como tales y por lo tanto alejándose de los prototipos indígenas. No tenemos respuestas categóricas, aunque sí algunos datos que pueden comenzar a aclarar tales cuestiones, algo de lo que hasta ahora carecíamos. En primer lugar contamos ya con una fecha aproximada en torno al 27-28 a.C. que nos trasmite el hallazgo de la Loma (n. ${ }^{\circ}$ 16). Y por lo tanto, según las características ya vistas, los ejemplares de Palencia capital (n. $\left.{ }^{\circ} 23\right)$ y también Monte Cildá ( . $^{\circ} 22$ ) sería posible fecharlos, con prudencia, dentro del último cuarto del siglo I a.C. Coincidiendo plenamente con la daga de Oberaden (11-10/8-7 a.C.). No obstante la daga de Palencia posee un paralelo formal muy significativo en España pese a que su empuñadura difiere respecto a aquel en la configuración sencilla de su estructura, más acorde con los modelos indígenas. El dobleglobular del Raso de Candelada (Ávila) al que antes nos referimos parece por este detalle ser algo más antiguo, y de hecho se fecha en torno al 47 a.C. (Fernán-

5 El tema de líneas sinuosas se muestra sobre la cruceta de una daga dobleglobular enfundada procedente de las necrópolis de Carratiermes (Soria) y hoy en el Museo de Barcelona (Luik, 2002: Abb. 53.9; Schüle, 1969-II: Taf. 46.5), cuya estructura formal se encuentra muy cercana a lo que posteriormente con Roma serán estos puñales.

6 Esta característica también la tienen dos dagas de Numancia (n. ${ }^{\text {os } 38-39) ~(f i g . ~} 13.9$ y 10) siendo probable que también puedan fecharse en estos momentos, pero al presentar unas características formales tan sumarias debido a su estado de conservación, y además, al proceder de muy antiguas excavaciones, no podemos (ni debemos) pronunciarnos de forma categórica.

7 Estas características también las muestra uno de los fragmentos de hoja hallados en Arcobriga (n. ${ }^{\circ}$ 2) (fig. 15.7), pero al tratarse de un conjunto de objetos exhumados con la metodología en uso a principios del siglo XX, nos ha privado de conocer el contexto de su enterramiento y por lo tanto de una cronología que nos hubiera sido esclarecedora. 
dez Gómez, 1986-I: 521-522) ${ }^{8}$, si bien es verdad que la empuñadura de Herrera de Pisuerga (n. ${ }^{\circ}$ 17) (fig. 6), posterior al 20-15 a.C., presenta el mismo sistema; a no ser que se tratase de una antigüedad y que esta fuese una de las razones por las que se desechó en un vertedero. Pese a todo sería razonable pensar que Candelada sea uno de los primeros modelos de dagas romanas. Y también que esta sencillez volumétrica y formal donde se han perdido todas de las características vistas en las empuñaduras sea indicativa de modernidad, y tanto Herrera como Numancia (n. $\left.{ }^{\circ} 29\right)$ y Chalonnais sean los últimos dobleglobulares romanos. En cuanto a su perduración no hay datos por ahora que avalen la creencia de que el modelo dobleglobular sobrepasase el cambio de era.

\section{IV.2. LAS DAGAS CON EMPUÑAdURAS DE POMO EN «D»}

La antigüedad de las dagas de Titelberg (30-12 a.C.) (Vanden Berghe y Simkins, 2001-02) y Dangstetten (15-9 a.C.) (Helmig, 1990) parece confirmar que las empuñaduras dobleglobulares coexistieron durante un periodo indeterminado del último cuarto del siglo I a.C. ${ }^{9}$ con otros puñales que presentaban una estructura en varios aspectos diferente. Sobre todo en lo que a la empuñadura se refiere, mostrando estos un nuevo pomo en forma de «D» invertida ${ }^{10}$. En este sentido y para España lamentablemente no es viable utilizar los únicos hallazgos conocidos de posible contemporaneidad entre los dos modelos - Herrera de Pisuerga (n ${ }^{\text {os }} 17-18$ ) y Numancia (n. ${ }^{\text {os }} 29$ a 36) - ya que fueron obtenidos en excavaciones antiguas y no existen datos sobre si fueron recogidos en horizontes estratigráficos de coexistencia. Lo mismo podemos decir con respecto a la necrópolis de Eras del Bosque (Palencia), los más completos y antiguos por ahora de toda la Península.

Quizás los ejemplares más antiguos de estas dagas y como no podría ser de otra manera las encontramos en el norte peninsular. Nos referimos a tres (n. $\left.{ }^{\text {os }} 25-27\right)$ - uno de ellos en su funda- (figs. 8-12) de los seis puñales que aparecieron en la capital de Palencia, y que probablemente formaron parte de los ajuares de tumbas en la desaparecida necrópolis de Eras del Bosque $^{11}$. Muestran una simple y ya conocida estructura metálica tripartita en su empuñadura, pero resultan más esclarecedoras las características de sus hojas. De espigo plano sin llegar al pomo y nervio central, muestran también unos filos con delineación escasamente ondulante. Los hombros se muestran oblicuos, cuyos extremos se prolongan en cortos apéndices que hacen menos ancha y triangular la base de la hoja, siendo envueltos por los extremos de las

8 Los futuros estudios sobre el origen de la daga romana no deberían perder tampoco de vista los ejemplares indígenas de la necrópolis soriana de Carratiermes (Museo de Barcelona y tumba 215 de las excavaciones de J. L. Argente) (Argente, Díaz y Bescós, 2001), por lo que de parecido formal conllevan.

9 No compartimos la valoración de las efigies de dagas supuestamente de esos mismos tipos, que se muestran en el reverso del denario de Bruto como muestra de esta contemporaneidad (Vanden Berghe y Simkins, 2001-02: 76), dado que la simplicidad formal, tratada más como recurso artístico que con un afán identificador abundante en detalles reales significativos, impide desde todo punto de vista la identificación con cualquiera de los dos tipos. El pomo en cruz de la daga situada a la izquierda del yelmo itálico nos recuerda vivamente al de la daga de Tarent (Obmann, 2000: Taf. 29).

10 Algunas empuñaduras muestran un pomo cuya forma actual se parece más a un óvalo que a una «D» invertida propiamente dicha. Ante la ausencia de datos concluyentes y teniendo en cuenta que se trata de objetos tan oxidados que han perdido todo resto de metal, de momento consideraremos que la fragilidad que conlleva una total mineralización es el motivo que los ha deformado.

11 En nuestra primera publicación sobre estos objetos así lo creíamos (Fernández Ibáñez 1999b), pero con posterioridad retrasamos equívocamente la cronología dentro de la primera mitad del siglo I d.C. (hasta época de Claudio) influenciados por la funda de Exeter - una exclusiva funda de hierro calada - (Scott, 1991), sin ponderar adecuadamente otros elementos que aquí analizamos (Fernández Ibáñez, 2006b: 285-285; 2007). F. Quesada (2007) siempre estuvo de acuerdo con la primera propuesta cronológica. 
crucetas. También vemos esto último en Dangstetten y Titelberg, aunque en este último esta parte se remacha mediante cuatro roblones; aquel y los españoles solo con dos. Las empuñaduras de Dansgstetten, Titelberg y Palencia son parecidas en su estructura, forma y número de roblones tanto efectivos como decorativos. Pero existen diferencias significativas. Titelberg posee pequeños relieves triangulares decorativos como en las empuñaduras dobleglobulares indígenas ya vistas, de lo cual carecen las de Palencia. Y su hoja es más estrecha, con filo ondulante también más cercano a las dagas celtibéricas. Por lo tanto en Titelberg (30-12 a.C.) quizás nos encontremos ante el prototipo de una daga con empuñadura en «D», mientras que las de Palencia tal vez sean más modernas. Se encuentran morfológicamente más cerca de Dangstetten; quizás cerca del cambio de era. El problema se complica cuando vemos la daga augustea de Gravenvocrem (Bélgica) (Vanden Berghe, 1996: 66, fig. 4) que pudiendo ser más tardía, muestra hombros oblicuos y una hoja prácticamente igual a la de Titelberg. Pero la empuñadura es de una modernidad evidente según lo que veremos en todo el siglo I d.C. Está claro que las hojas se reaprovechaban y reutilizaban.

De esta época y en lo que a vainas se refiere solo contamos con un ejemplar de Palencia (n. ${ }^{\circ}$ I), en la cual se encuentra enfundado su puñal y ambos unidos mediante productos de corrosión (figs. 8 y 10). Es de un tipo sencillo fabricado en hierro, y como ocurrió con la daga parece haber sido heredada a partir de modelos indígenas de la II Edad del Hierro. La estructura es de dos rieles o cantoneras de sección en «U» por donde se deslizan los filos del arma, unidos entre sí en anverso y reverso mediante cuatro láminas-puente (dos de ellas hacen también las veces de embocadura) con restos de una decoración espigada. Los remaches que unen las láminas a las cantoneras laterales recogían cuatro laminillas que en «U» sustentarían la funda al tahalí por medio de argollas. La buterola en la que remata el extremo inferior es un disco que muestra una cruz grabada. Se trata de una armadura que protegería un forro de materia(s) orgánica(as). Es un modelo del mismo tipo que la funda de Titelberg o una de las de Dangstetten (Obmann, 2000: Taf. 28). Pero en Europa en estos momentos finales del siglo I a.C. se conocen también otros tipos de fundas metálicas compuestas por láminas de hierro cerradas y también con forro de materia orgánica, y cuyo decorativo sistema de suspensión mediante pequeñas bridas remachadas en los bordes perdurará a lo largo del todo el siglo I d.C. Se trata de la vaina de Rittergasse (Suiza) que se fecha en un momento anterior al año 15 a.C. (Helming, 1990) y la ya vista de Dangstetten (Obmann, 2000: Taf. 25-2 y 3), esta última en muy precario estado de conservación.

De la primera centuria contamos con unos veintiocho ejemplares en la Península Ibérica, y tan solo siete de los cuales han sido obtenidos en excavaciones modernas (n. ${ }^{\circ} 8,13,14,15,18$, 19, 52) (figs. 15-17, 25) (láms. III-V) con muy escasa información aprovechable por tratase de empuñaduras o bien presentar muy deficiente estado de conservación. Otros, como son los conjuntos hallados en Arcobriga (n. ${ }^{\text {os }} 1-6$ ) (fig. 15) o Numancia (n. $\left.{ }^{\text {os } 29-43)}\right)^{12}$ (fig. 13.14), proceden de excavaciones de principios del pasado siglo XX siendo también escaso el beneficio de su conocimiento. Y múltiples aspectos más (acciones furtivas, hallazgos de superficie...) para los cuales hemos de recurrir a la comparación con otros puñales que hayan aportado información más enriquecedora. En este caso las fundas que están asociadas a las dagas son de particular interés como veremos.

En el siglo I d.C. los puñales del ejército parece que se encontraban unificados, al menos en lo que a la empuñadura se refiere, cuyo pomo tenía forma en «D»; se conocen objetos donde

12 Nada sabemos de dos hojas más de daga en hierro aparecidas en las excavaciones de A. Schulten. Una proviene de unos de los campamentos del cerco con arista y espigo plano (Schulten, 1927: Taf. 34-3), y la otra de la ciudad de Numancia, con estrecha cintura, y hombros oblicuos (Schulten, 1931: Taf. 58, inferior derecha). 
esto no es así, son consideradas como reparaciones (dagas de Rißtissen y Neath) (Scott, 1985: 201 y 205). Durante este siglo ocurre lo mismo en la Península Ibérica, estando formada la empuñadura por las tres conocidas partes metálicas más dos de materia orgánica, ya sea madera (n. $\left.{ }^{\circ} 35,48\right)$ (fig. 13.2) o hueso (n. $\left.{ }^{\text {os }} 15,19,30\right)$ según el modelo analizado en Colchester (Scott, 1989: 153, 156-157). Este conjunto permanece unido por al menos siete roblones, normalmente dos en el frente del pomo (a veces con tres más adicionales de carácter decorativo en la parte superior), y el resto a lo largo de la caña y la cruceta. No es posible obtener otro tipo información. En cuanto a las hojas no se cumple el esquema tripartito que Scott (1989: 153154) establece para Britannia, apareciendo tan solo en la península su Tipo I. En la antigua Hispania, aunque solo contamos con doce hojas más o menos completas (Arcobriga -n. ${ }^{\circ} 1-$, Monte Castrelo -n. ${ }^{\circ} 8$-, Cuesta del Burro -n. $.^{\circ} 12-$, Corporales -n. ${ }^{\circ} 15-$, dos en Palen-

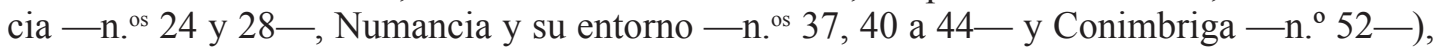
mayoritariamente solo hemos constatado un tipo de hoja con filos que delinean una marcada «S» y nervio central convexo ${ }^{13}$. Por el momento no se conocen las amplias acanaladuras paralelas, ni tampoco varios nervios dispuestos también en paralelo, ni las superficies lisas (Scott, 1989: pl. 73). Los espigos son siempre láminas planas no existiendo ni un solo ejemplo de tipo cilíndrico o barrita de sección más o menos cuadrada, Tipo II de Scott para estos apéndices estrechos (Scott, 1989: 153). Los hombros de la base de la hoja parece ser que siguen siendo oblicuos como vimos en las dagas más antiguas. Solo los dos puñales flavios de Palencia capital conservan una leve inclinación (figs. 18 y 20) en concordancia con lo que vemos en otros lugares de Europa (Gerhartl-Witteven y Hubrecht, 1990: figs. 10-12). Desaparecieron completamente, eso sí, los pequeños apéndices laterales. Naturalmente hay excepciones a estas características generales como son algunos ejemplares de Arcobriga (n. ${ }^{\circ}$ 2) (fig. 15.9) y el de Conimbriga (n. ${ }^{\circ}$ 52) (fig. 27.1). Este último procede del foro Flavio y del primero no estamos nada seguros debido a que no conocemos nada sobre él.

Por su exclusividad de momento no podemos pronunciarnos en torno al par de hojas procedentes de los campamentos del entorno de Numancia (n. ${ }^{\text {s }}$ 41-42) (fig. 14.2 y 3). De ellas no hemos hallado otro paralelo más cercano que el que incluyó Luik (2002: Abb. 52.8) procedente de Haltern (en torno al cambio de era). Con espigo plano es una hoja cercana a nuestro ejemplar de Molino ( $^{\circ}$ 41) en cuanto a su delineación, pero la daga alemana muestra signos de antigüedad en la anchura y oblicuidad de los hombros, contrario a lo que nuestra hoja nos muestra. Los hombros horizontales de las dagas del cerco numantino también pudieran llegar a interpretarse como signo de antigüedad según los vemos en las armas blancas prerromanas; máxime al tratase de un campamento del siglo II a.C. Además tienen pedicelo estrecho. Estas características también se nos pueden mostrar cercanas a la centuria siguiente, no así la estrechez de la hoja.$^{\circ} 2$ de la fig. 14, más propia como a continuación veremos de finales del primero. Una vez visto esto y teniendo en cuenta que no contamos con fiabilidad alguna por la antigüedad de la excavación, hemos de obrar con prudencia y esperar hallazgos futuros.

Para finalizar el apartado de los puñales de esta primera centuria solo nos quedan por tratar el conjunto de relaciones existentes entre las dagas de Monte Castrelo (n. ${ }^{\circ} 8$ ) (lám. III) y Corporales (n. ${ }^{\circ}$ 15) (fig. 17). Ambas deben responder a un mismo cuerpo de ejército con idénticas o muy parecidas motivaciones respecto a su presencia. Ambas también muestran un tipo de hoja muy similar y particular entre las de este siglo I, ya que son las más estrechas (con reducida cintura) halladas hasta ahora, de hombros oblicuos y similares en la delineación de

13 No hemos identificado acanaladuras a ambos lados de este nervio central, pero este dato no lo hemos constatado como característica de las dagas de Hispania. Ya que los característicos estados de conservación (normalmente muy deficientes) en que se presenta la materia de hierro en la que están forjados, fácilmente puede haber hecho desaparecer estas leves concavidades. 
sus filos. Si bien solo una presenta nervio central. La primera se encuentra fechada a finales de este siglo en un castro minero de Asturias, pero la segunda no fue posible adscribirla a uno de los dos momentos cronológicos determinados en el castro de origen (Fase I, 45/50-60/70 d.C. y la Fase II, 70/75-100/120 d.C.), también minero, y geográficamente muy cercano (fig. 1.3 y 10). A la vista de esto creemos no resulta muy descabellado suponer que la daga de Corporales cronológicamente corresponda a esta segunda - y última - fase de ocupación. Curiosamente Scott, con respecto a las hojas, crea y agrupa en la segunda mitad de este siglo: IV (hojas estrechas), V (hojas con poca cintura) y VI (hojas con nervio central poco resaltado). Son las últimas dagas, y atribuye esta característica reducción volumétrica al ahorro de metal (Scott, 1985: 164-165).

Con respecto a las fundas nada sabemos de las que fueron usadas por el ejército durante la primera mitad de este primer siglo. Solo contamos con anillas y sobre todo presillas para la suspensión procedentes del área de San Millán en Herrera de Pisuerga (n. $\left.{ }^{\circ} \mathrm{V}\right)$. Esta última al ser de tipo moldurado (fig. 29.3) quizás nos esté hablando del uso de tipos cerrados que nada tienen que ver con los modelos que derivan de las fundas indígenas vistas en una de las dagas de Palencia; aunque tampoco debemos descartar en absoluto esta posibilidad. Otra cosa bien diferente es lo que se observa durante la segunda mitad de este siglo, amplio momento cronológico donde pueden ser integradas las que proceden de Palencia capital (tres ejemplares, n. ${ }^{\text {os }}$ II-IV), un magnífico ejemplar sin procedencia (n. ${ }^{\circ}$ VII), Fuente de la Mora (n. ${ }^{\circ} \mathrm{VI}$ ) y Conimbriga (n. ${ }^{\circ}$ VIII) de las cuales solo estas dos últimas han sido halladas en contexto.

En función de su aspecto formal es claramente factible clasificar estos hallazgos en tres tipos o grupos, a los cuales no es posible dar una seriación cronológica dentro de los últimos cincuenta años de este primer siglo. El primero sería aquel que agruparía a las fundas fabricadas en aleación de cobre cuyo anverso muestra una decoración mediante plaqueado con oro, grabada y calada (que deja entrever una lámina inferior), siendo lisa y de hierro la posterior. Varios roblones de voluminosa cabeza decorativa unen las placas de anverso y reverso y las cuatro presillas o bridas para la suspensión del arma al tahalí. Por un dibujo antiguo de una de ellas (fig. 20) sabemos que remataban en un disco. Es un modelo único que solo se ha encontrado hasta la hora en la Península, De tal manera que dada su exclusividad proponemos la denominación de «Hispánico» para este tipo, que estaría representado por los hallazgos de Palencia capital (fig. 19) y Conimbriga (fig. 27.2). La cronología relativa presenta un problema, ya que fue hallada entre los desmontes tardíos de estructuras flavias. Por lo que no resulta nada firme su actual consideración cronológica.

El segundo modelo se encuentra representado por los dos hallazgos de Palencia capital (n. ${ }^{\text {os }}$ III-IV) (figs. 23-24) ${ }^{14}$ y el magnífico ejemplar que se guarda en el Museo de Mainz (n. ${ }^{\circ}$ VII) (lám. VI). Son ejemplares de espectacular aspecto. Están fabricados mediante dos láminas recortadas en bronce y unidas por sus bordes, y cuyo esquema formal y decorativo es muy parecido al modelo anterior: dos rectángulos horizontales en las partes superior y media, unidos ambos por otro dispuesto en sentido vertical. La mitad inferior es triangular y remata en un ya clásico disco, cuya característica decoración nos hizo identificar el fragmento $\mathrm{n}$. $^{\circ} \mathrm{V}$ procedente del área de La Ribera en Herrera de Pisuerga (segunda mitad del siglo I d.C.). La decoración se encuentra básicamente compuesta por paquetes de líneas rectas y paralelas grabadas; en la funda del Museo de Mainz incluso acanaladuras. Los roblones (en número variable) que unen las láminas de anverso y reverso sirven a la vez para sustentar las anillas que son abrazadas por las bridas de suspensión. Las cabezas de tales elementos suelen sen voluminosas, a veces muy

14 Estos objetos presentan un ejemplo casi idéntico en una de las fundas del cementerio sur de Nijmegen (GerhartlWittereen y Hubrecht, 1990: 104 y 107; Obmann, 2000: Taf. 46.1). 
amplias, y también de evidente carácter decorativo. No existen datos, pero es posible que contuviesen un forro de materia orgánica que ajustase e inmovilizase el arma. Sin más precisión podemos incluir este modelo también en la segunda mitad del siglo I d.C.

De finales de este siglo es el último modelo representado por el hallazgo de Fuente de la Mora (n. ${ }^{\circ}$ VI) (fig. 29). Se trata de un modelo en hierro formado por cantoneras de sección en «U» y placas-puente entre ellas que recuerdan a las del siglo anterior e inicios de este, pero indudablemente es una variante tardía y muestra su pervivencia a todo lo largo de esta centuria. Tiene un claro paralelo en la funda de Exeter con una cronología entre el 55-75 d.C. (Scott, 1991), aunque aquella presenta un remate en disco lo que la española nunca parece haber tenido. Son fundas caladas, estuvieron sustentadas por cuatro anillas con sus respectivas bridas y la inglesa contuvo un forro de madera. Solo la que procede de Salamanca muestra restos de decoración plaqueda (cobre u oro). Este tipo de fundas fueron las que marcaron las modas en los siglos siguientes hasta la desaparición de esta arma.

Las dagas hispanas del siglo I d.C. poco tienen que ver con lo que se fabrica en estos momentos en áreas más militarizadas como es el limes britano-germano-danubiano. Nuevamente no es aplicable la tipología de Scott (1985: 165-167; 1989: 154-156): A, B, Bi, Bii. Se desconocen los modelos con barrocas decoraciones naturalistas y fundamentalmente geométricas a base de plaqueados de plata y vidriados de colores cuyos motivos copian representados en mosaicos y pinturas murales (Scott, 1985: 163-173; Obmann, 2000: 21). Lo mismo puede decirse en cuanto a las decoraciones de las empuñaduras con idénticos motivos y materias con los que se confeccionan, ya que en la península son inexistentes a no ser que no se hayan conservado debido a las exfoliaciones producidas por la oxidación del hierro base. Tampoco ha sido hallado ni un solo ejemplar de funda constituido por una lámina de hierro decorada de la misma manera, y que va unido a una estructura de madera y cuero (tipos Bi y Bii de Scott) que se fechan en los años de las dinastías claudio-flavia, desapareciendo con este siglo.

\section{LAS DAGAS DE LA SEGUNDA CENTURIA}

Hace algunos años aún leíamos algún tratado (hasta mediados de la década de los años ochenta de pasado siglo XX) donde se aseguraba que los puñales en el ejército romano desaparecieron al final de la primera centuria. Posiblemente la influencia de los relieves de Adamklissi en donde esta arma brilla por su ausencia, haya sido decisivo en esta errónea creencia. Esta aseveración también conllevaba una buena dosis de desconocimiento ante un nutrido conjunto de hallazgos arqueológicos, que al hecho de que si bien no eran en absoluto tan numerosos como hemos visto hasta ahora, se adicionaba el encontrarse geográfica y bibliográficamente muy dispersos y ser menos vistosos. A ello habría que añadir la representación de la gran daga que porta al cinto en su costado izquierdo el soldado C. Castricius Victor en su estela funeraria hallada en Aquincum (Hungría), aunque está fechada en el siglo III d.C. Bishop y Coluston (1993: 135) recogen el relato de Herodiano (170-240 d.C.), en el que en su obra histórica describe cómo el emperador Severo degradó a pretorianos despojándoles de los elementos más emblemáticos para un soldado de la antigüedad, como eran las dagas y los cinturones.

Para la Península Ibérica contamos con el hallazgo de ocho ejemplares - todos ellos forjados en hierro-, dándose a conocer la mitad de ellos como descubrimientos casuales; esto es, sin contexto arqueológico alguno. Su análisis hemos de llevarlo a cabo a través de su aspecto y las características más destacadas de su morfología. Que además nos servirán como marco de comparación con hallazgos obtenidos en contexto y con cronología. Esto nos impide que podamos realizar con todos ellos cualquier seriación sucesiva en el tiempo. 
El primer grupo lo forman un par de hojas procedentes de Rosinos de Vidriales (n. ${ }^{\circ} 47$ ) (fig. 30) en contexto militar (campamento de Ala II Flavia) y de la necrópolis de Ateabalsa (n. ${ }^{\circ}$ 50) (fig. 31). Como característica principal muestran filos con delineación en «S», hombros rectos y pedicelo estrecho y plano, siendo los primeros conocidos en la península que lo llevan, cuando en Europa el ejemplar más antiguo (aunque cilíndrico), el procedente de Usk, se fecha en época de Nerón (Scott, 1985: 162, 187-188). Ante la ausencia de remaches quizás el sistema utilizado para la sujeción a la empuñadura (tal vez de materia orgánica) fuesen anillas de presión. Otra característica que los hace comunes es el ser los únicos en contar con cronología, siendo respectivamente de mediados y finales de este siglo.

Otro conjunto pero esta vez de cuatro puñales presentan la particularidad de conservar íntegra la empuñadura, y al extremo de ella un pomo cuyo formato será característico de las dagas hasta su desaparición; no volveremos a encontrar ya la forma en «D» del pasado siglo; quizás la daga de la villa de Torre Palma (n. ${ }^{\circ}$ 53) pueda fecharse en este siglo. Poco más comparten aparte de ser hallazgos desafortunadamente sin contexto. El puñal de Aroche (n. ${ }^{\circ}$ 7) (fig. 32) nos muestra un nuevo diseño en lo que nosotros hemos denominado como «bilobulado o de mariposa» (Fernández Ibáñez, 2007) conformado por una concavidad o escotadura en la zona superior. Dicho pomo - y el resto de la estructura de la empuñadura como veremos - muestra evidentes paralelos con la daga del campamento auxiliar (de la Cohors I Augusta Iturearorum y de la Cohors II Nervia Brittonum) de Buciumi —Rumanía- (106-115 / 115-275 d.C.) (Chirila et al. 1972: 62, lám. LVII). Este pomo presenta la particularidad de tener los costados convexos y la concavidad superior tan corta y profunda que forma sendas cúspides. Esto mismo lo observamos en la empuñadura de Bar Hill realizada en aleación de cobre y fechada a mediados del siglo II d.C. (Roberson, Scout y Keppie, 1975: 99 nota 15, fig. 32.15). No obstante, estas dagas comparten una característica que no poseen las dagas española y rumana, y es que los costados no son cóncavos ya que a la mitad de su desarrollo se produce una leve inflexión o carena que con el tiempo llegará a modificar la fisonomía del pomo en la centuria siguiente. Un extremo de parecidas características posee la daga de Pinilla de Toro (n. ${ }^{\circ} 46$ ) (fig. 33), pero aunque entra a formar parte de este nuevo tipo muestra un modelo sensiblemente diferente, ya que sus lóbulos son redondeados.

Los dos pomos que nos restan por analizar son el de una daga procedente de Bolmir (n. $\left.{ }^{\circ} 9\right)$ (fig. 34) y otra sin procedencia (n. ${ }^{\circ}$ 54) (fig. 35). Resultan tan sumamente característicos que son los únicos que se conocen, quizás también se trata de una especialidad de la Península. $\mathrm{Su}$ forma en creciente lunar está decorado en uno de los casos mediante una gráfila de puntos en relieve, o con extremos apuntados el otro al extremo de una empuñadura con decoración geométrica nielada al estilo de cómo se hacían un siglo antes (Obmann, 2000: Taf. 30-32) ${ }^{15}$. Hasta hoy es el único elemento de empuñadura decorado de esta manera en toda la península. Pero no estamos seguros que en el caso de estos dos ejemplares nos encontremos ante dagas de esta centuria, debido a su exclusividad, careciendo de paralelos o bien de otros datos de orden cronológico. Nos encontramos en la misma situación que las fundas caladas de raigambre hispana (n. ${ }^{\text {os }}$ II y VIII) que vimos a finales del siglo anterior.

La estructura de las empuñaduras (fabricadas en hierro y aleación de cobre) de esta época presenta también otras peculiares características. Aparte de los distintivos pomos, vemos como los abultamientos centrales antideslizantes se reducen ostensiblemente. De tal manera es así que ya son leves apéndices convexos o bien adoptan una forma triangular. La estructura

15 El «enrejillado» que presenta la caña de esta empuñadura como decoración, lo podemos remontar hasta época celtibérica como muestran las empuñaduras de las dagas dobleglobulares de la tumba 1387 de la necrópolis de La Osera (Ávila) (Cabré Herreros y Morán Cabré, 1989: figs. 1 y 2.A), o bien el ejemplar sin procedencia que se custodia en el Museo de Mainz (Egg, 1986; Obmann, 2000: Taf. 47). 
parece no contener ya elementos de materia orgánica, ósea, todo resulta ser metal. No obstante en la daga ${ }^{16}$ de Bolmir (n. ${ }^{\circ}$ 9) hemos detectado una nueva lámina metálica de aleación de cobre interpuesta entre las cachas y el pedicelo plano que sube de la hoja. Esto es algo nuevo y no constatado hasta ahora, que no parece estar muy extendido ya que Pinilla de Toro (fig. 33) parece no poseerlo, y pese al precario estado de conservación la de Aroche (fig. 32) tampoco parece contar con esta pieza. Esta lámina va desde la cruceta hasta el pomo, delineando todo el perfil de la empuñadura. Suponemos que se trata de un refuerzo ante la ausencia de elementos de materia orgánica, ya que el grosor de la empuñadura se reduce ostensiblemente. Quizás es un eco en el recuerdo de la estructura dobleglobular que veíamos a finales del siglo I a.C. (fig. 3 ), aunque si bien es verdad aquellos elementos también de aleación de cobre se interponían por otra cuestión bien diferente. El conjunto queda firmemente unido mediante roblones cilíndricos remachados en sus extremos, tres en la caña y al menos dos en la cruceta.

Como no nos ha sido posible obtener algún tipo de información sobre la daga de la villa de Torre Palma (Portugal) (n. ${ }^{\circ}$ 53), nos es imposible realizar acertadas disquisiciones. Es un ejemplar muy curioso ya que a su ancha hoja lisa en hierro se une lo que parece ser un pomo en «D», aunque la cuestión está poco clara debido a la rotura que sufre. La hemos incluido entre las dagas de este siglo porque a la factura de su empuñadura, aparentemente en aleación de cobre, se une el pequeño engrosamiento triangular en el centro de la caña. Vimos que estas particularidades son características de este siglo, aunque tampoco hemos de descartar que perteneciese al siguiente.

Las hojas es una parte poco característica en las dagas de este periodo. Formalmente variadas, cuantitativamente predominan las de nervio convexo en el centro de unas hojas cuyas anchuras y delineación de filos son dispares, de tal manera que sin contexto es difícil adscribirlas a este siglo si no aparecen acompañadas de su empuñadura. Otras hojas como las de Nida-Heddernhem (Reuter, 1999: 121, Abb. 3) o Tuchyňa donde Bishop y Coulston (2006: 134, fig. 80.3) las han fechado en este siglo mientras que Krekovič (1994: fig. 13, sin esgrimir argumentos) lo fecha en el siglo III d.C. Los hombros siempre son rectos habiendo desaparecido la oblicuidad, lo que nos hace pensar que las que proceden de Santa Cruz de Camazos (n. ${ }^{\circ}$ 44) (fig. 22) y Castrillo de la Reina (n. ${ }^{\circ} 12$ ) (fig. 23) —esta última con un reducido engrosamiento central en la empuñadura- y ambas recogidas en superficie, quizás pertenezcan a este siglo. Los pedicelos estrechos son minoría, no conociéndose en la península los de sección cilíndrica. Esta variación puede llegar al punto de lo que observamos en la hoja daga de Bolmir (n. ${ }^{\circ}$ 9) (fig. 34). Muestra tres acanaladuras - posiblemente en ambas caras - de una esbelta configuración de sinuosos filos. Tipológicamente más propia de la segunda mitad del siglo I d.C. según ejemplos hallados en Britannia o el limes continental (Bishop y Coulston, 2006: fig. 39.5; Feugére, 1993: 164; Scott, 1989: pl. 73.V6 y V7; Scott, 1985: fig. 1.53), que característica de Hispania un siglo más tarde tal y como creemos que evidencia su empuñadura. Quizás pudiésemos estar ante un caso de la reutilización de una antigüedad, pero nos encontramos con el handicap de que sus hombros son rectos, siendo oblicuos para Europa continental como vimos en las dagas de aquella segunda mitad del siglo I.

Finalmente nos encontramos con un pequeño conjunto dispar, en cuyo seno agruparíamos aquellos hallazgos que no solamente no encajan morfológica y dimensionalmente los que hasta ahora hemos visto, sino que cada hallazgo supone un objeto único; hablamos de las dagas de la villa de Tolegassos (n. ${ }^{\circ}$ 10) (fig. 37) (lám. VII) y los de la antigua ciudad de Cara (n. ${ }^{\text {os }}$ 48-49) (fig. 36). Comparten ambos la proveniencia de núcleos civiles, por lo que no estamos seguros de su adscripción militar con la que solamente tal vez pudieron estar de alguna manera

16 Nos ha sido imposible su análisis ya que de momento esta daga se encuentra en paradero desconocido. 
relacionados. Hallazgos en este siglo de dagas, llamémoslas poco convencionales, se conoce más de un caso, pudiéndose citar solo a modo de ejemplo las de Volubilis (Boube-Piccot, 1994: pl. 25.231), Gloucestershire y Camulodunum (Scott, 1989: pl. 74-V 10 y pl. 75-V 19) y Vindonissa (Unz y Dechler-Erb, 1997: Taf. 10).

En la Península Ibérica no se conoce un solo ejemplo de funda para estos u otros puñales. Suponemos que sigan la sintonía - al menos la mayoría - de lo que se percibe en Tuchyňa (Bishop y Coulston, 2006: 134, fig. 80.2). O sea, fundas confeccionadas con lámina de hierro o aleación de cobre, caladas, aparentemente sin decoración, quizás con buterola terminal al estilo de las que veremos para el siguiente siglo y dos anillas de suspensión a cada costado; recubren un forro de materia orgánica. Que a tenor de los hallazgos de Exeter y Fuente de la Mora que son del mismo tipo, aunque fabricados en el siglo anterior, vemos que el modelo no llega a desaparecer.

\section{VI. ¿EL FINAL DE LAS ARMAS BLANCAS?: EL SIGLO III}

Esta centuria - como la anterior - también gozó en otro tiempo de haber sido considerada entre las que se aseguraba que las dagas ya no formaban parte del ejército de Roma. Los hallazgos arqueológicos que comentaremos, más las representaciones estelares de C. Castricius Victor procedente de Aquincum y otra más de Augsburg (Bishop y Coluston, 1993: 135) lo demienten.

En lo que a hallazgos arqueológicos se refiere encontramos parte de la producción de la fabricae de Kastell Künzing (59 dagas y 29 fundas) fechada a mediados del siglo III d.C. (Herrmann, 1969; 1972). A este gran hallazgo que aporta gran información sobre las características de las dagas que se fabricaban en esta época, habría que adicionar otras como la de Copthall Court (Londres) que fue hallada junto a su funda (Spencer, 1961: 214-215), las hojas de Eining (una de ellas con los restos de una funda) y la vaina de Speyer (Bishop y Coulston, 1993: 135, fig. 95). Se caracterizan por ser grandes puñales de hierro con una longitud en torno a los $400 \mathrm{~mm}$ (la de Londres tiene una longitud de $422 \mathrm{~mm}$ ), en los que las hojas son anchas y esbeltas, con hombros rectos, nervio central enmarcado por acanaladuras, filos ondulantes (más raros son los rectos) con estrecha cintura, y espigo plano o bien muy estrecho y de sección cuadrada. En Künzing hay varios ejemplares con decoraciones espigadas o de líneas grabadas que hacen realzar ondulantes serpentiformes. Estas características han servido para dar contexto cronológico a ciertas hojas que no lo tenían como las de Carnuntum, Tuchyňa o Nida Heddemheim, lo que creemos resulta solo hasta cierto punto arriesgado. Como en la centuria anterior las empuñaduras aparentemente parecen ser más características. Las cachas pueden haber sido de materia orgánica, y cuando metálicas, en «T» invertida de sección en «V» y engrosamiento central con leves resaltes triangulares, que han desaparecido en algún ejemplar muy especial también hallado en de Künzing. Se suelen remachar con siete roblones, cuatro de los cuales se aplican a la cruceta. También y como hemos visto para el siglo II estas dagas presentan un característico pomo muy similar a aquellos, pero hemos creído apreciar alguna diferencia que discutiremos.

Hasta la fecha no contábamos en la península con ningún ejemplar que hubiera podido ser atribuido su fabricación en este siglo. Creemos no obstante que la daga de Sotopalacios (n. ${ }^{\circ}$ 11) (fig. 38) muestra unas particularidades tipológicas (ya que fue hallada fortuitamente en superficie) por las cuales podemos fecharla en algún momento de este siglo. La hoja es ancha, de hombros rectilíneos, y si bien muestra algo tan poco característico en las superficies como son las acanaladuras (al igual que en la daga de Bolmir para el siglo II), se encuentra decorada con 
unas muy características líneas espigadas al igual que vemos de forma exclusiva en Künzing (Herrmann, 1972). Son los dos únicos lugares conocidos que muestran esta peculiaridad. La estructura de la empuñadura (la parte que seguimos considerando algo más determinante) se caracteriza por cinco elementos metálicos, que al igual que lo que vimos en Bolmir, también lleva entre las cachas y el espigo plano una lámina cuya forma delinea el perfil completo de la empuñadura, desde el pomo a la cruceta; no parece haber tenido elemento orgánico alguno. Todo el conjunto queda unido mediante remaches: cuatro en la cruceta, tres en la caña y dos en el pomo. El engrosamiento central es mínimo, de relieves triangulares al igual que el pasado siglo y como muestran los demás hallazgos de esta época, llegando a conseguirse la mínima expresión. Que no obstante, comienzan a desaparecer tal y como apreciamos en dos tipos de puñales hallados en Künzing, con pomos globulares o bien angulados de amplia escotadura.

Al extremo de la empuñadura continúa diseñándose un pomo de extremos apuntados. En la daga hallada en Sotopalacios la configuración general es oblonga en sentido vertical, diferente a lo que hemos visto en Künzing, quizás más redondeados. Los extremos apuntados se muestran aquí muy destacados producto de la gran concavidad existente. Volviendo a Künzing observamos también que los pomos cambian, y además se diversifican. Junto a los redondeados que citamos antes, comparten contemporaneidad otros de estructura angulosa (más bien pseudo-losángica) o con leve escotadura y otros con esta más amplia, troncopiramidales. Los hay también oblongos en sentido horizontal. Se percibe también una tendencia genérica en varios modelos a la angulación, algo que ya apreciábamos en Bar Hill la pasada centuria. Es por ahora difícil dar sentido a todo esto, pero las preferencias creemos que son las expuestas; varias tendencias proclives a cambios que ya se han ido produciendo.

Con respecto a las fundas nada podemos decir en nuestro territorio de estudio pues no se conoce ejemplar alguno.

\section{COMENTARIOS SOBRE REPRESENTACIONES DE DAGAS EN PIEDRA Y OTRAS MATERIAS}

Como complemento al estudio de los restos arqueológicos que acabamos de tratar, hemos recogido todo aquel tipo de evidencias (representaciones y objetos) de época romana en la Península Ibérica que hayan tenido la daga como tema, y de las cuales realizaremos algunos comentarios. Cuatro han sido los lugares donde estos han aparecido, todos ellos en España.

En primer lugar entre los seis fragmentos de relieves en piedra caliza hallados en la ciudad de Clunia (Coruña del Conde, Burgos) (fig. 1.A) (fig. 40) cuatro representan dagas, una por fragmento. Formaron parte de un mausoleo o arco. De los cinco lugares de España donde han aparecido (Clunia, Coria, Mérida, Sofuentes, S. Esteban de Gormaz) es el único donde se representa esta arma. Forman parte de un tipo de representación conocido como congeries armorum o armas amontonadas, no mostrándose como representaciones fidedignas sino más bien se encuentran tratadas como recurso artístico. Su carácter se considera más simbólico que ornamental, tema de raíces arcaicas que mostraba la victoria ante el enemigo acumulando sus armas como rito apotropaico relacionado con la magia de la guerra. Este símbolo concentra su poder en la fuerza de las armas y los espíritus que por medio de ellas hace posible llegar a la victoria (Acuña Fernández, 1974; Salcedo Garcés, 1983).

En la Colección E. Fontaneda del castillo de Ampudia (Palencia) se encuentra un magnífico ejemplar de miniatura (fig. 41). De $50 \mathrm{~mm}$ de longitud y pulido en hueso representa una daga con empuñadura de pomo con parte superior cóncava y caña con engrosamiento central 
triangular. La hoja es de filos rectos y los hombros oblicuos. La arista central se ha comenzado a grabar (sin haberse finalizado), como también se encuentran grabados los roblones - solo en la cara del anverso-, y en los costados la estructura triple de la empuñadura. Procede de una tumba en la ya destruida necrópolis de Eras del Bosque de Palencia capital, por lo tanto presenta un valor tanto funerario como simbólico. Al igual que otras armas de estas características halladas en el corazón de Europa mucho más elaboradas (hierro y hueso) y con más detalle ya que incluso se encuentran protegidas por una vaina tallada, y decorada también en hueso (Béal y Feugère, 1987). Es común la deposición de este tipo de objetos en santuarios galorromanos entre los siglos I a.C. y II d.C. (Gabaldón Martínez, 2004: 326). Los detalles de este objeto palentino apuntan hacia los siglos I-II d.C.

De la población de San Juan de Beleño (Ponga, Asturias) (fig. 1.D) (Diego Santos, 1959: 114-117) procede una estela funeraria que se expone en el Museo Arqueológico de Oviedo. Sobre una piedra troncopiramital de tipo calizo se ha grabado en su anverso el epitafio del enterrado (Lucio Septimio Silo) de la tribu vadiniense, sobre un caballo, un ciervo y dos arboriformes. Se fecha en un momento avanzado del siglo II d.C. en función de la onomástica que muestra. En la parte superior se encuentra también grabado un puñal (fig. 42) que siempre se ha considerado de antenas pero que para nosotros no es tal, tratándose más bien de una daga romana considerando el tipo de pomo y el engrosamiento en el centro de la empuñadura. La hoja muestra hombros rectos y varias acanaladuras como en una de las dagas de Künzing. A nuestro entender presenta concomitancias formales con la daga de Bolmir (fig. 34) vista anteriormente. Es más, poco tendría que ver la representación de un arma de al menos quinientos años más antigua en un momento tardío como este. La fecha propuesta para el cipo funerario concuerda bien con la cronología vista, y que además hemos propuesto anteriormente para con los puñales de pomo en creciente lunar. Hasta hoy no se ha encontrado sentido y relación a su presencia junto a este epitafio.

Finalmente en plena región de Las Hurdes (Alta Extremadura) han sido hallados varios enclaves donde se ha constatado un curioso fenómeno único hasta ahora en la península, como es la agrupación de varios conjuntos grabados representando armas. En lo que aquí nos interesa y en el paraje conocido como Collado de las Chivas (Torrecilla de los Ángeles, Cáceres) (fig.1.D), como motivos allí representados se encuentran una espada, en torno a ocho puntas de lanza y cinco hojas de daga (fig. 43). Es difícil determinar la época en que fueron grabadas estas últimas, que presentan cierta similitud con las de época imperial. Pero a tenor de los intentos de clasificación tipológico y cultural de todos los temas allí figurados parece que fueron diseñadas a lo largo de varios siglos, desde época romana a la antigüedad tardía. Lo que en cierta medida se ve corroborado con inscripciones anejas latinas de época romana y visigoda (González Cordero, 2000). La motivación y el sentido de tales diseños es algo que por ahora dista lejos de poderse siquiera intuir.

\section{CONCLUSIONES PROVISIONALES}

La estructura tan característica que muestra el puñal romano y otros elementos aquí tratados confirman y refuerzan la tan extendida como aceptada idea que este deriva de la daga indígena celtibérica. La aceptación cultural se produjo en tierras de Hispania durante las guerras de conquista, que según Quesada Sanz (2000; 2007: 390; 2008: 23-24) y Luik (2002: 90) se produjo al final de las campañas celtibéricas. En primer lugar pasó por un período de adaptación, siendo portada quizás solo por algunos soldados (quizás mandos) sin transformación alguna. Muestra de ello quizás serían las dagas halladas en Cáceres el Viejo (Cáceres), La Caridad (Teruel) o La Azucarera de Calahorra (La Rioja) en contexto de la guerra sertoriana. Con el 
tiempo y como ocurre con cualquier adopción cultural fue transformándose a los gustos y las necesidades de la cultura receptora. Estos cambios también se produjeron en tierras hispanas de la Meseta Norte, posiblemente en el transcurso del segundo cuarto de esta primera centuria a.C. quizás no de forma generalizada. En cuya zona septentrional como es el extremo norte de la actual provincia de Palencia creemos haber podido identificar un taller, quizás la misma fabricae de la legio IIII Macedonica. Nos encontramos a finales del siglo I a.C. en un área fuertemente militarizada, en y tras la guerra con las poblaciones cántabras donde las modas y los cambios se encuentran dirigidos por los soldados según sus gustos y necesidades. En este fin de siglo convivieron dos tipos diferentes de dagas, más bien dos formas de confeccionar la empuñadura: dobleglobular tradicional y la innovación con pomo en «D». Nada sabemos sobre el origen de este último modelo, y si colgaba de los cinturones de los soldados destinados a Hispania (es muy probable que así fuese), pero está claro que perduró durante todo el siglo I d.C. mientras que el modelo tradicional bidiscoidal quizás no sobrepasa el cambio de era.

La primera centuria para las dagas del ejército hispano muestra un panorama muy particular, marcadamente más provincial según avanzan los años y producto de una situación social más o menos pacificada; sin grandes eventos militares. Las hojas varían en anchura y longitud, siendo más estrechas, esbeltas y con reducida cintura en la segunda mitad del siglo, mayoritariamente con nervio central y forjándose en hierro. El espigo es siempre plano y no llega al pomo. Este último siempre es en «D» (las formas ovales deben responder a estados de conservación) con cinco roblones de cabeza decorativa. La empuñadura es de tipo clásico estando formada por cinco elementos, siendo dos de ellos de materia orgánica (madera o hueso) permaneciendo todos unidos en la caña (con engrosamiento central circular que a veces puede llegar a ser oval) por remaches cilíndricos que se disimulan mediante pulido. Como en el resto de las dagas conocidas en el imperio los hombros son oblicuos. No observamos variaciones apreciables en el diseño, pareciendo ser pura continuidad.

No observamos las abigarradas y vistosas decoraciones de plata/latón ni en las fundas ni en las empuñaduras. Tampoco resto alguno de vidrio. No obstante hemos de tener presente la húmeda climatología del sur de Europa, sobre todo en su área septentrional donde se agrupan buena parte de los hallazgos. Este clima hace de los objetos de hierro un amasijo sin apenas forma, solamente analizables sus características tras un conveniente tratamiento de limpieza. Tampoco vemos las esbeltas hojas (que se corresponden con aquellas fundas) con varias acanaladuras o nervios que confluyen en el extremo agudo. Ello quizás nos está indicando que por lógica las modas y sus cambios se encuentran donde se concentran un gran número de soldados, y esto ocurre en primera línea, o sea en los campamentos de frontera y geografías anexas. Hispania avanzado ya este siglo primero ha dejado de ser un territorio militarizado, pese a que la legio VII Gemina continúe sus trabajos en el ángulo NW. Más relacionados con otros quehaceres como pueda ser por ejemplo la minería, que con acciones bélicas, inspección o vigilancia más propias de su condición básica. Esta situación aleja a la tropa del principal foco de cambio e innovación, y pese a que puedan llegar ciertas influencias lo cierto es que en la península parecen regirse por otros gustos quizás más tradicionales y menos refinados. La soldada de un militar de Limes con mayor riesgo inherente a su físico tendría un mayor nivel adquisitivo que un soldado de retaguardia. Quizás también aquel no gozaría de una variedad para el consumo tan vasta y atractiva, por lo que tal vez gastaría su dinero en otras cuestiones más relacionadas con su aderezo reglamentario.

Las dagas no desaparecen en el siglo II d.C., pero sufren algunos cambios. El primero es cuantitativo y debe responder a que su uso no es tan frecuente debido quizás a que su valor como símbolo ya no es lo que se consideraba. Da la impresión como si solamente las conservan las tropas auxiliares, y comienzan frecuentemente a aparecer en núcleos civiles. Si bien 
se incorporan innovaciones sobre todo en la empuñadura como son los espigos estrechos, la reducción ostensible del engrosamiento antideslizante de la caña y sobre todo el pomo, distintivo inequívoco de estos siglos finales. Nada sabemos acerca de lo que produjo esta variación. Formalmente quizás pudiera haber surgido de crear una escotadura cada vez más profunda en la plataforma superior de aquellos ya antiguos pomos en «D». En la estructura desaparecen las láminas de materia orgánica, y vuelve a ser otra vez de cinco partes metálicas como a inicios del imperio. Pero diferente, interponiendo láminas que reproducen el perfil completo de la empuñadura; aunque este es un punto que aún está poco claro, ya que también lo vemos en la única daga hispana del siglo siguiente (Sotopalacios). Las hojas no son variadas respecto a las formas, de nervio central y con la forma y delineación de filos tantas veces vista, llegando a perdurar incluso una vez despareció el Imperio (fig. 39). Se percibe una menor uniformidad, si es que esta palabra tuvo alguna vez sentido entre las tropas romanas. No existe el refinamiento decorativo de empuñaduras y vainas. Estas últimas continúan una tradición que, iniciada antes del cambio de era, nunca se extinguió, fabricando las de tipo calado con forro orgánico más funcionales que vistosas. No conocemos ninguna en la península.

Por el momento no tenemos datos que expliquen por qué aparentemente su número va en regresión, y ya en el siglo III d.C. el número de hallazgos es muy exiguo. La continuidad formal es evidente en cuanto a la empuñadura y sobre todo a la forma de su pomo, pero indudablemente nos muestran su personalidad, ya que es un hecho el que llega a cambiar tanto (pomos globulares y engrosamientos mínimos o inexistentes) que hacen irreconocibles sus orígenes. Son difíciles de identificar cronológicamente a la hora de discernir qué daga es de este siglo y cuál del anterior. Aparte de la empuñadura, no sabemos si resulta muy osado el adelantar que las hojas con nervaduras (a veces decoradas con espigados, etc.) puedan ser identificativas de esta época. En tal caso las dagas con pomo en «media luna» de Bolmir (n. ${ }^{\circ}$ 9) y otra sin procedencia ( . $\left.^{\circ} 54\right)$, tan exclusivas hasta hoy de la península, no sean un siglo más tardías de cómo las hemos identificado.

Si bien es necesario hacer hincapié en que todavía no tenemos datos de lo contrario, la posible pérdida de la antigua identidad de la daga hace que su símbolo cambie radicalmente y su importancia decrezca, hasta el punto de ser tan ocasional su presencia que por ahora no nos es posible vislumbrar las motivaciones de su esporádico uso. Quizás se corresponda con la evolución del equipamiento militar, un cambio en el aspecto del soldado, pérdida simbológica o al cambio en sus formas de equipamiento o en el combate. Las últimas corrientes investigadoras consideran que el puñal no formaba parte del equipamiento militar «estándar» del legionario, sino que más bien era junto con el cinturón (balteus) un elemento distintivo y de parada/exposición/enaltecimiento/distinción, etc., militar. Debido a la rica decoración que a veces suelen presentar (sobre todo en época flavia), por formar parte de un equipamiento como se viene argumentando por diversos autores interpretándolo como «simbólico» en las estelas del Limes europeo, como también por no haberse hallado ninguna representación de soldado utilizando el arma motivo de nuestro interés. Si bien, podría servir para realizar otras funciones... Aunque en este último punto hemos de decir que su capacidad en la lucha es evidentemente muy reducida.

La daga romana en Hispania, tan desconocida hasta ahora, es harto reveladora en muchos aspectos. Uno que habíamos dejado para este final es el de su distribución geográfica (fig. 1). En aquel mapa observamos una inusual concentración entre los ríos Carrión, Ebro y Duero, en un triángulo irregular cuyos extremos se situarían entre la daga de Bolmir (n. $\left.{ }^{\circ} 4\right)$ al norte, las de Sta. Cruz (n. $\left.{ }^{\circ} 17\right)$ y Armedilla (n. $\left.{ }^{\circ} 18\right)$ al SE, y las de Numancia y Arcóbriga al este. En esta zona, de las 57 dagas estudiadas se han recogido 41 . O sea, un área que ocupa aproximadamente $17.400 \mathrm{~km}^{2}$ y supone el $2,9 \%$ del territorio peninsular, acoge el $71,9 \%$ de todos los 
puñales aquí analizados; más cinco de las ocho fundas. La fracción restante, o sea dieciséis, en la superficie de la Península Ibérica sobrante y que ocupa una extensión de $583.254 \mathrm{~km}^{2}$. Vemos claramente y una vez más cual fue en Hispania el territorio (o uno de los territorios) más conflictivos en su antigüedad. Y que coincide con poblaciones tan belicosas como Cántabros, Vacceos y Celtíberos tal y como las fuentes escritas así nos lo relatan.

\section{AGRADECIMIENTOS}

Durante la elaboración de este trabajo, que se ha llevado a efecto durante varios años, hemos necesitado la concesión de permisos, ayudas y otro tipo de colaboraciones de una serie de personas que de forma amable y desinteresada a ello se han prestado. En virtud de lo cual, hemos de hacer patente mediante sus nombres y cargos nuestro sincero agradecimiento. Estos son:

D. Constancio del Álamo, Conservador de la Sección de Arqueología, Escultura y Textiles de la Hispanic Society of America de Nueva York; D. José Carlos Álvarez y D. Pablo Rodríguez, Arqueólogos de la Sociedad Cooperativa Especum S.L. de León; D. Mariano del Amo y D. Javier Pérez, Directores que fueron del Museo de Palencia y D. Jorge Juan Fernandez, quien lo es en la actualidad; D. Alberto Bescós, Director del Museo de Salamanca; D. Emilio Campomanes, Arqueólogo de la empresa de arqueología Talactor S.L. de León; Peter Smith; Dña. Cristina Fontaneda, Directora del Museo Patio Herreriano (Valladolid); Dña. Rosario García, Directora del Museo de Zamora; D. Eliseo Gil, Director de las excavaciones en la ciudad romana de Iruña-Veleia (Álava); D. Miguel A. Hurtado, Director del Museo de Navarra; D. Emilio Illarregui, Director de las excavaciones en Herrera de Pisuerga; Dña. Amparo López, Directora que fue (hoy Conservadora) del Museo de Santander y a D. Pedro Fernández, quien lo es en la actualidad; Dña. Aurora Martín, Directora del Museo de Girona; Dña. Marta Negro, Conservadora del Museo de Burgos; Museo del Monasterio de Silos (Burgos); D. Eduardo Peralta Labrador, Director de las excavaciones en el yacimiento de La Loma (Palencia); Museo de León: Luis Grau —-Director—, Manuel García - Conservador- y Myriam Hernández - Conservadora-Restauradora-; Museo de Valladolid: D. Fernando Pérez, su Conservador; D. Fernando Quesada, Profesor Titular de Arqueología de la Universidad Autónoma de Madrid; Dña. M. ${ }^{a}$ Salete da Ponte, Profesora del Instituto Politécnico de Tomar (Portugal); D. Elías Terés Navarro y Dña. M. a Ángeles Arlegui, Director y Conservadora del Museo Numantino de Soria; Dña. M. ${ }^{a}$ Victoria Romero y D. Santiago Carretero, Profesores Titulares de Arqueología de la Universidad Valladolid; D. Tomás Vega, Arqueólogo del Grupo Arqueolóxico Larouco de Ourense; D. Ángel Villa, Arqueólogo de la Consejería de Cultura del Principado de Asturias; D. Luis C. Zambrano, Conservador-Restaurador del Museo de Cádiz.

Es de justicia reconocer la labor de nuestro compañero Julián Diez en la elaboración de una buena parte de los dibujos que ilustran este estudio de dagas. Una vez más hacemos público nuestro agradecimiento a su predisposición y a su trabajo.

Post Scriptum: Durante la impresión de este texto falleció nuestro compañero y buen amigo Julián. Queremos nuevamente recordarle aquí. El resultado de nuestras investigaciones ya no será lo mismo sin sus dibujos.

\section{BIBLIOGRAFÍA}

Abásolo Álvarez, J. A. y Ruiz Vélez, I. (1977): Carta arqueológica de la provincia de Burgos. Partido Judicial de Burgos. Diputación Provincial, Burgos.

ACuña Fernández, P. (1974): Los relieves romanos de Clunia decorados con motivos militares. Valladolid, Universidad de Valladolid, Studia Archaeologica, 30. 
AlarCão, J. et alii (1979): Fouilles de Conimbriga VII. Trouvailles diverses - Conclusions génerales. Paris, de Boccard.

Alonso Gregorio, O. A. (2004): «Sobre el hallazgo de un puñal biglobular en Monte Cildá (Aguilar de Campoo, Palencia): La panoplia militar indígena al servicio de Roma». Sautuola, X: 35-45.

Argente, J. L., Díaz, A. y Bescós, A. (2001): Tiermes V. Carratiermes. Necrópolis celtibérica. Valladolid, Junta de Castilla y León.

Bailly, A. (1977): «Les armes d'époque romaine, dans la vallée de la Saone». Mémoires de la Societé d'Histoire et d'Archéologie de Chalon, 47: 159-172.

BeAl, J.-C. y Feugére, M. (1987): «Épées miniatures à fourreau en os, d'époque romaine». Germania, 65-1: 89-105.

Bishop, M. C. y Coulston, J. C. N. (1993): Roman military equipment. London, B. T. Batsford Ltd, (2006, 2. ${ }^{\mathrm{a}}$ ed.).

Boube-Piccot, Сн. (1994): Les bronzes antiques du Maroc - IV. L'équipement militaire et l'armement. Paris-Rabat, Recherche sur les civilisations-Institut national des sciences de l'archéologie et du patrimoine.

CABRÉ, J. (1931): «Tipología del puñal, en la cultura de "Las Cogotas"». Archivo Español de Arqueología, XXXI: 221-241.

Cabré Herreros, E. y Morán Cabré, J. A. (1991): «Puñales dobleglobulares con probable simbología astral en el pomo de la empuñadura». Actas del XX Congreso Nacional de Arqueología. Zaragoza, Secretaría General de los Congresos Arqueológicos Nacionales: 341-348.

Casas i Genover, J. (1989): L'Olivet d'en Pujol i els Tolegassos. Girona, Centre d'Investigacions Arqueològiques, Sèrie Monogràfica, 10.

CAsas Genover, J. y Soler Fusté, V. (2003): La villa de Tolegassos. Una explotación agrícola de época romana en el territorio de Ampurias. Oxford, J. \& E. Hedges, BAR International Series, 1101.

Chevallier, R. (1976): «Trophées et monuments commémoratifs». La Colonne Trajane. Les Dossiers de l'Archéologie, 17: 107-115.

Chirila, E. et al. (1972): Das Römerlager von Buciumi. Cluj, Muzeul de Istorie si Arta Zalau.

Connolly, P. (1997): «Pilum, Gladius and Pugio in the Late Republic». Journal of Roman Military Equipment Studies, 8: 41-57.

Diego Santos, F. (1959): Epigrafia funeraria de Asturias. Oviedo, Instituto de Estudios Asturianos.

EGG, M. (1986): «---------», Jahrbuch Romisches Germanischen Zentralmuseum Mainz, 33(2): 906907.

Esparza Arroyo, A. (1988): «Materiales de la Edad del Hierro», La Colección Arqueológica del Padre Saturio González en Santo Domingo de Silos. Burgos, Diputación Provincial: 115-158.

Fernández Gómez, F. (1986): Excavaciones arqueológicas en el Raso de Candelada. 2 vols., Ávila, Diputación Provincial.

FernáNDEZ IbÁÑEZ, C. (1999a): «Placa de tahalí para la suspensión de las dagas en el ejército romano: entre la República y el Imperio. A propósito de un hallazgo en el campamento de la Legio IIII Macedónica (Herrera de Pisuerga, Palencia, España)», Estudios en Homenaje al Profesor Dr. García Guinea. Sautuola, VI: 335-345.

Fernández IbáÑez, C. (1999b): «Puñal». Cántabros: la génesis de un pueblo. Santander, Comisión del Centenario de Caja Cantabria: 278.

Fernández IbÁÑez, C. (1999c): «Puñal». Cántabros: la génesis de un pueblo. Santander, Comisión del Centenario de Caja Cantabria: 292.

FernándeZ IbÁÑEZ, C. (2002): «Objetos metálicos de carácter militar en la bibliografía de algunos yacimientos romanos de la Península ibérica española». Trabajos de Arqueología en Cantabria, V: $77-82$.

FERnÁNDEZ IBÁÑEZ, C. (2004): «Metalistería militar romana en el norte de la Península Ibérica durante los periodos republicano y altoimperial», C. Fernández Ochoa y P. García (eds.), III Coloquio Internacional de Arqueología en Gijón: Unidad y Diversidad en el Arco Atlántico en Época Romana. Oxford, J. \& E. Hedges, BAR International Series, 1371: 203-228.

FERnÁNDEZ IBÁÑEZ, C. (2006a): «Objetos metálicos del asentamiento militar de Herrera de Pisuerga (Palencia). Excavaciones de A. García y Bellido (1960-61)», M. Bendala et alii (eds.), La arqueología clásica peninsular ante el tercer milenio. En el centenario de A. García y Bellido (1903-1972). Madrid, CSIC, Anejos de Archivo Español de Arqueología, XXXIV: 187-202. 
FERnÁNDEZ IBAÑEz, C. (2006b): «Post Vestigium Exercitus. Militaria romana en la región septentrional de la Península Ibérica durante la época Altoimperial», A. Morillo (ed.), Actas del II Congreso de Arqueología Miltar Romana en Hispania. León, Universidad de León-Ayuntamiento de León: 257308.

FERNÁNDEZ IBÁÑEZ, C. (2007): «La metalistería militar de Hispania en época altoimperial», C. Fernández Ibáñez (ed.), Metalistería Romana de Hispania. Sautuola, XIII: 403-426.

FERNÁNDEZ IBÁÑEz, C. (e.p.): «La daga militar romana de la llanura de Bolmir (Cantabria)». Sautuola, XIII, Santander.

Fernández IbÁÑEz, C. y CAVAdA Nieto, M. (2005): «Hebilla de balteus militae en hueso de época altoimperial procedente de Herrera de Pisuerga (Palencia)». Sautuola, XI: 213-219.

Feugére, M. (1993): Les armes des romains. Paris, Errance.

Gabaldón Martínez, M. a del M. (2004): Ritos de armas en la Edad del Hierro. Madrid, CSIC, Anejos de Gladius, 5.

García y Bellido, A., (1963): «Parerga de arqueología y epigrafía hispanorromanas (II)». Archivo Español de Arqueología, XXXVI (107/108): 191-206.

García y Bellido, A. (1993): Álbum de dibujos de la colección de bronces antiguos de Antonio Vives. Madrid, CSIC, Anejos de Archivo Español de Arqueología, XIII.

García y Bellido, A., Fernández de Avilés, A. y García Guinea, M. A. (1970): Excavaciones y exploraciones arqueológicas en Cantabria. Madrid, CSIC, Anejos de Archivo Español de Arqueología, IV.

Gerhartl-Witteveen, A M. y Hubrecht, A. V. M. (1990): «Survey of swords and daggers in the Povinciaal museum G.M.Kam, Nijmegen». Journal of Roman Military Equipment Studies, 1: 99-107.

GonzÁlez Cordero, A. (2000): «Armamento tardorromano-visigodo en los grabados urdanos». Actas del Congreso Internacional de Arte Rupestre Europea. Vigo, Ayuntamiento de Vigo (edición en CD).

Heleno, M. (1962): «A villa lusitano-romana de Torre de Palma (Monforte)». O Arqueólogo Portugués, 4: 313-338.

Helming, G. (1990): «Hispaniensis Pugiunculus. Technologische Aspekte und Anmerkungen zum Fund einer Militärdolchseide aus Basel». Archäologie der Schweiz, 13(4): 158-164.

Hermann, F. R. (1969): «Der Eisenhortfund aus dem Kastell Künzing». Saalburg Jahrbuch, 26: 129-141.

Hermann, F. R. (1972): Die Ausgrabungen in dem Kastell Künzing/Quintana. Stuttgart, Limes-Museum Aalen.

KREKOVIČ, E. (1994): «Military equipment on the territory of Slovakia». Journal of Roman Military Equipment Studies, 5: 211-225.

Lorrio, A. (1997): Los celtíberos. Madrid-Alicante, Universidad Complutense de Madrid-Universidad de Alicante.

Luik, M. (2002): Die Funde aus den Römischen Lagern um Numantia im Römisch-Germanischen Zentralmuseum. Mainz, Habelt.

Maloney, S. J. y Hale, J. R. (1996): «The villa of Torre de Palma (Alto Alentejo)». Journal of Roman Archaeology, 9: 275-294.

Mañanes, T., Gutiérrez, M. ${ }^{a}$ A. y Agundez, C. (1987): El mosaico de la villa romana de Santa Cruz (Cabezón de Pisuerga, Valladolid). Valladolid, Diputación Provincial.

Martín Valls, R. y Delibes de Castro, G. (1975): «Hallazgos arqueológicos en la provincia de Zamora (II)». Boletín del Seminario de Arte y Arqueología, XL-XLI: 445-476.

MaYA, J. L. (1988): La cultura material de los castros asturianos. Estudios de la Antigüedad, 4/5. Universidad Autónoma de Barcelona.

Mezquíriz Irujo, M. a A. (2006): «La antigua ciudad de los carenses». Trabajos de Arqueología Navarra, 19: 147-267.

Monteverde, J. L. (1975): «Puñal romano de Sotopalacios». Boletín de la Institución Fernán González, 141: 792-795.

Obmann, J. (1992): «Zu einer elfenbeinernen Dolchgriffplatte aus Nida Heddemheim/Frankfurt am Main». Journal of Roman Military Equipment Studies, 3: 37-40.

Obmann, J. (2000): Studien zu römanischen Dolchscheiden des 1. Jahrhunderts n. Chr. Rahden/Westf.

Peralta Labrador, E. (2007): «Equipamiento militar romano de la conquista de la antigua Cantabria», C. Fernández Ibáñez (ed.), Metalistería Romana de Hispania. Sautuola, XIII. 
Peréx Agorreta, M. ${ }^{a}$ J. y Unzu Urmeneta, M. (1997-98): «Necrópolis y poblado de época romana en Espinal (Navarra). Memoria de las campañas de 1986, 1987 y 1988». Trabajos de Arqueología Navarra, 13: 75-126.

Peréx Agorreta, M. ${ }^{\text {a J }}$ y Unzu Urmeneta, M. (2008): «Las necrópolis de Iturissa (Espinal)», La tierra te sea leve. Arqueología de la muerte en Navarra. Pamplona, Gobierno de Navarra, 156-160.

Quesada Sanz, F. (1997): El armamento ibérico. Monographies Instrumentum, 3.2 vols. Montagnac.

QuesADA, F. (2000): «Puñal legionario». La Aventura de la Historia, 15: 100-101.

QUESADA, F. (2007): «Hispania y el ejército romano republicano. Interacción y adopción de tipos metálicos», C. Fernández Ibáñez (ed.), Metalistería Romana de Hispania. Sautuola, XIII: 379-402.

Quesada, F. (2008): Armas de Grecia y Roma. Madrid, La Esfera de los Libros.

Reuter, M. (1999): «Späte Militärdolche com Typ Künzing-Anmerkungen zur Datierung und Verbreitung». Journal of Roman Military Equipment Studies, 10: 121-124.

Roberson, A., Scott, M. y Keppie, L. (1975): Bar Hill: A roman fort and its finds. Oxford, J. \& E. Hedges, BAR International Series, 16.

Salcedo Garcés, F. (1983): «Los relieves de armas del teatro de Mérida». Lvcentum, II: 243-283.

Sánchez Palencia, J. y Fernández-Posse, M. ${ }^{a}$ D. (1985): La corona y el castro de Corporales. Madrid: Ministerio de Cultura, Subdirección General de Arqueología y Etnografía, Excavaciones Arqueológicas en España, 141.

Sánchez Palencia, J., Ruiz del Arbol, M. y López Jiménez, O. (2003): Tierra, agua y oro. Arqueología del paisaje en la Sierra de Francia. Salamanca, Consejería de Cultura y Turismo.

Schüle, W. (1969): Die Mesetakulturen der Iberischen Halbinsel. 2 vols., Berlin.

Sсотт, I. R. (1985): «First century military daggers and the manufacture and supply of meapons for the roman army». The Production and Distribution of Roman Military Equipment. Oxford, J. \& E. Hedges, BAR International Series, 275: 160-213.

Scotт, I. R. (1989): «Daggers», W. H. Manning (ed.), Catalogue of the Romano-British Iron Tools, Fittings and Weapons in the British Museum. London, British Museum: 152-159.

Sсотт, I. R. (1991): «Military equipment», N. Holbrook y P. T. Bidwell (eds.), Roman Finds from Exeter. Exeter, Exeter City Council and The University of Exeter: 263-265.

Spencer, B. W. (1961): «Two additions to the London Museum». Transactions of the London and Middlesex Archaeological Society, XX: 214-217.

Schulten, A. (1927): Die Lager des Scipio. Numantia. Die Ergebnisse der Ausgrabungen 1905-1912, Band - III. München, Verlag Von F. Bruckmann A.-G.

Schulten, A. (1931): Die Stadt Numantia. Die Ergebnisse der Ausgrabungen 1905-1912, Band - II. München, Verlag Von F. Bruckmann A.-G.

Unz, Ch. y Deschler-Erb, E. (1997): Katalog der militaria aus Vindonissa. Brugg, Veröffentlichungen Der Gesellschaft Pro Vindonissa - Band XIV.

Vanden Berghe, L (1996): «Some roman military equipment of the first three centuries AD in Belgian museums». Journal of Roman Military Equipment Studies, 7: 59-93.

Vanden Berghe, L. y Simkins, M. (2001-02): «Construction and reconstruction of the Titelberg dagger». Journal of Roman Military Equipment Studies, 12-13: 75-84.

Villa Valdés, A. (2003): «Castros y recintos fortificados en el occidente de Asturias: estado de la cuestión». Boletín Auriense, XXXIII: 115-146.

Villa Valdés, A. (2007): «Mil años de poblados fortificados en Asturias (siglos IX a.C.-II d.C.», J. Fernández-Tresguerres (coord.), Astures y Romanos: Nuevas Perspectivas. Oviedo, Real Instituto de Estudios Asturianos: 27-60.

VV. AA. (1938): The Hispanic Society of America. New York.

Recibido: $20 / 07 / 2008$

Aceptado: 19/09/2008 
FIGURAS Y LÁMINAS

CATÁLOGO DE DAGAS Y FUNDAS DE LA PENÍNSULA IBÉRICA

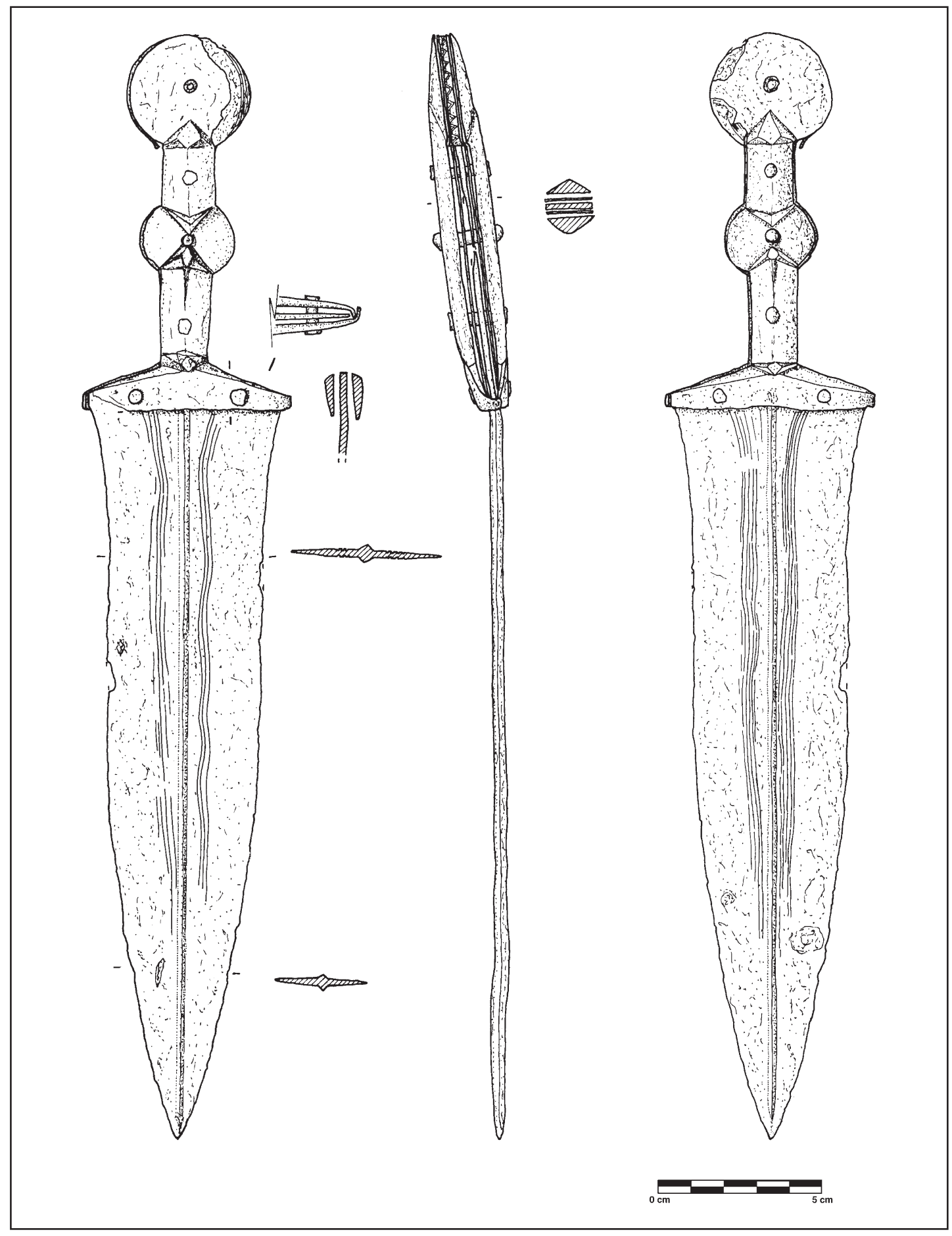

Figura 2. Daga dobleglobular de Eras del Bosque (Palencia capital). 


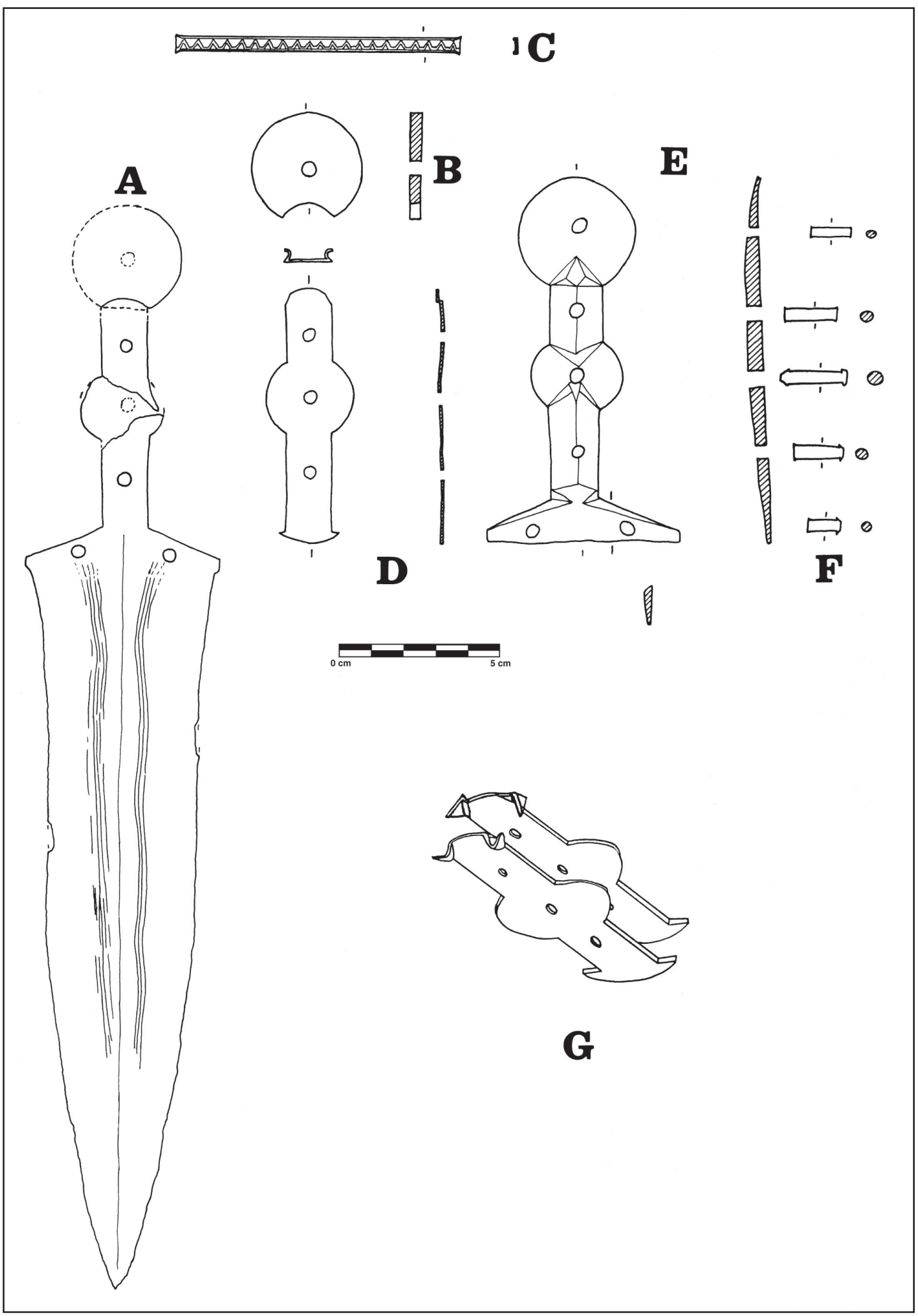

Figura 3. Despiece de la estructura de la daga dobleglobular de Eras del Bosque. 


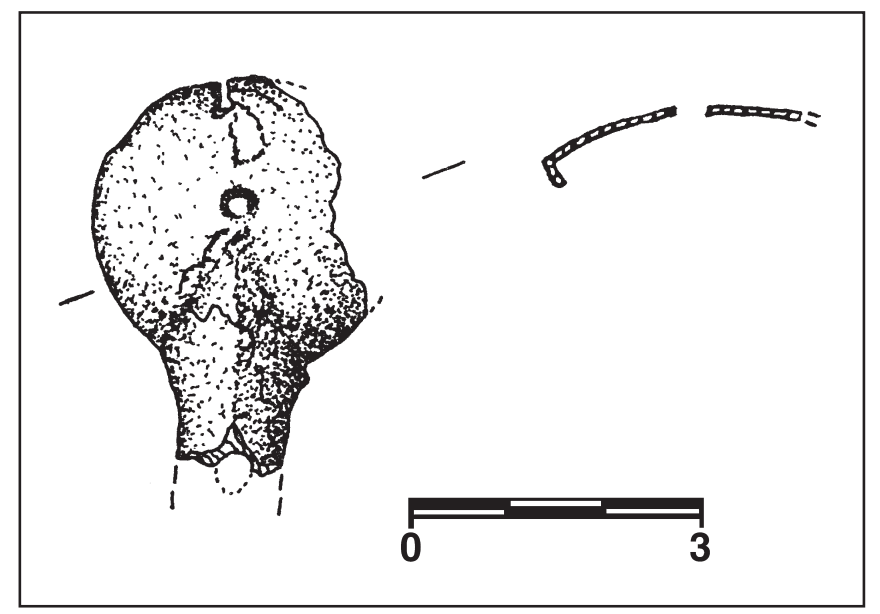

Figura 4. Fragmento de pomo de La Loma (Palencia). 


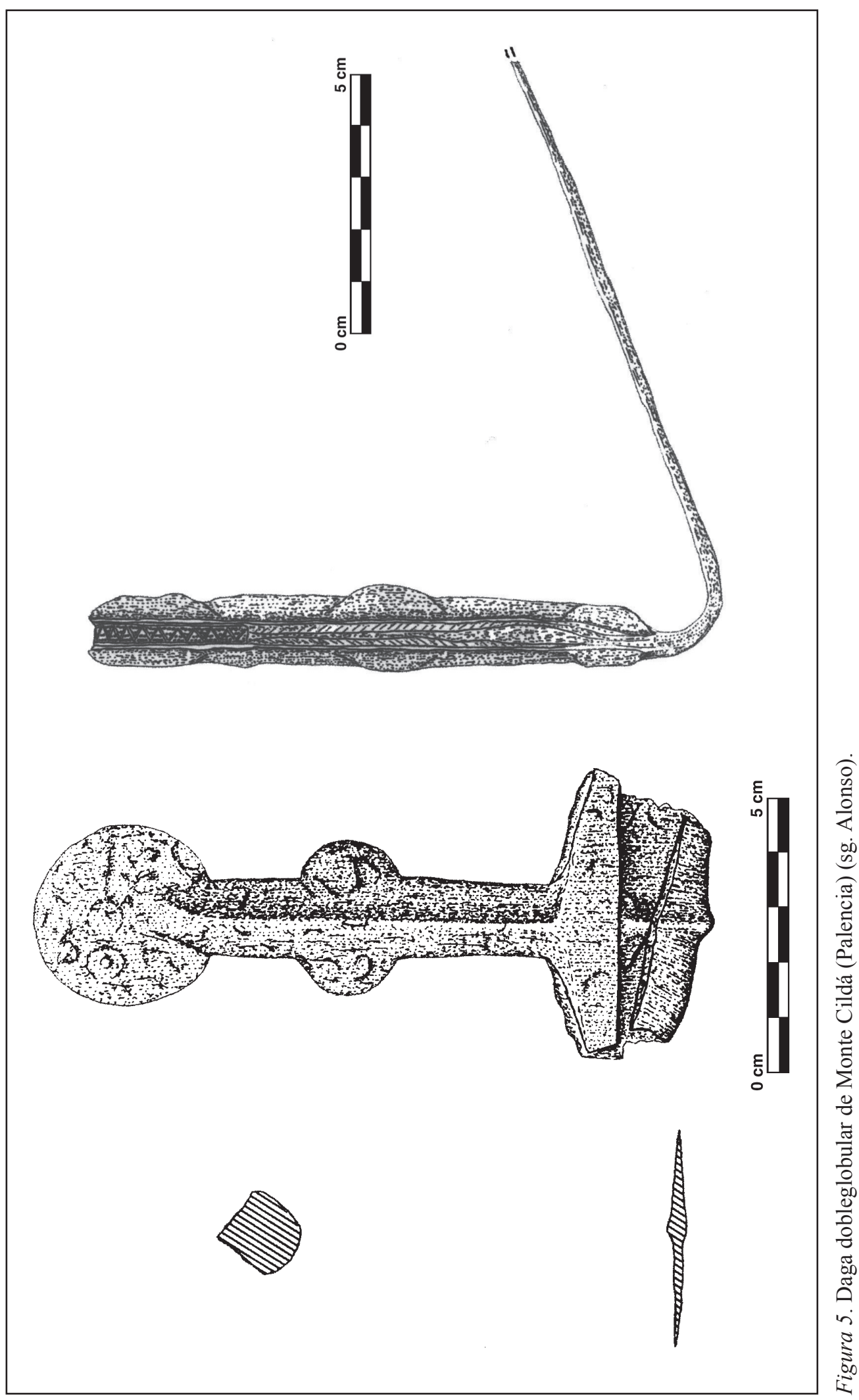

Gladius, XXVIII (2008), pp. 87-175. ISSN: 0436-029X 

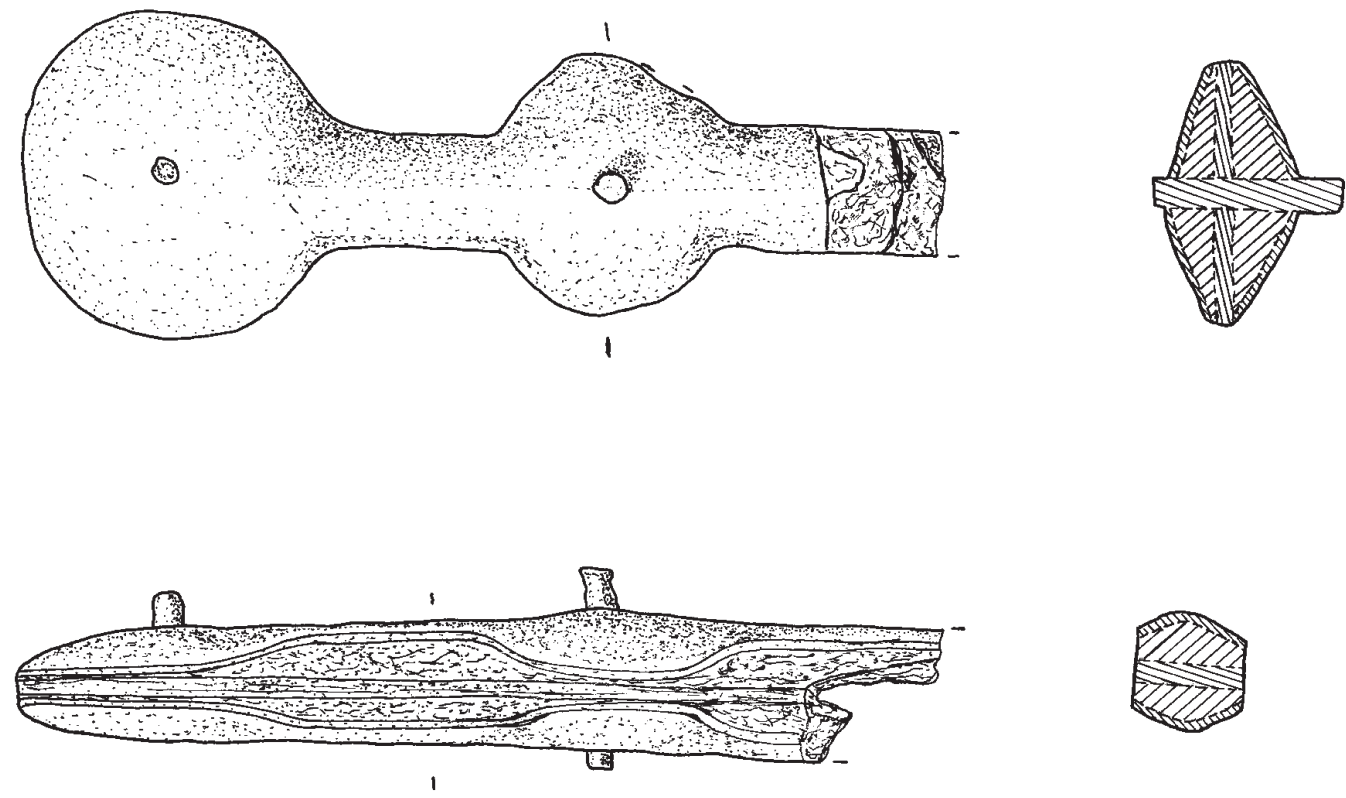

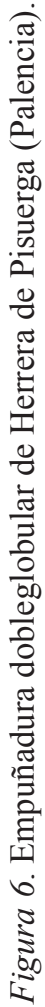
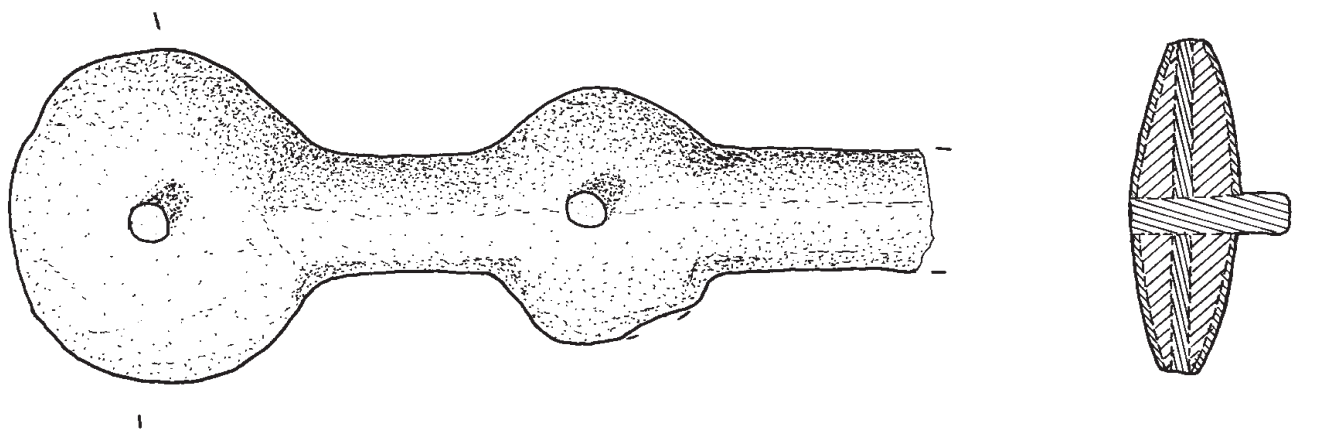


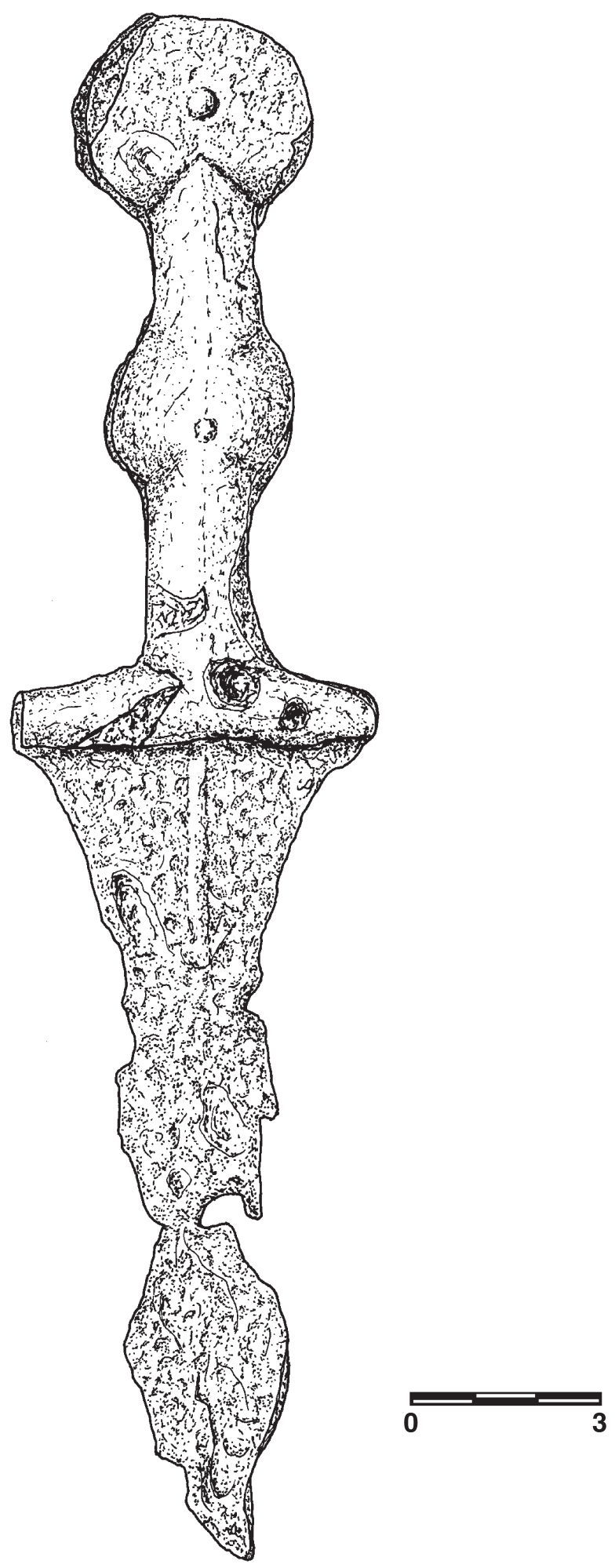

Figura 7. Daga dobleglobular de Numancia (Soria).

Gladius, XXVIII (2008), pp. 87-175. ISSN: 0436-029X 


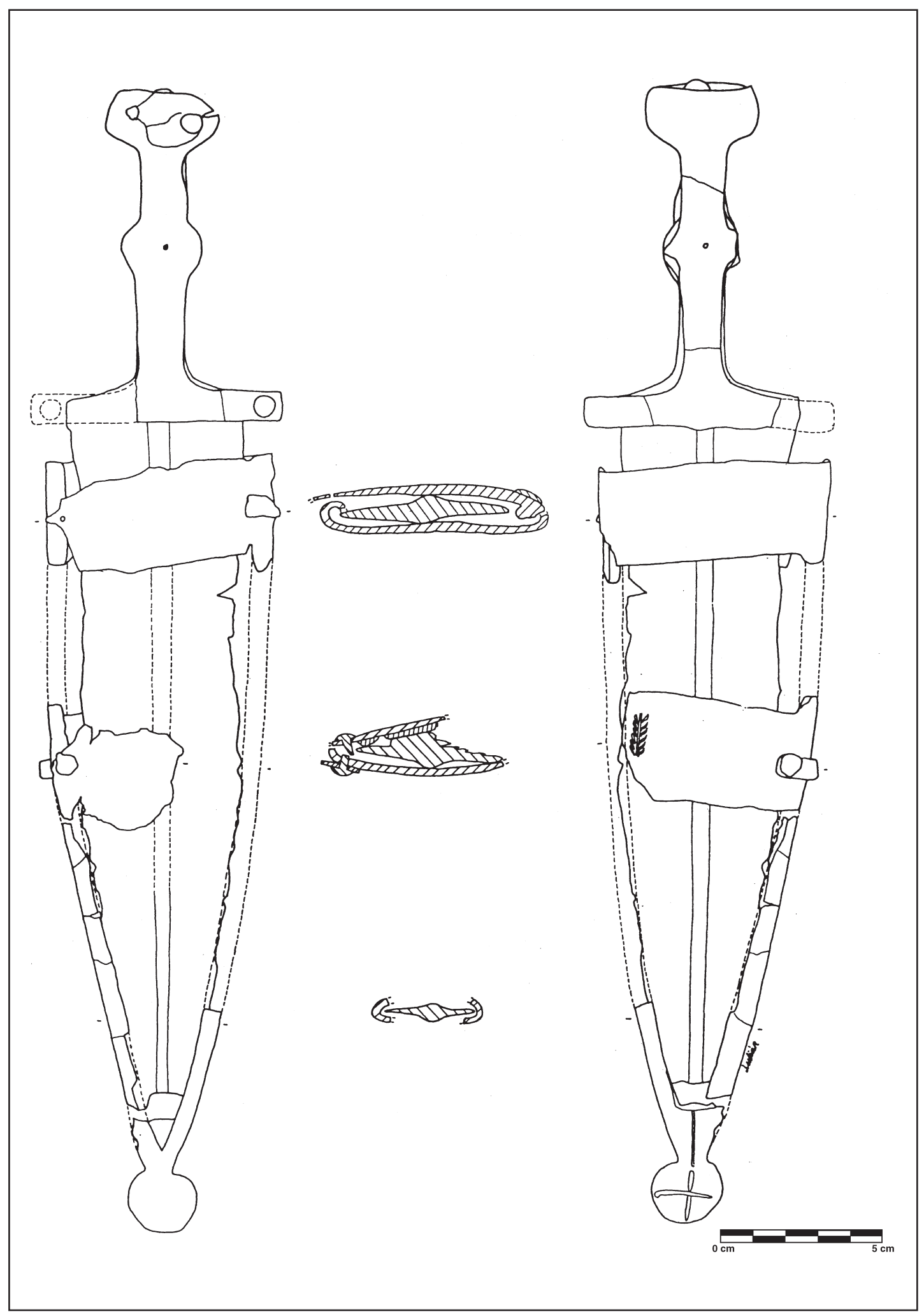

Figura 8. Daga envainada de Palencia capital, tal y como se conserva en el Museo de Palencia. 


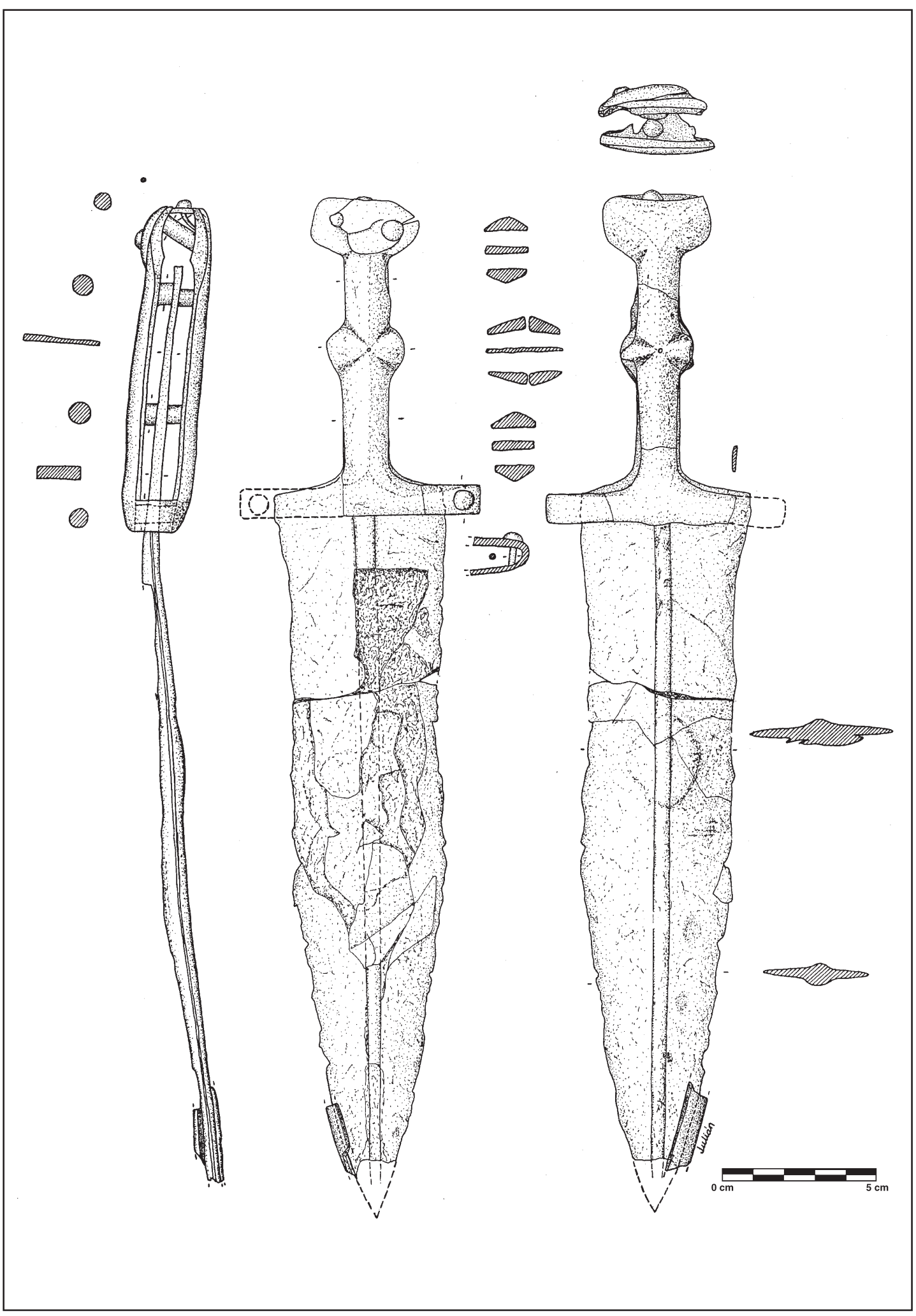

Figura 9. Daga de la figura anterior.

Gladius, XXVIII (2008), pp. 87-175. ISSN: 0436-029X 


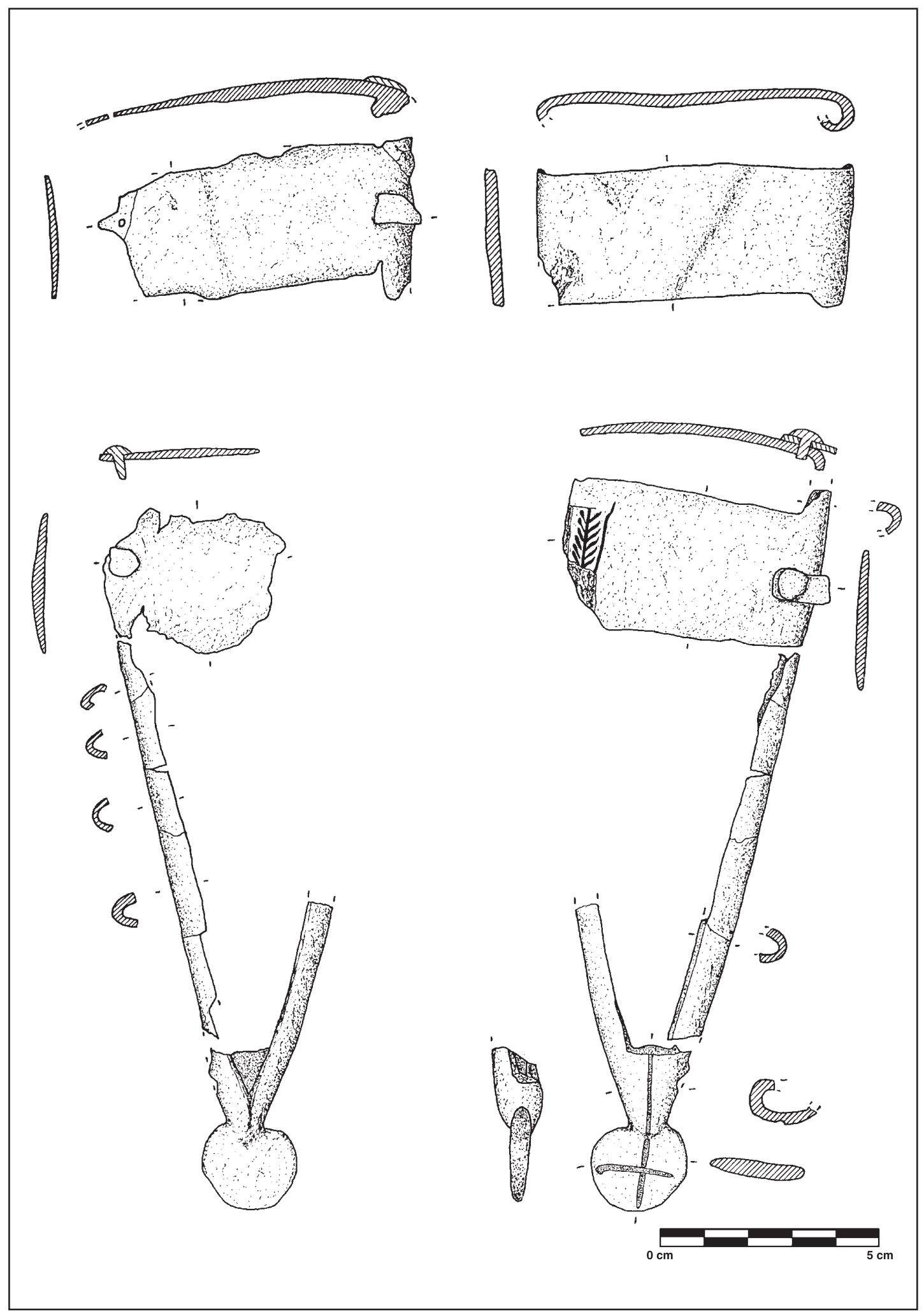

Figura 10. Desarrollo de la vaina de la figura 8. 

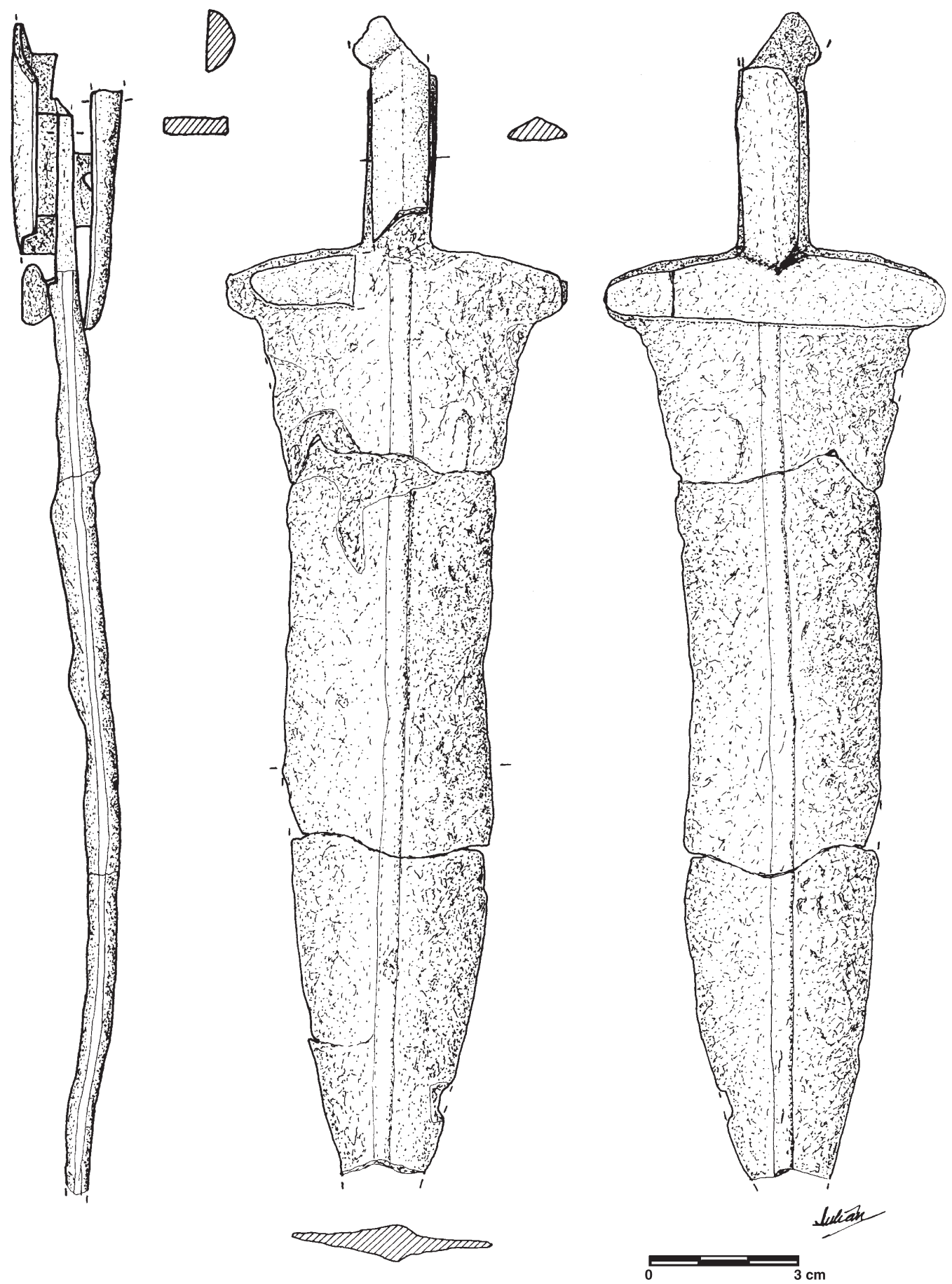

Figura 11. Daga de Palencia capital, segunda de las que se conservan en el Museo de Palencia. Gladius, XXVIII (2008), pp. 87-175. ISSN: 0436-029X 


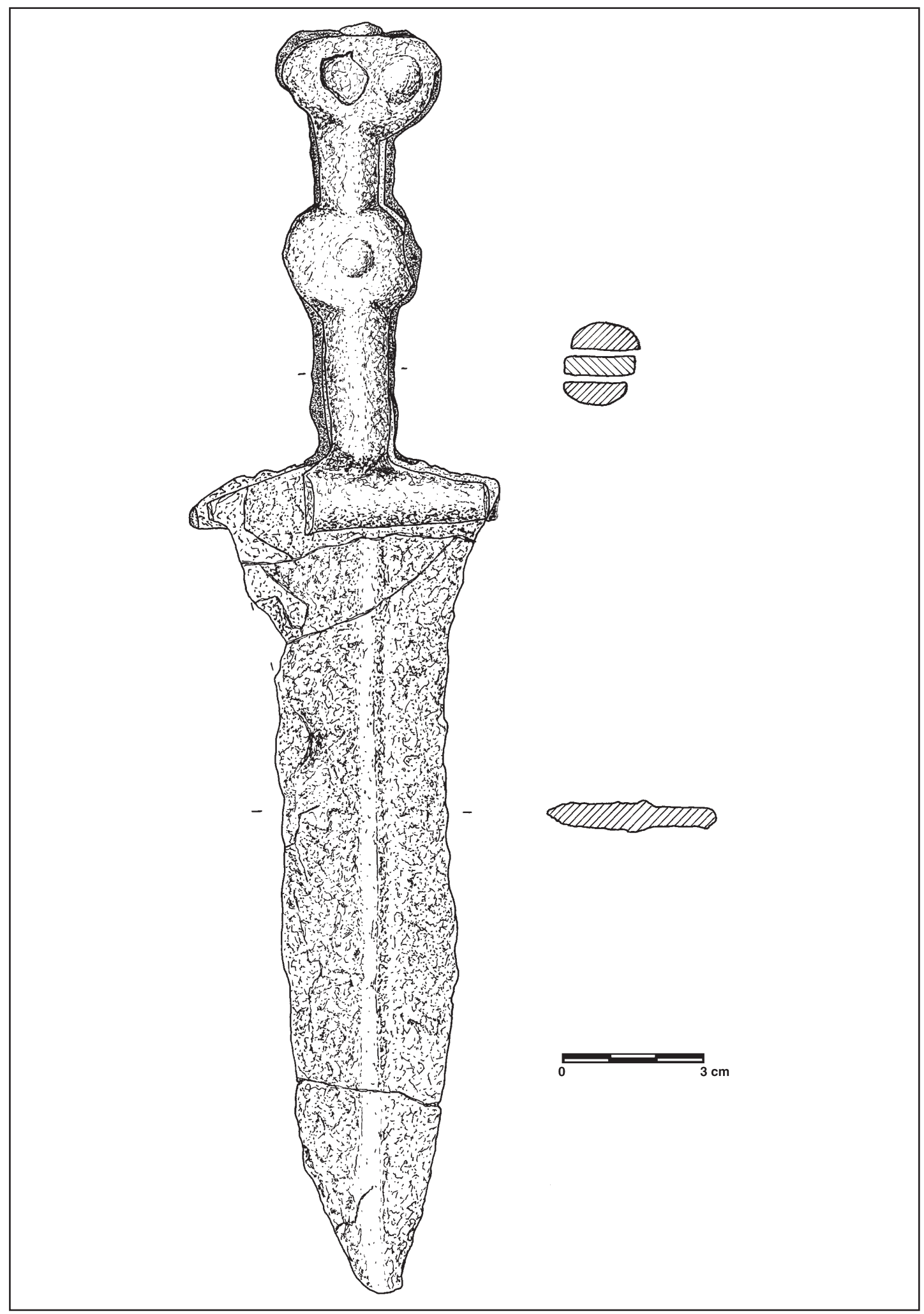

Figura 12. Daga de Palencia capital conservada en el Museo Arqueológico Nacional. 


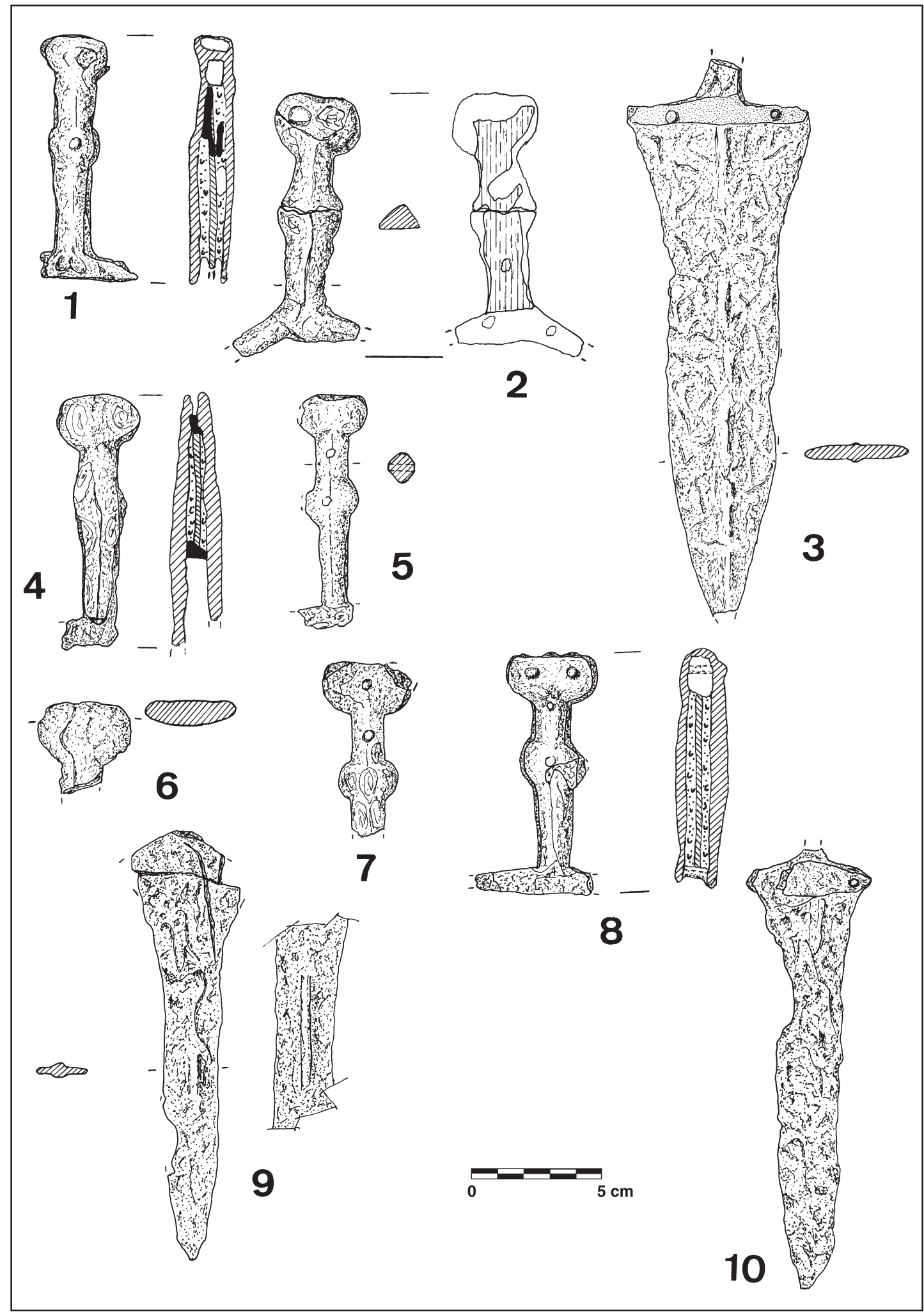

Figura 13. Conjunto procedente de Numancia (Soria). 


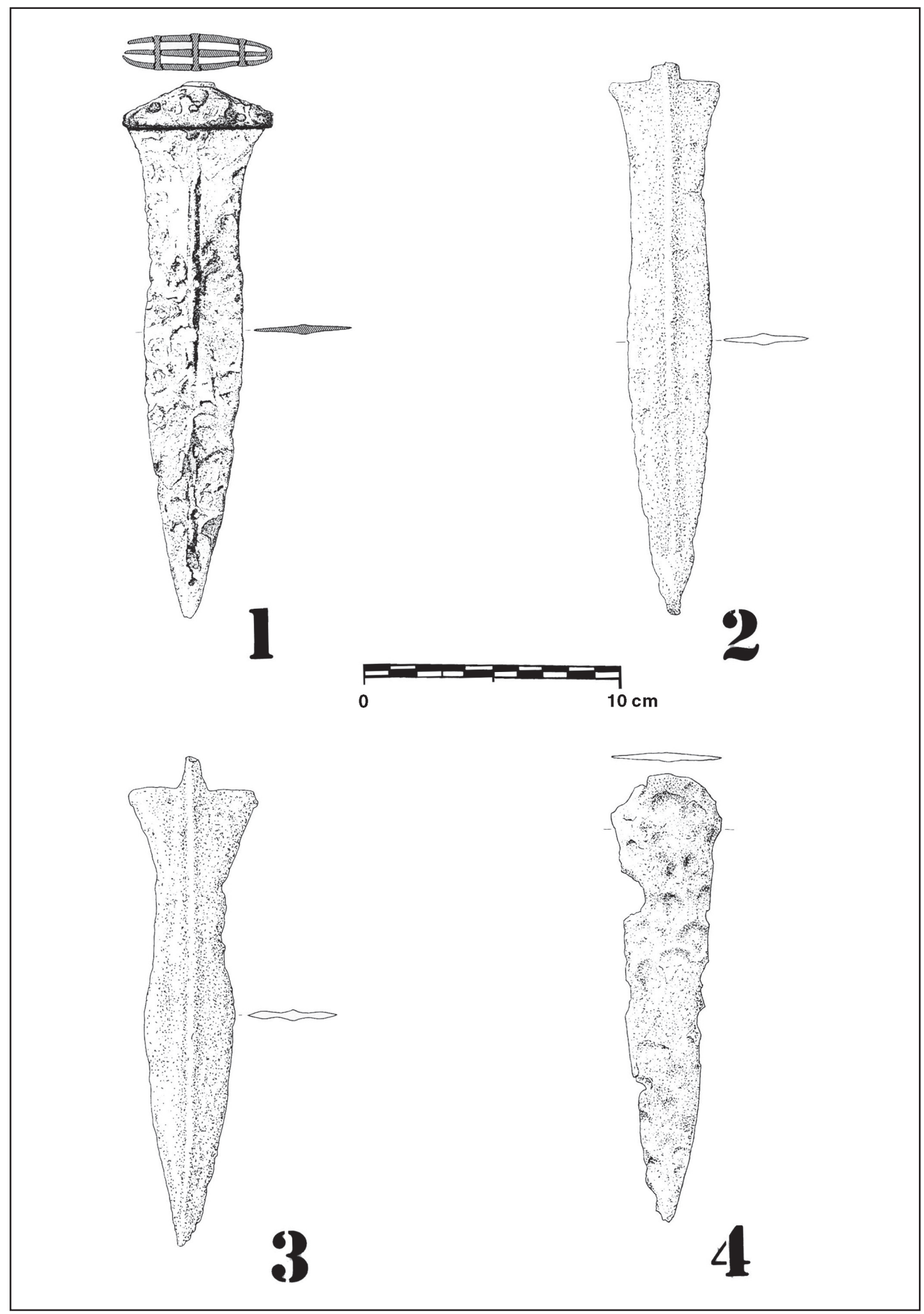

Figura 14. Campamento de Castillejo: 1, Campamento del Molino: 3, Numancia: 2 y 4 (sg. Luik). 


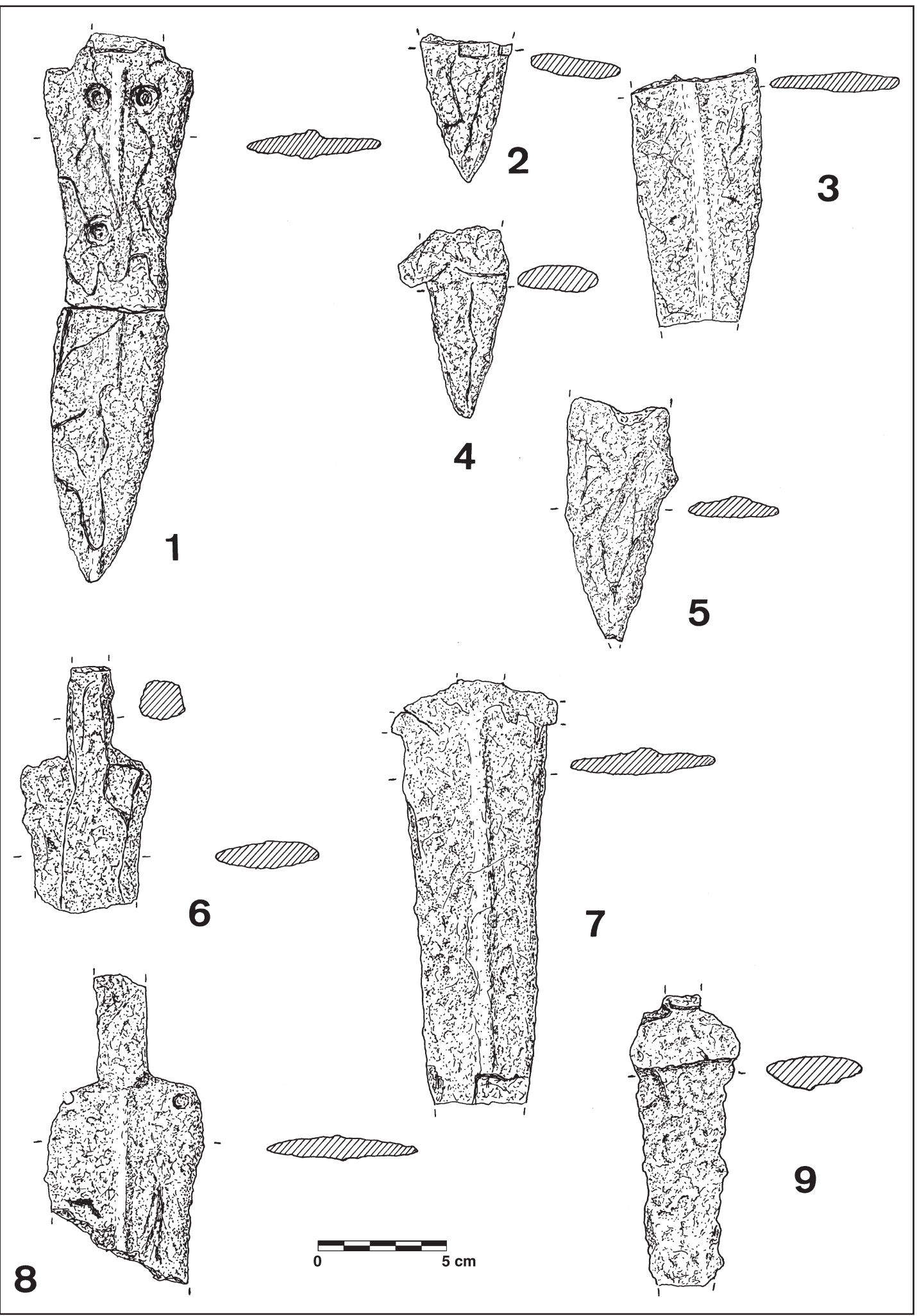

Figura 15. Conjunto procedente de Arcobriga (Monreal de Ariza, Zaragoza). 

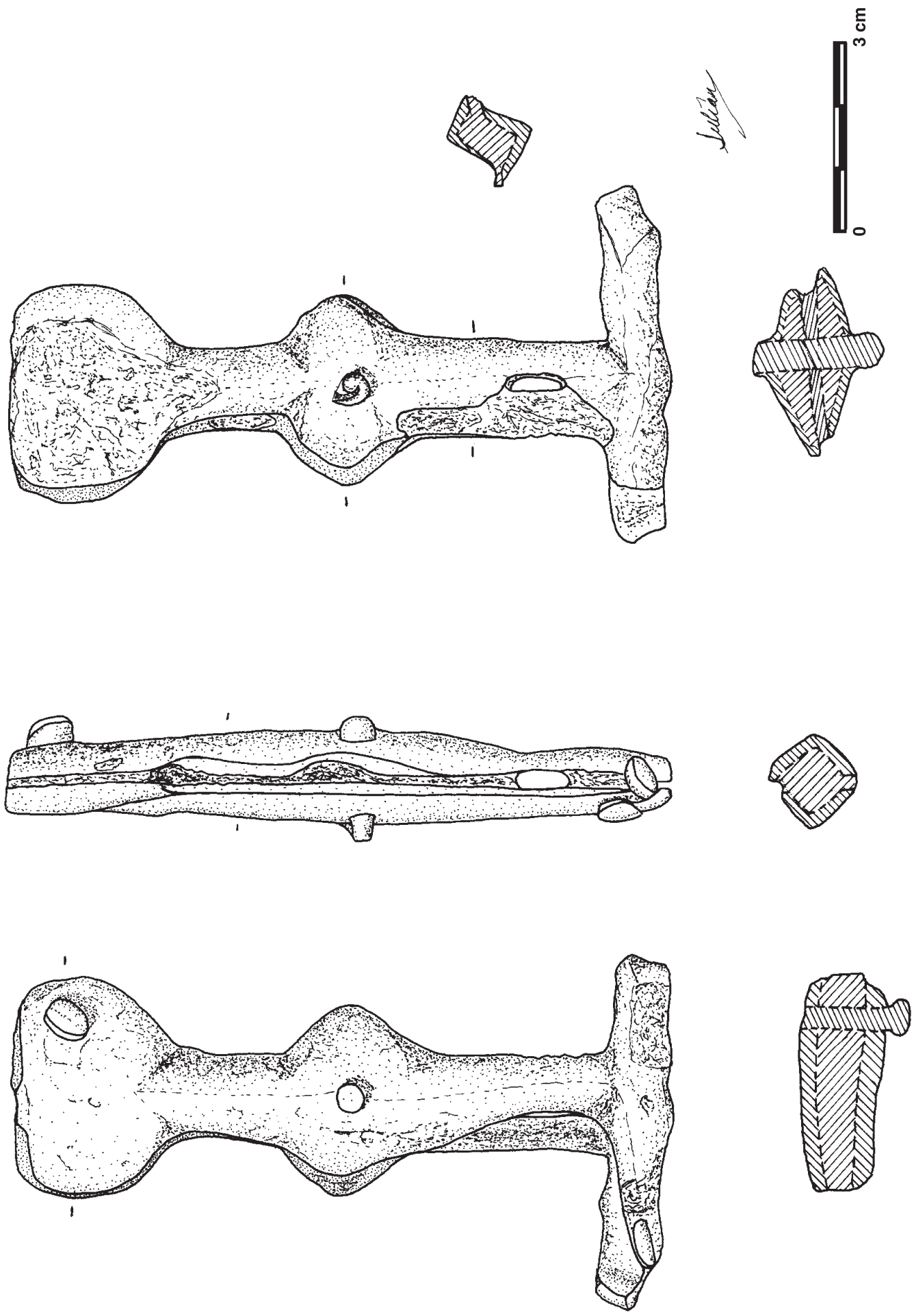

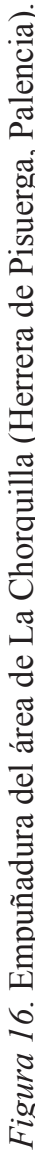




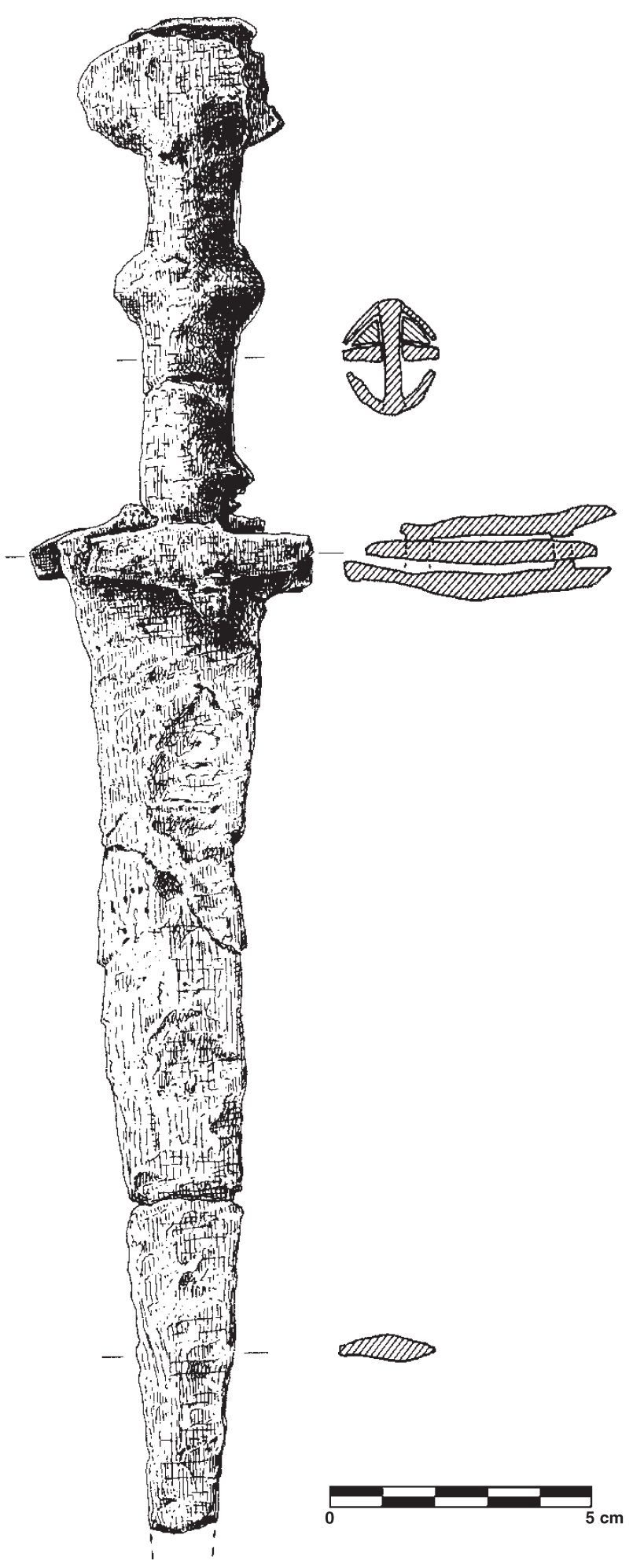

Figura 17. Castro de Corporales (Truchas, León) (sg. Schez. Palencia y Fdez. Posse). 


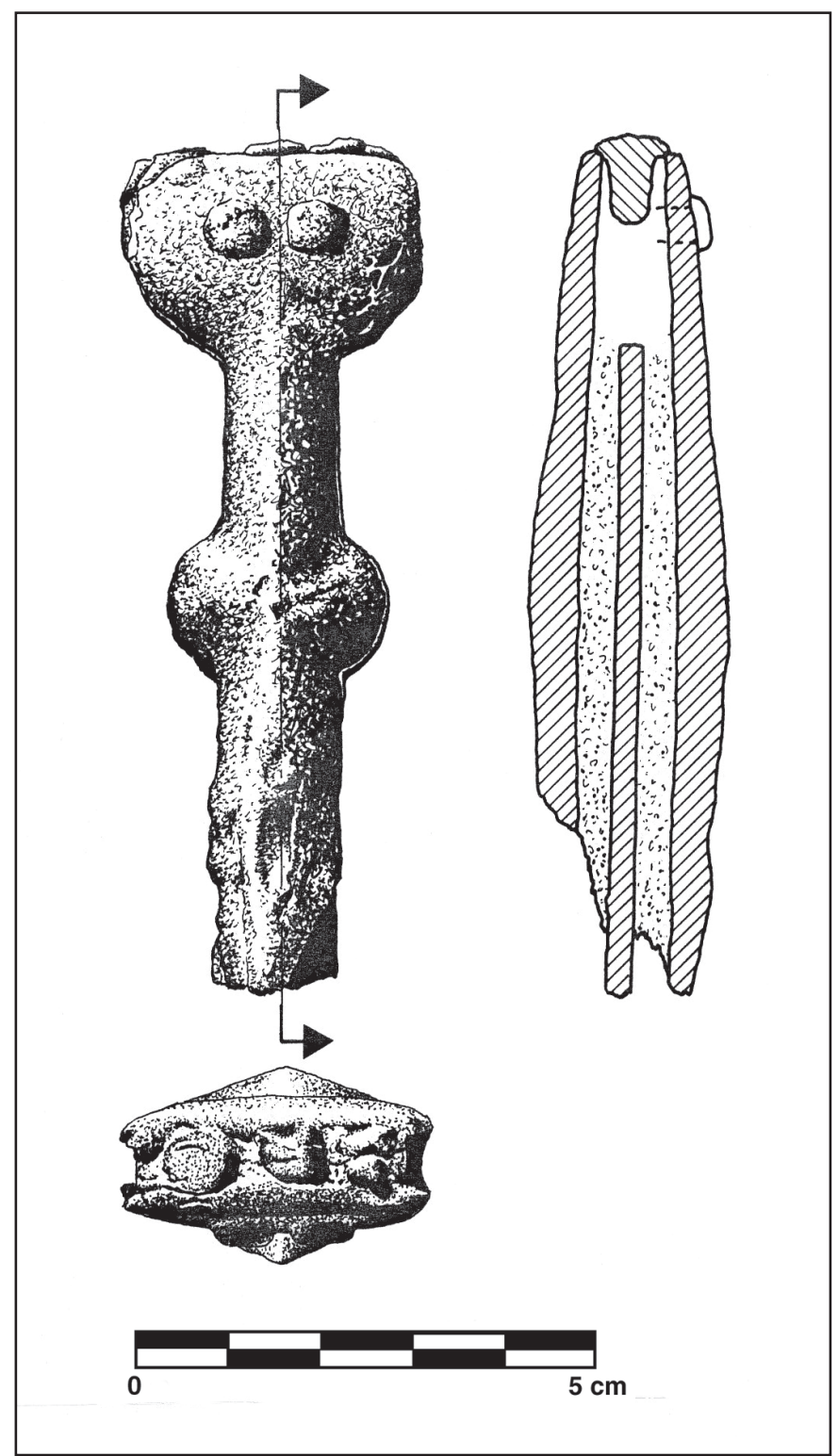

Figura 18. Empuñadura del área de La Ribera (Herrera de Pisuerga, Palencia). 


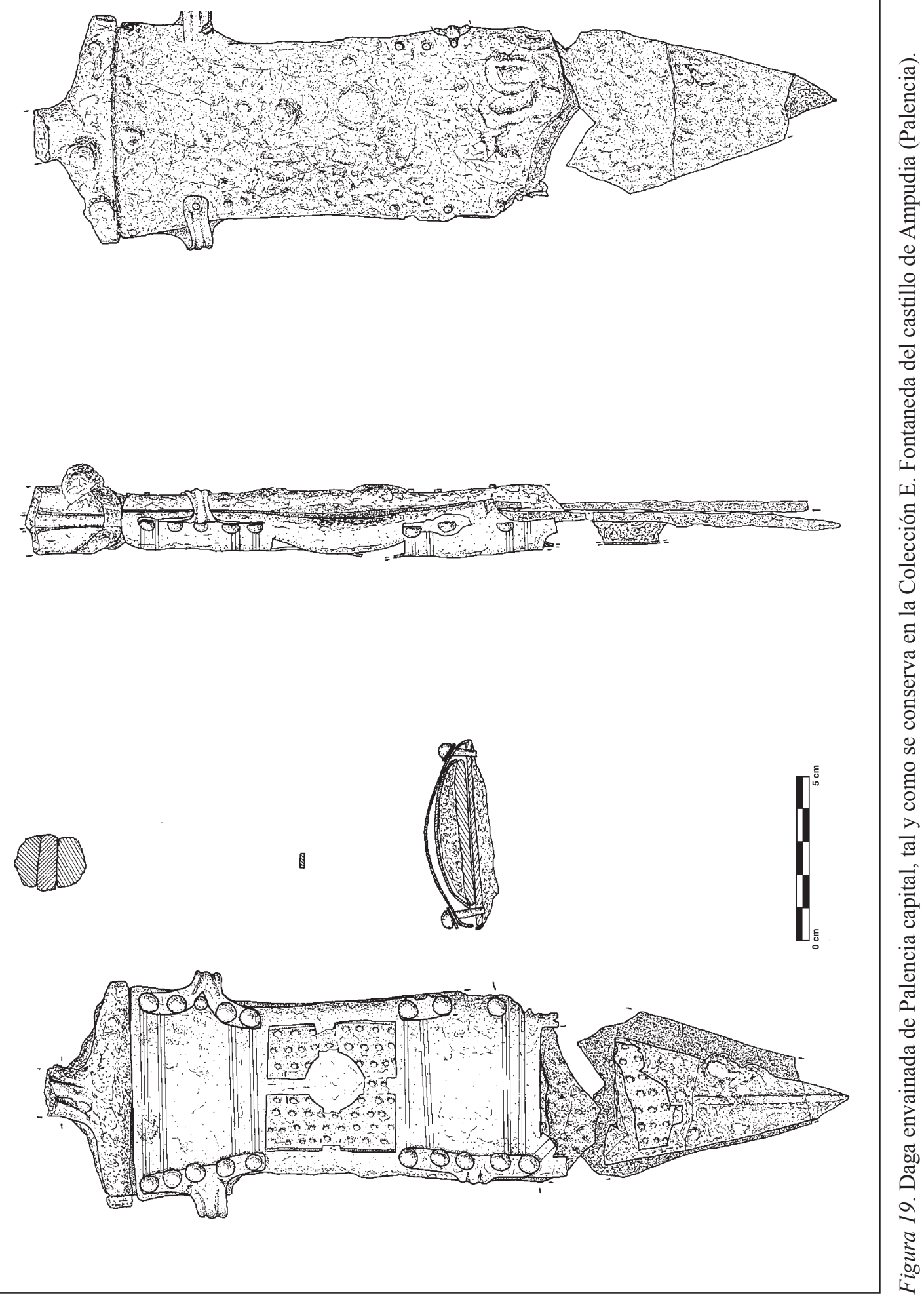

Gladius, XXVIII (2008), pp. 87-175. ISSN: 0436-029X 


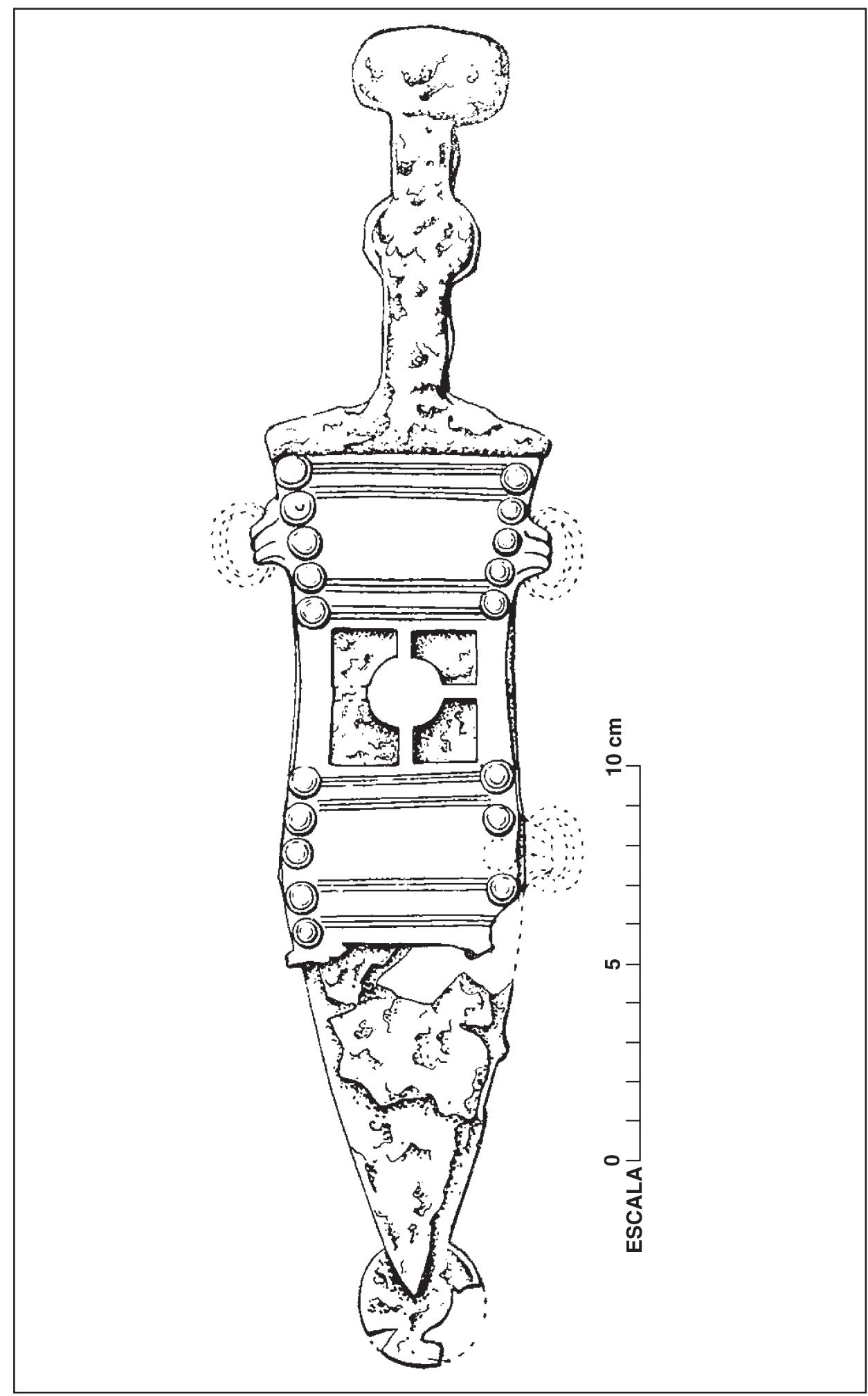

Figura 20. Daga y su funda de Palencia vista en la figura anterior tal y como se conservaba en origen (sg. Cabré). 


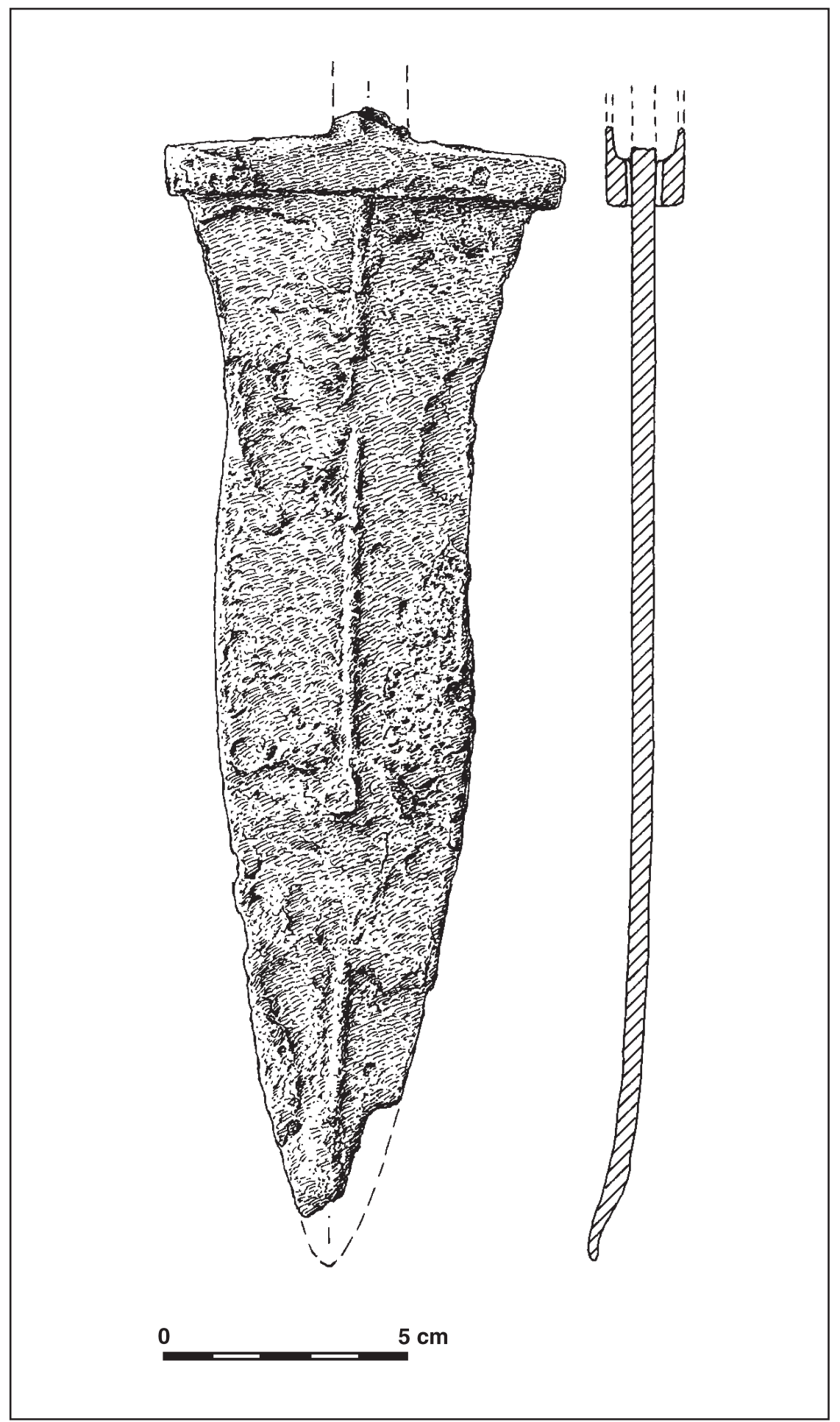

Figura 21. Hoja de Santa Cruz de Camazos (Valladolid) (sg. Mañanes et al.). 


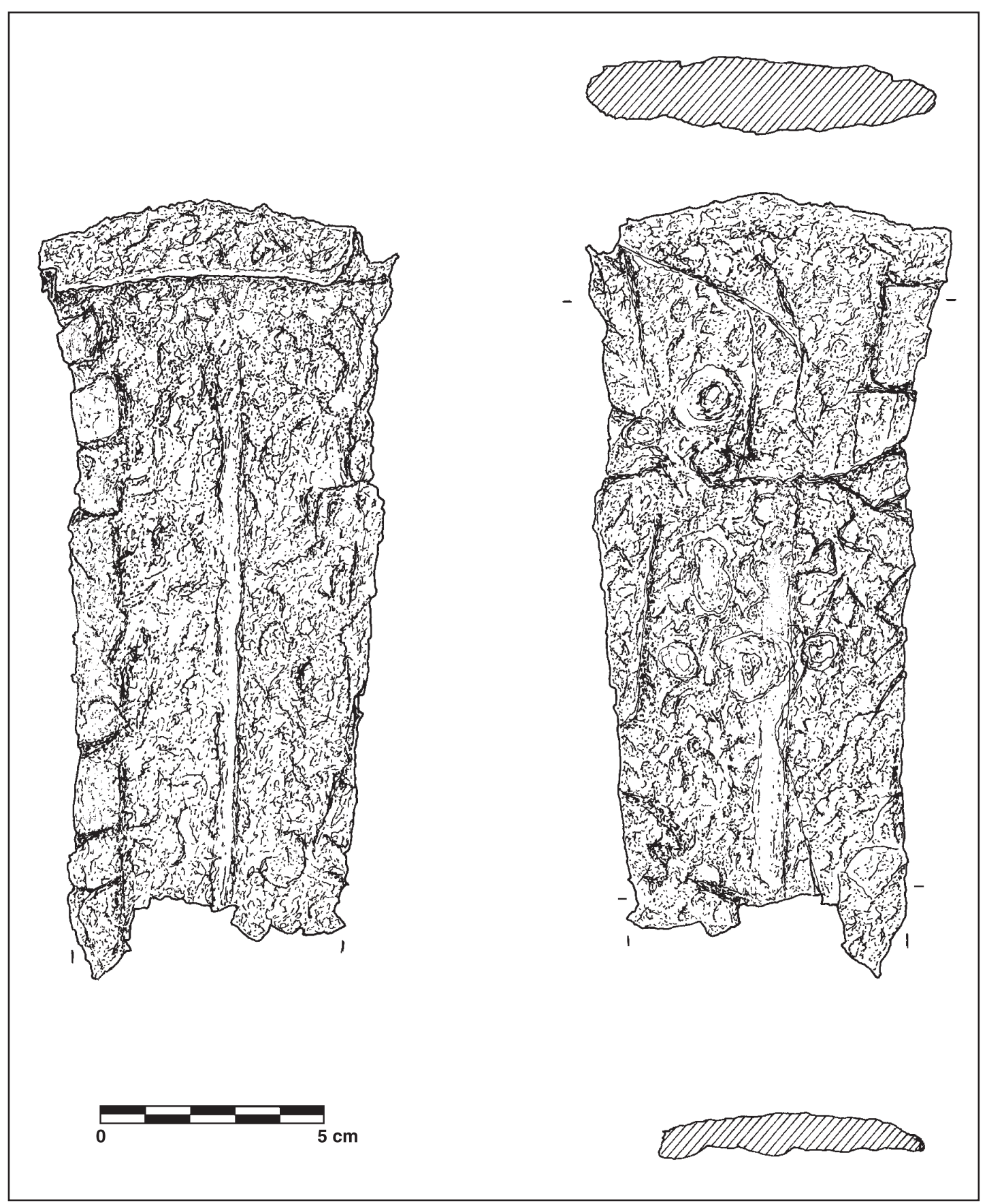

Figura 22. Fragmento de hoja conservado en la funda de la Figura 25 procedente de la capital de Palencia. Dibujo basado en un borrador de la Hispanic Society of America (C. del Álamo). 


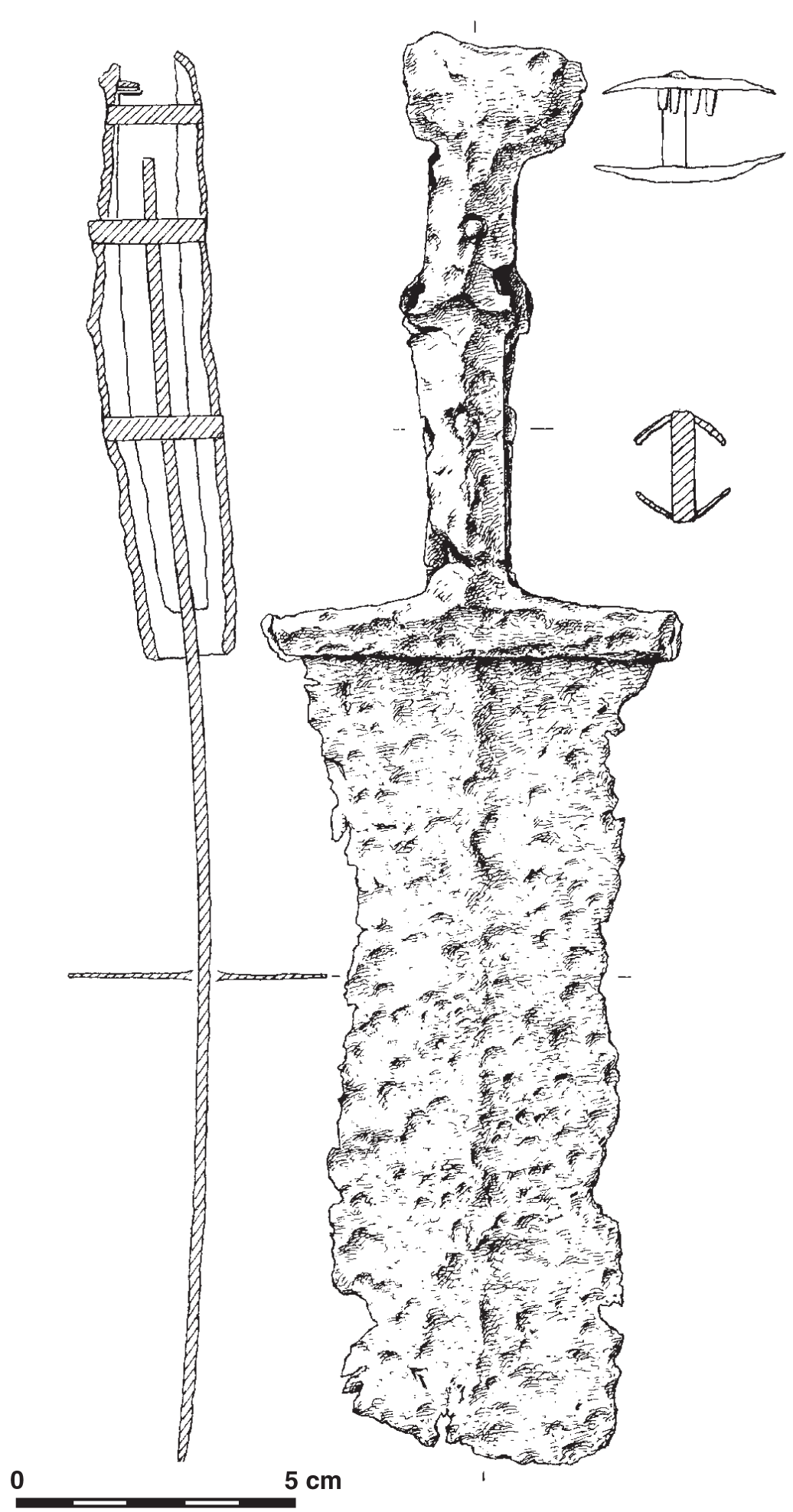

Figura 23. Daga de Castrillo de la Reina (Burgos) (sg. Esparza). 


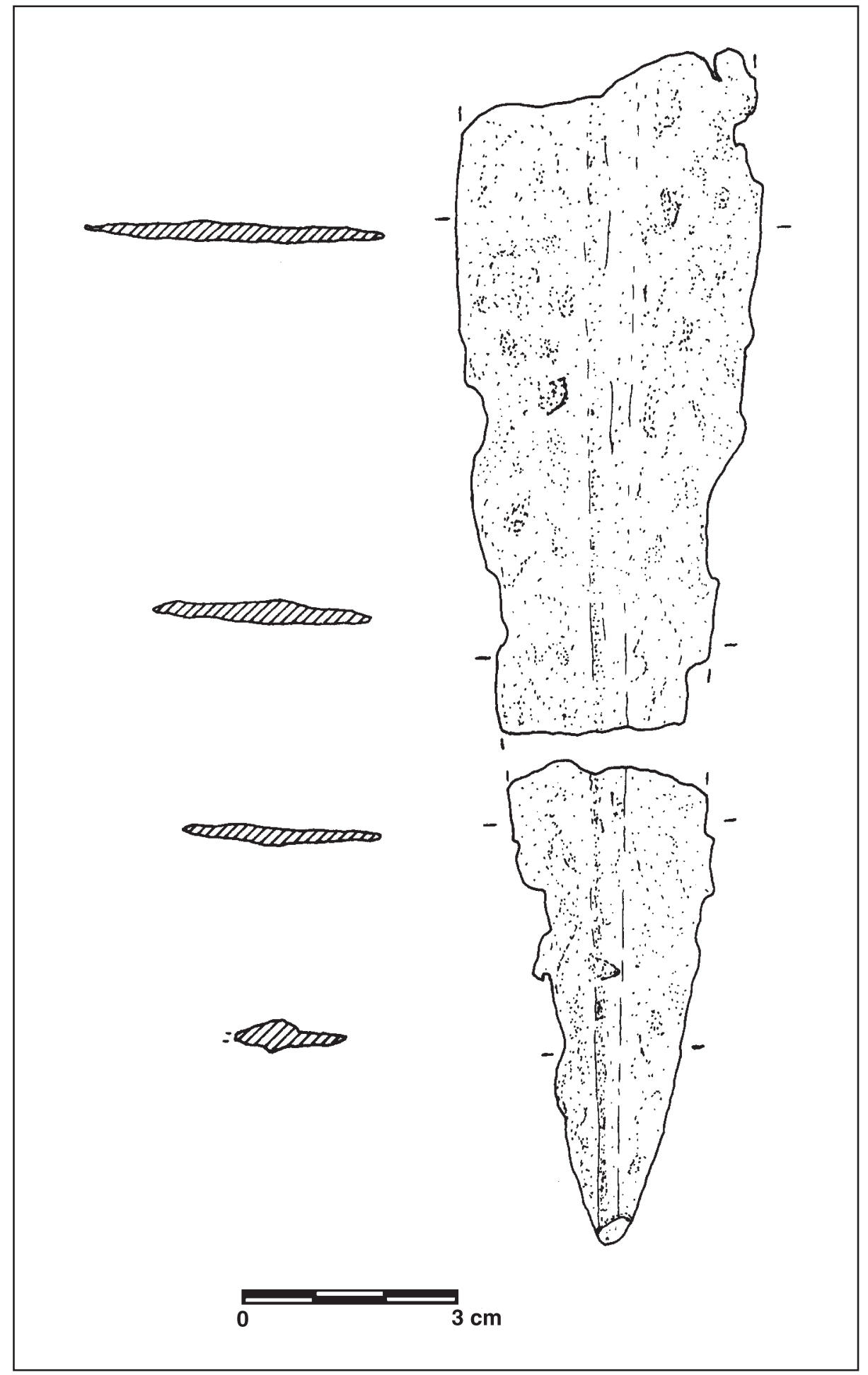

Figura 24. Hoja de Olmos de Ojeda (Palencia). 

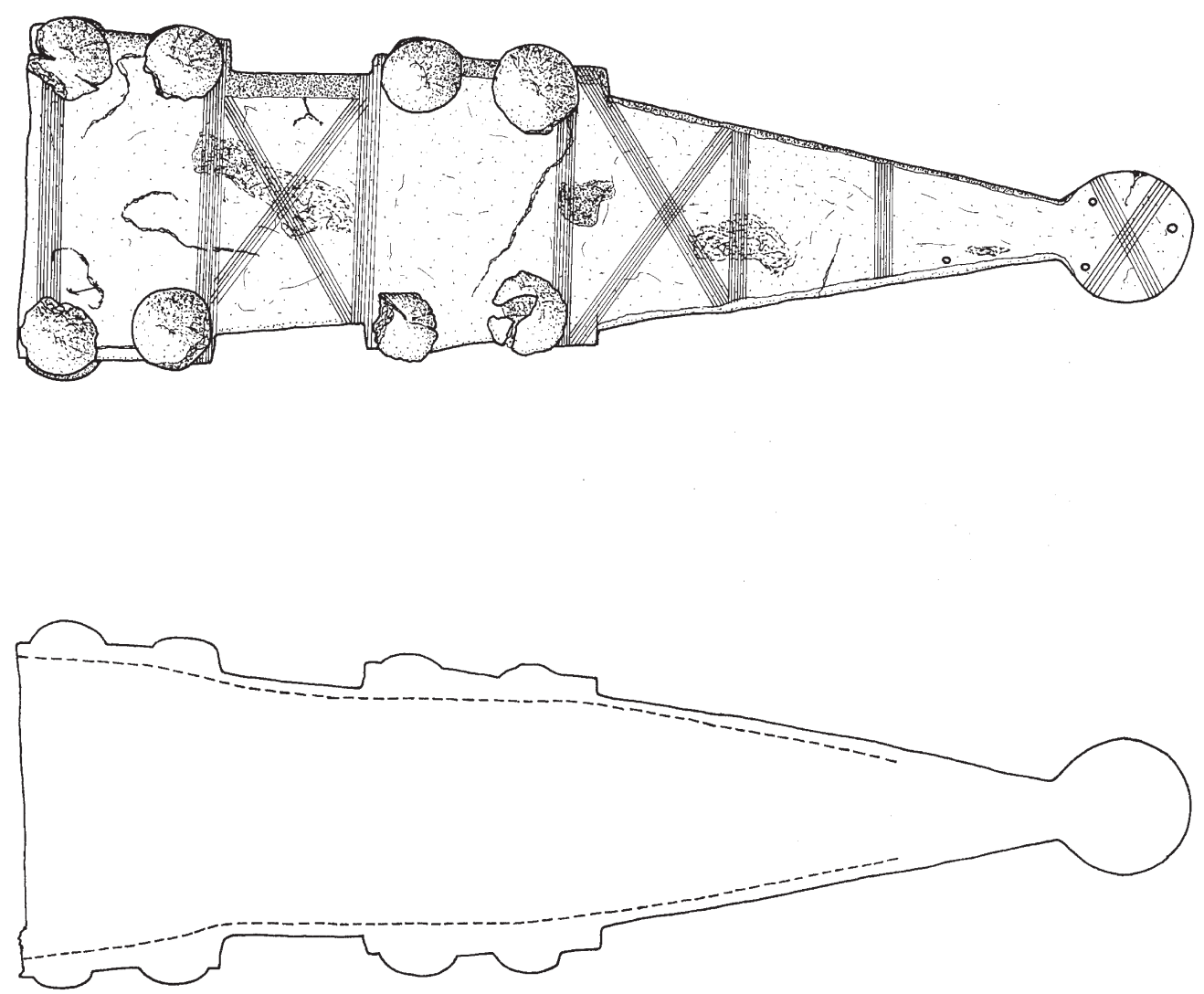

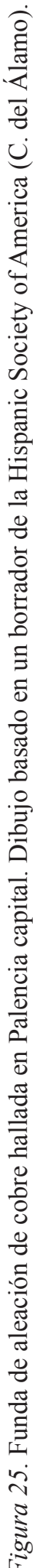

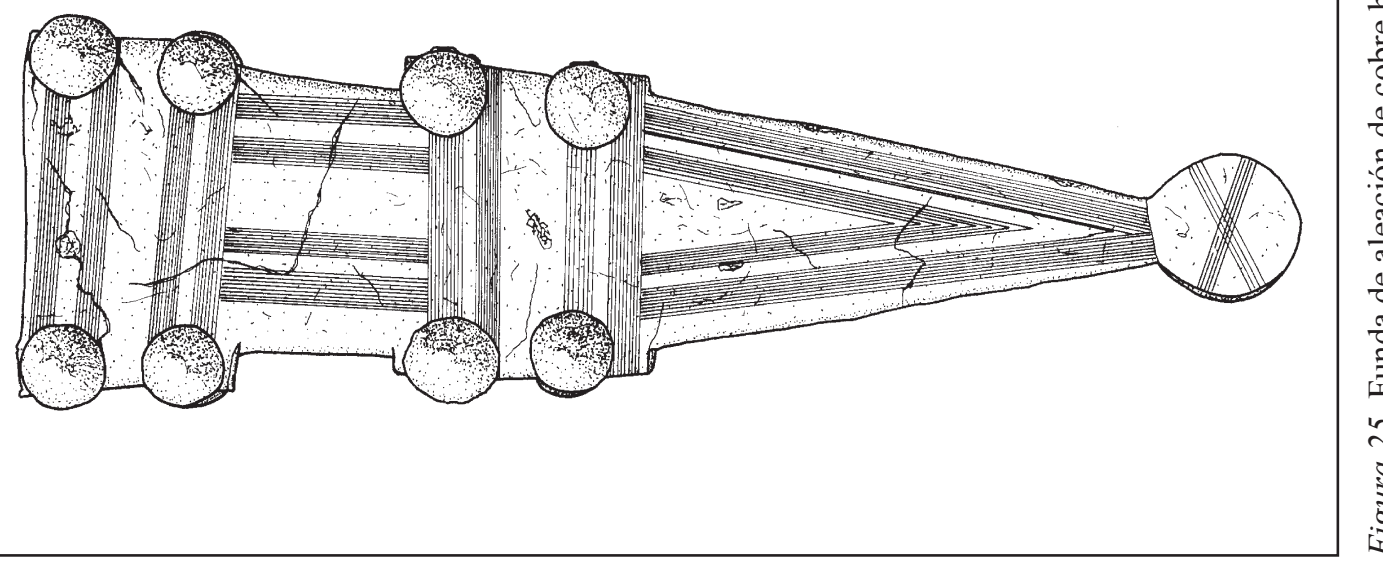

Gladius, XXVIII (2008), pp. 87-175. ISSN: 0436-029X 


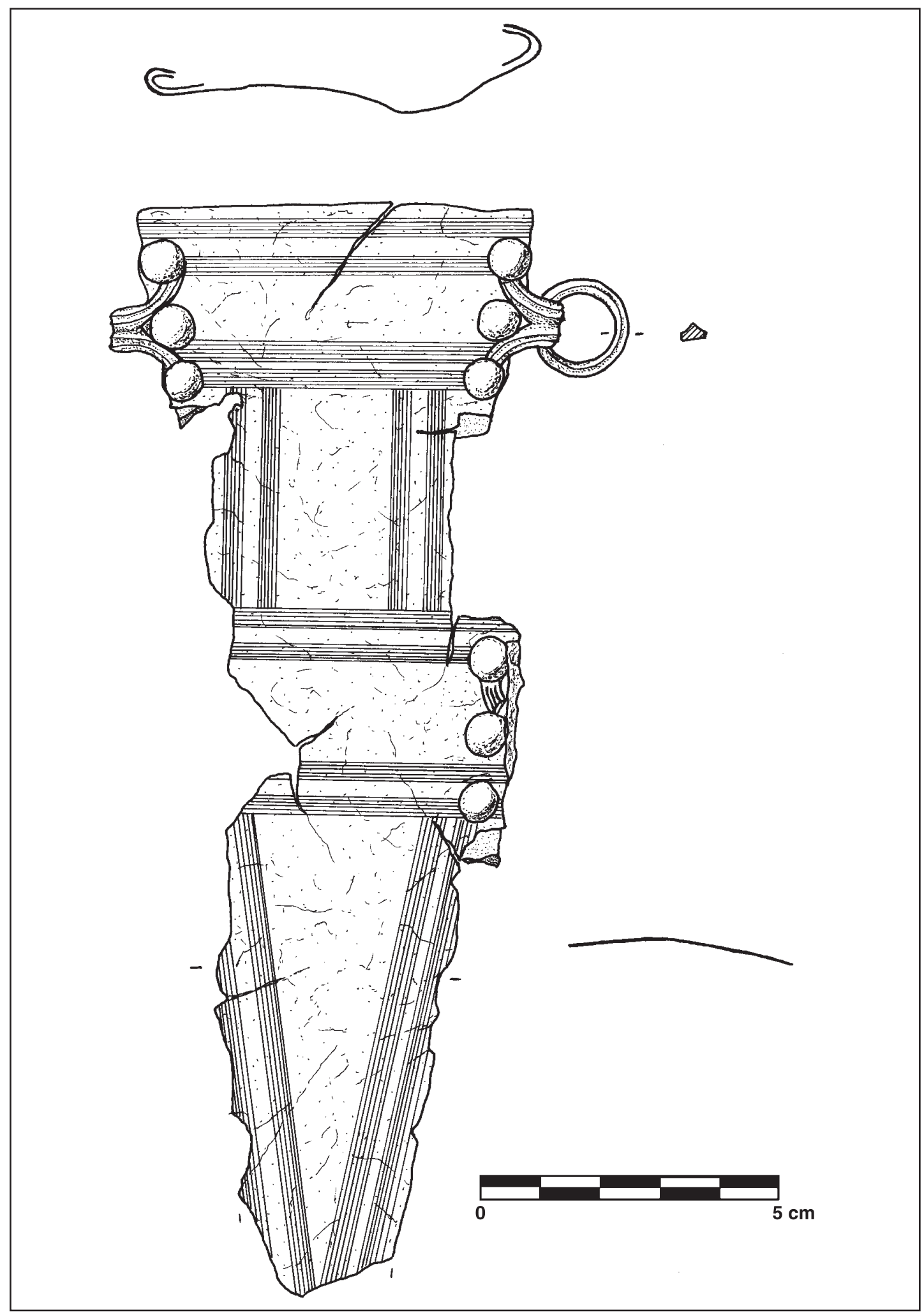

Figura 26. Lámina de funda procedente de Palencia capital. 


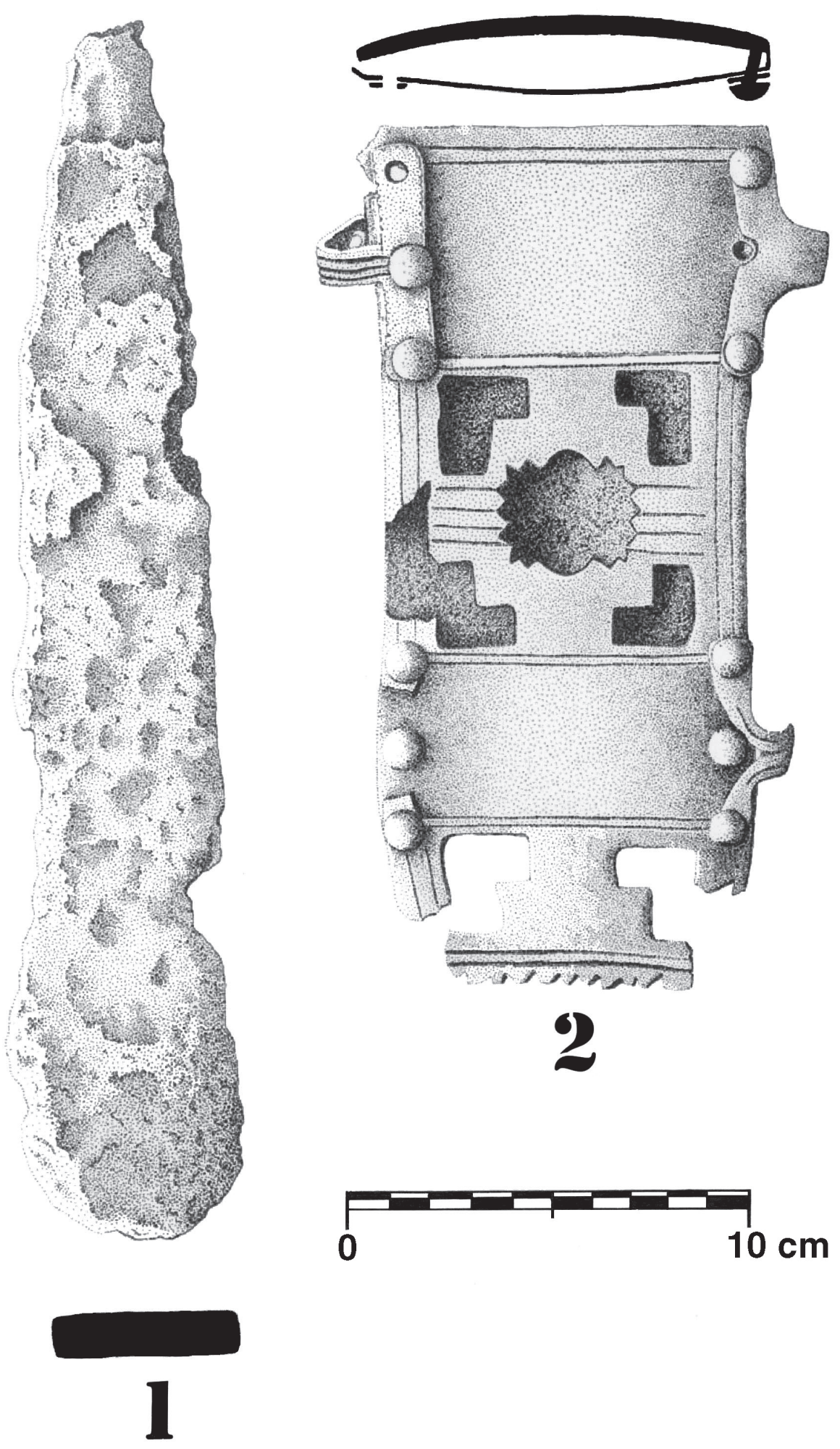

Figura 27. Conimbriga (Portugal): hoja de daga (1) y funda (2) (sg. Alarcão et al.). 


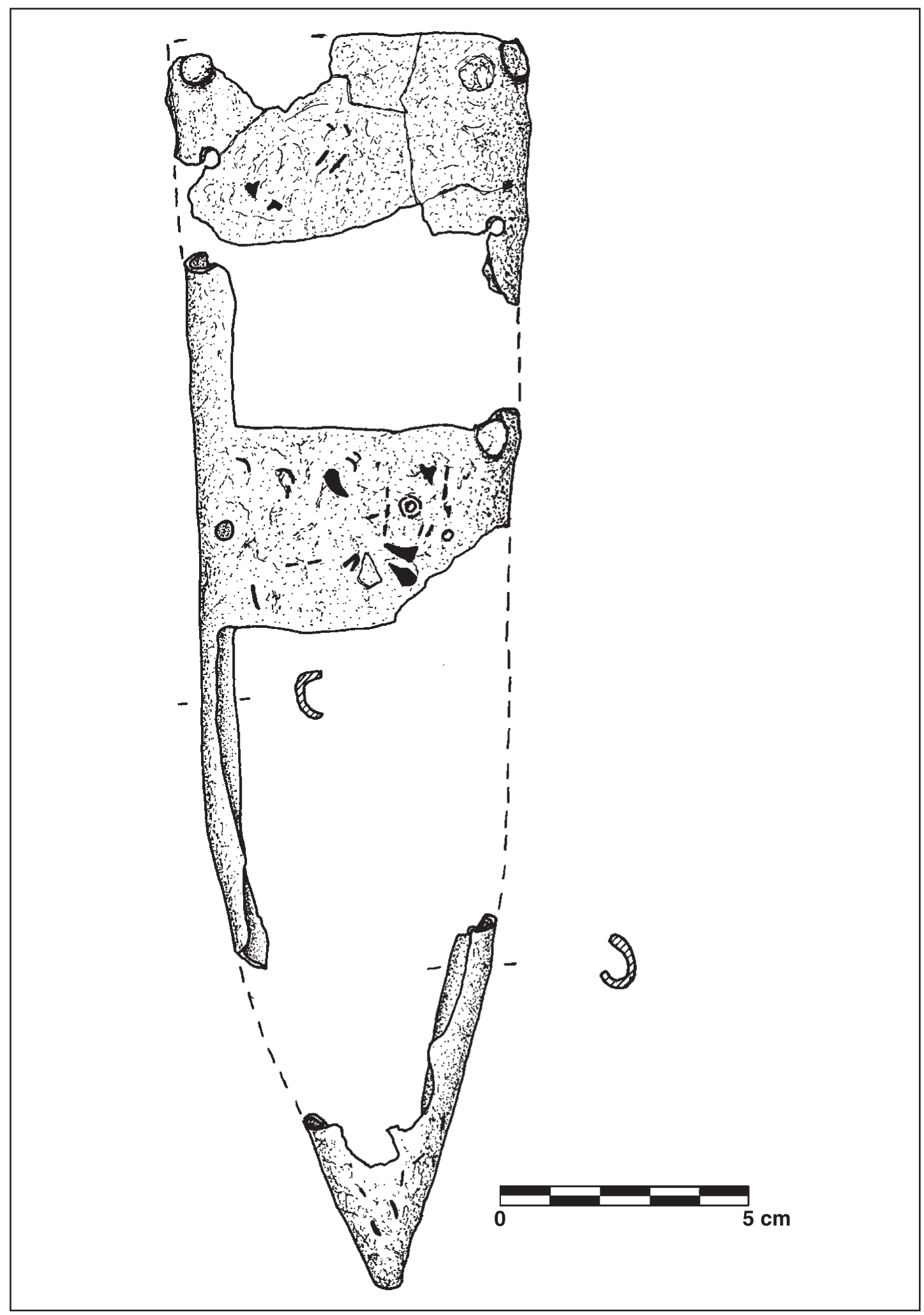

Figura 28. Funda de hierro de Fuente de la Mora (Salamanca). 


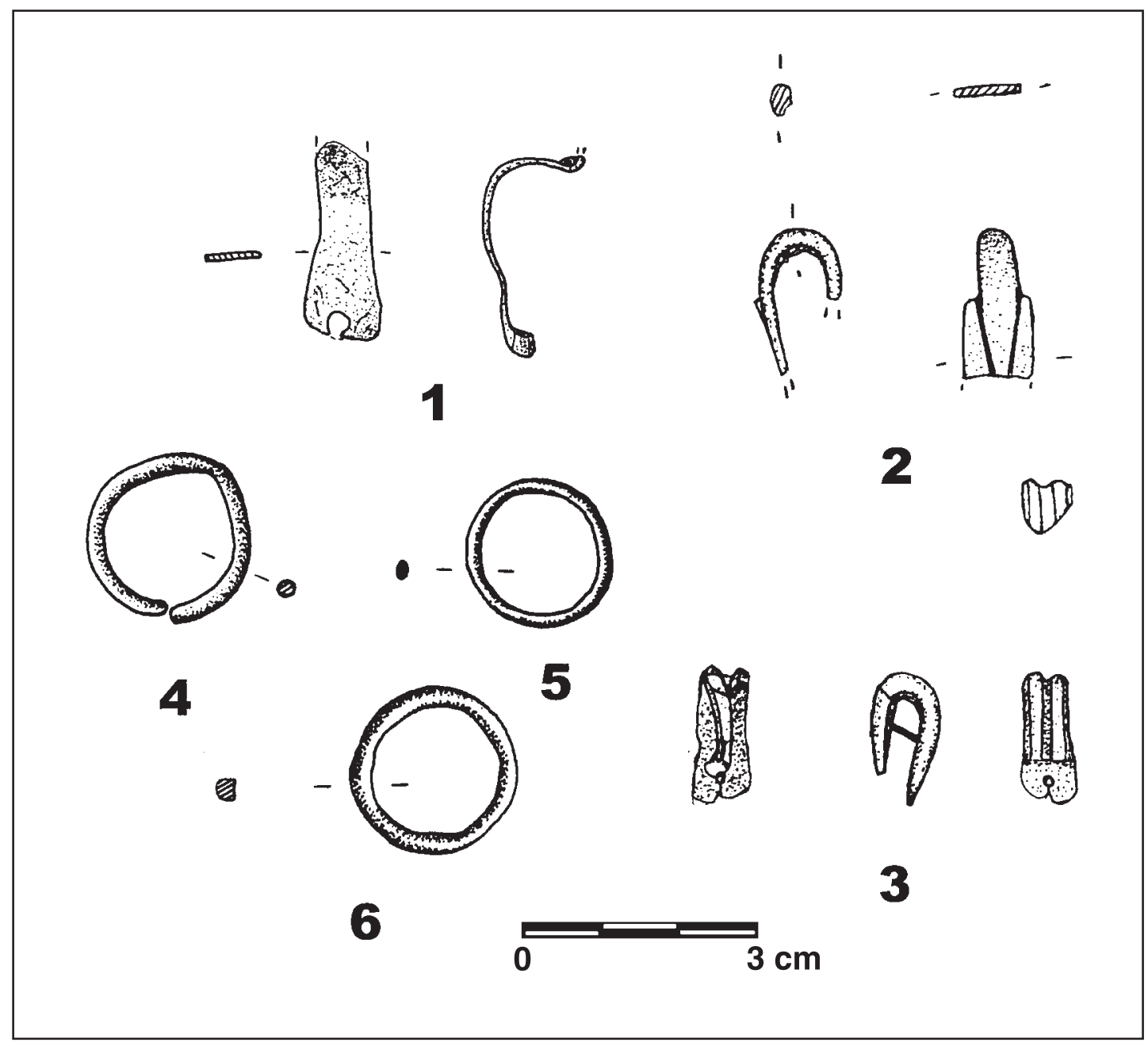

Figura 29. Herrera de Pisuerga (Palencia). Varios elementos de fundas: bridas o presillas para las anillas (Asilo 1, San Millán 2-3) y anillas de suspensión (San Millán 3-6). 


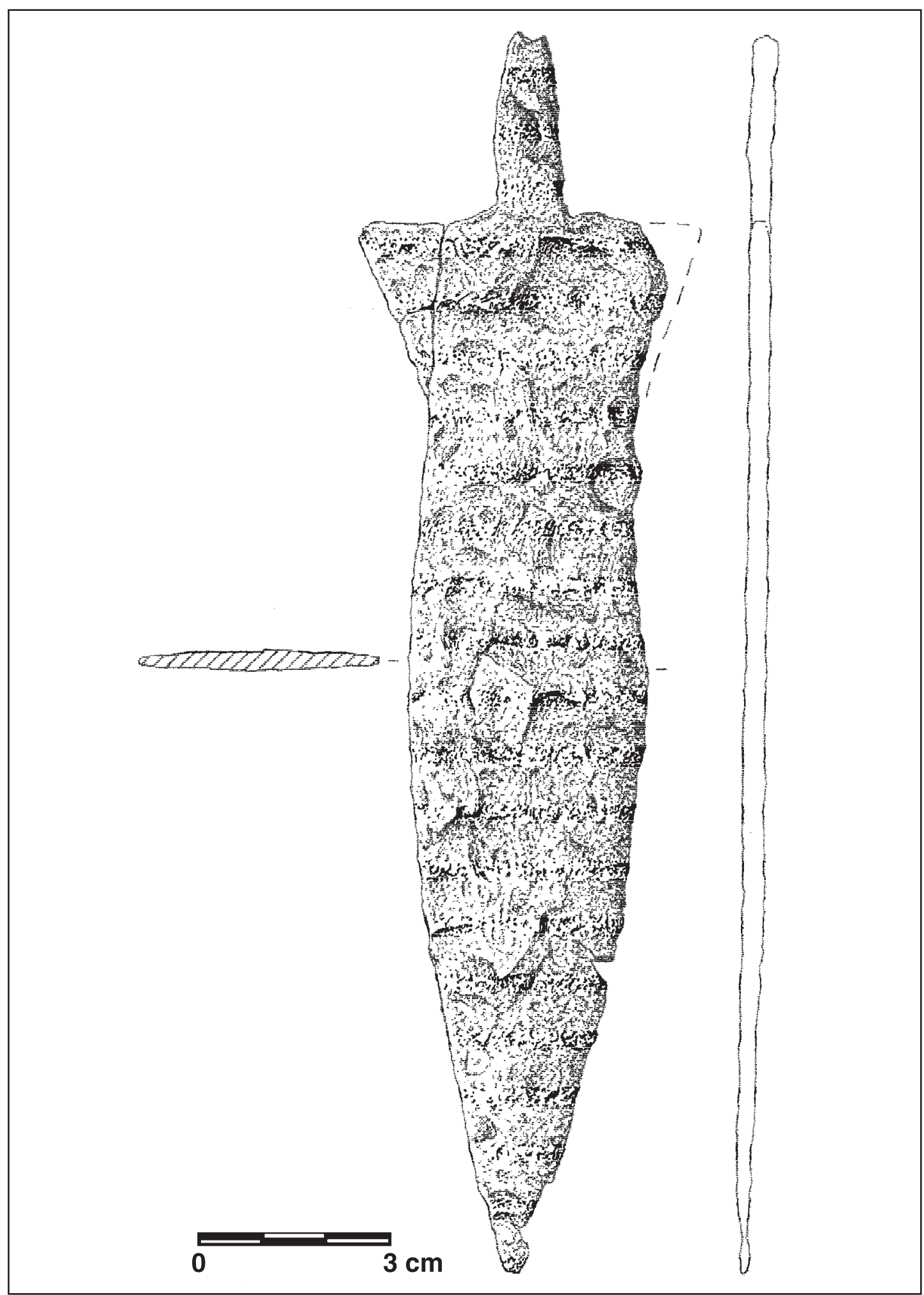

Figura 30. Hoja de daga procedente del campamento de Rosinos de Vidriales (Zamora) (sg. Romero y Carretero). 


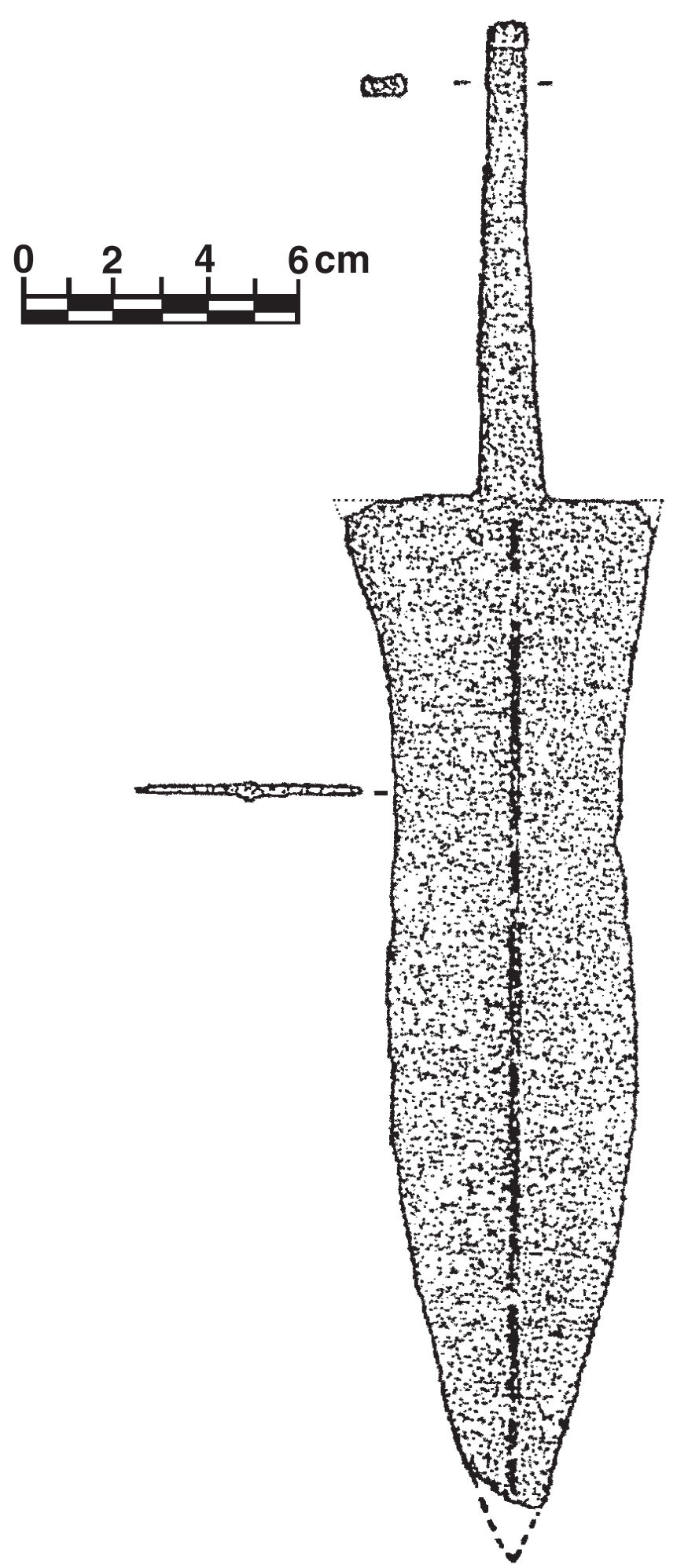

Figura 31. Hoja de daga procedente de la necrópolis de Ateabalsa (Navarra) (sg. Pérex y Unzu). 

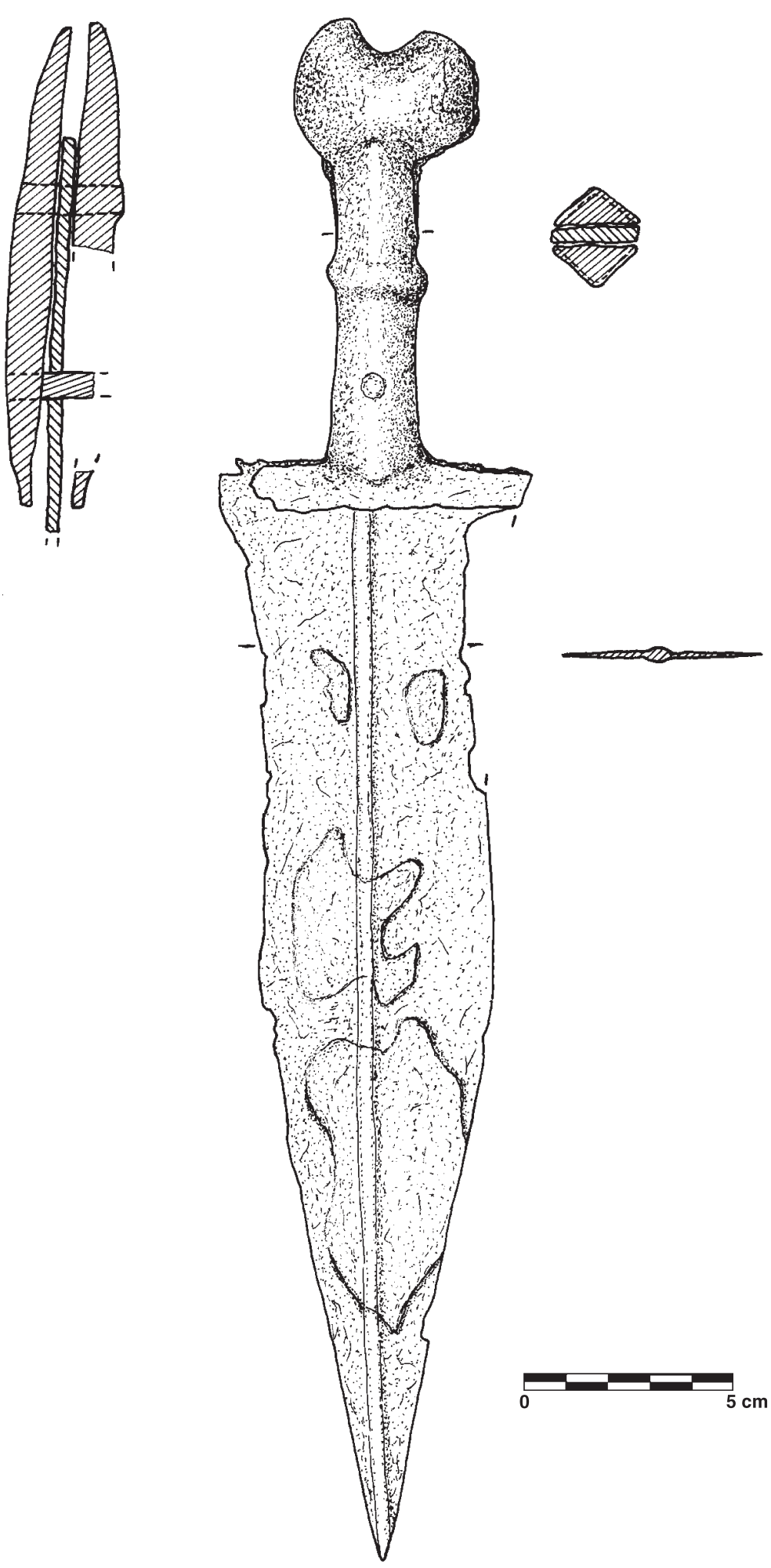

Figura 32. Daga de Aroche (Huelva). 


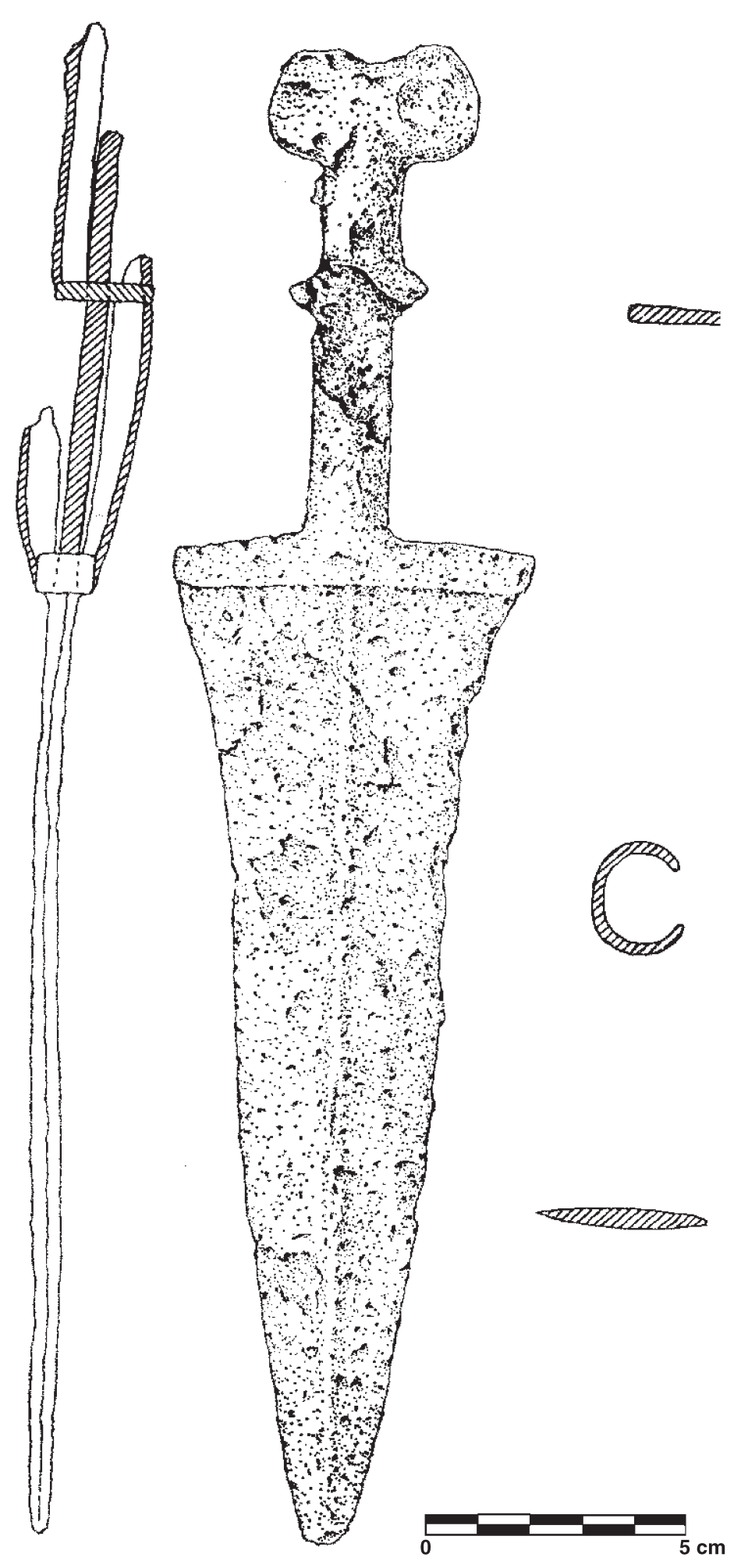

Figura 33. Daga de Pinilla de Toro (Zamora) (sg. Valls y Delibes). 


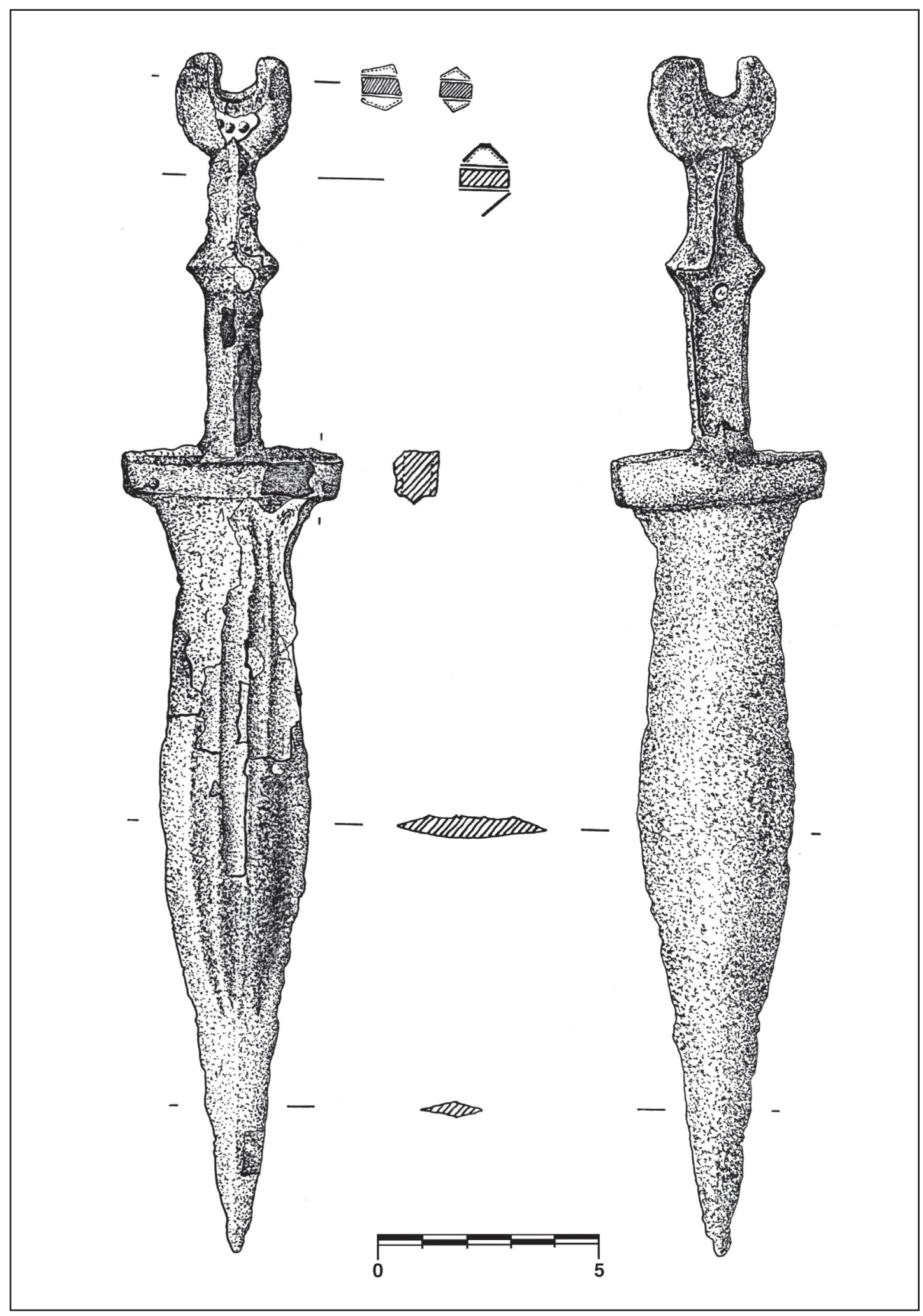

Figura 34. Daga de Bolmir (Cantabria). 


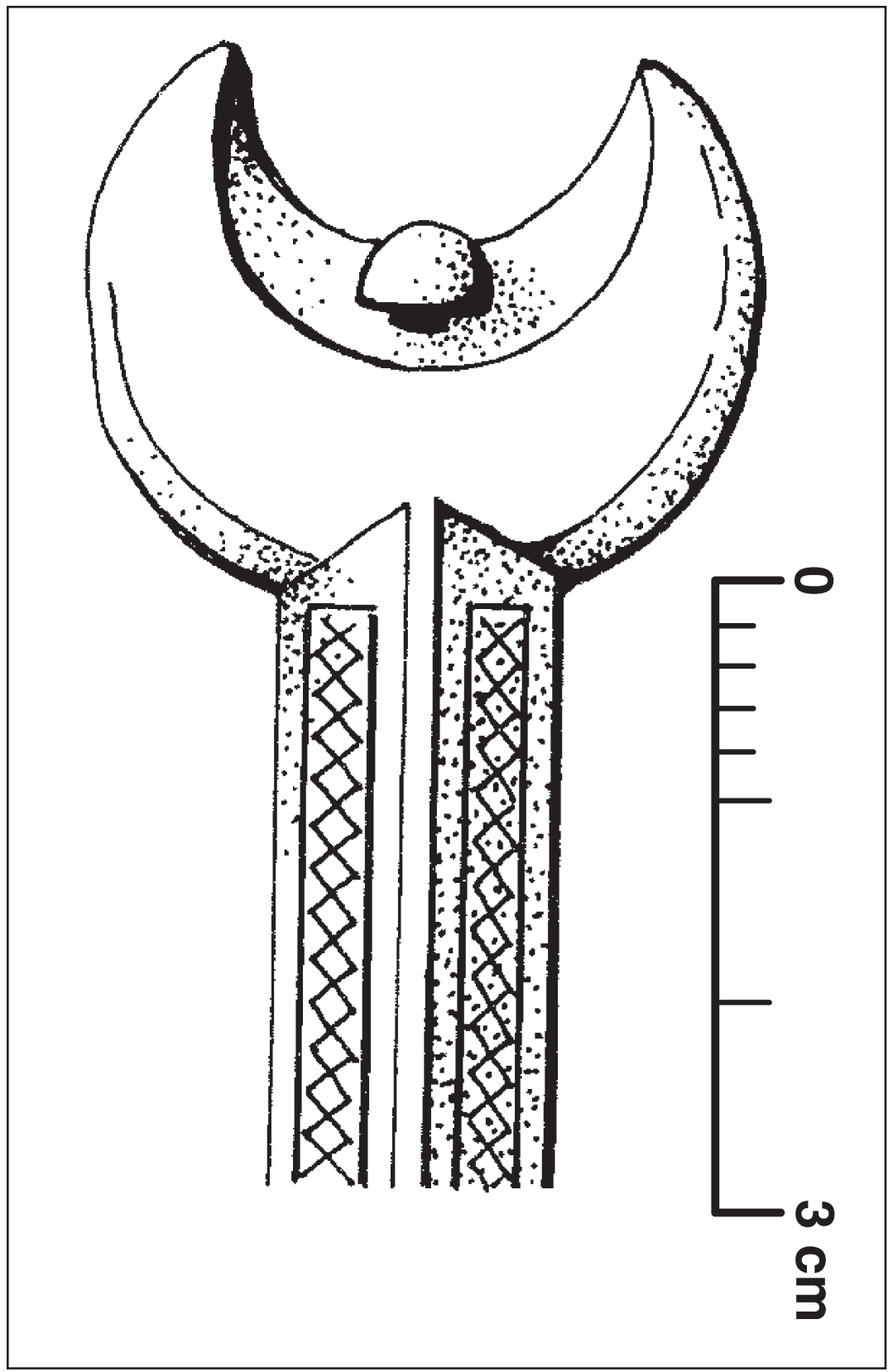

Figura 35. Empuñadura de una daga de procedencia desconocida (sg. Cabré y Morán). 


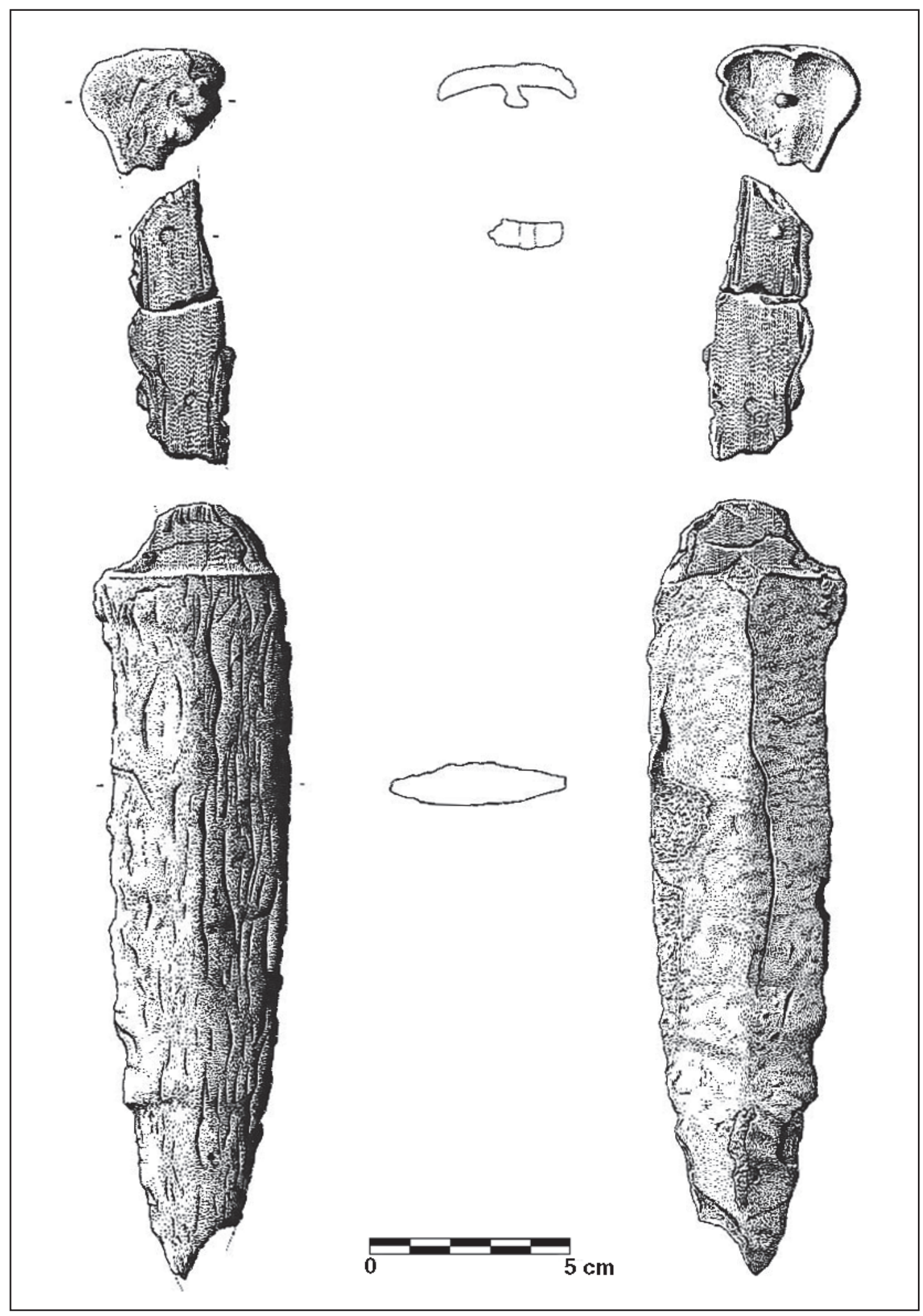

Figura 36. Daga de Santacara (Navarra) (sg. Mezquíriz). 


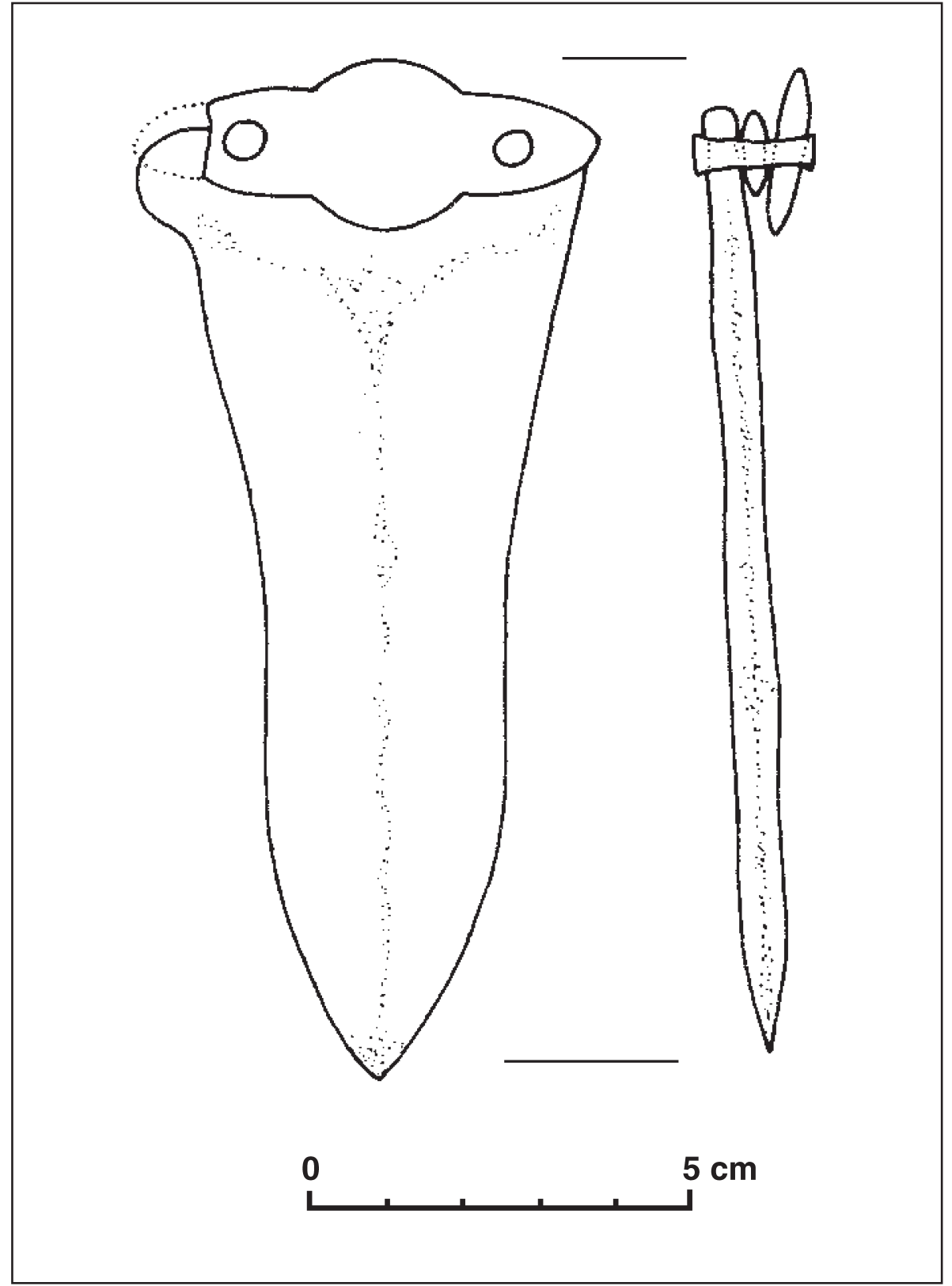

Figura 37. Hoja de daga de la villa de Tolegassos (Girona) (sg. Casas y Soler). 


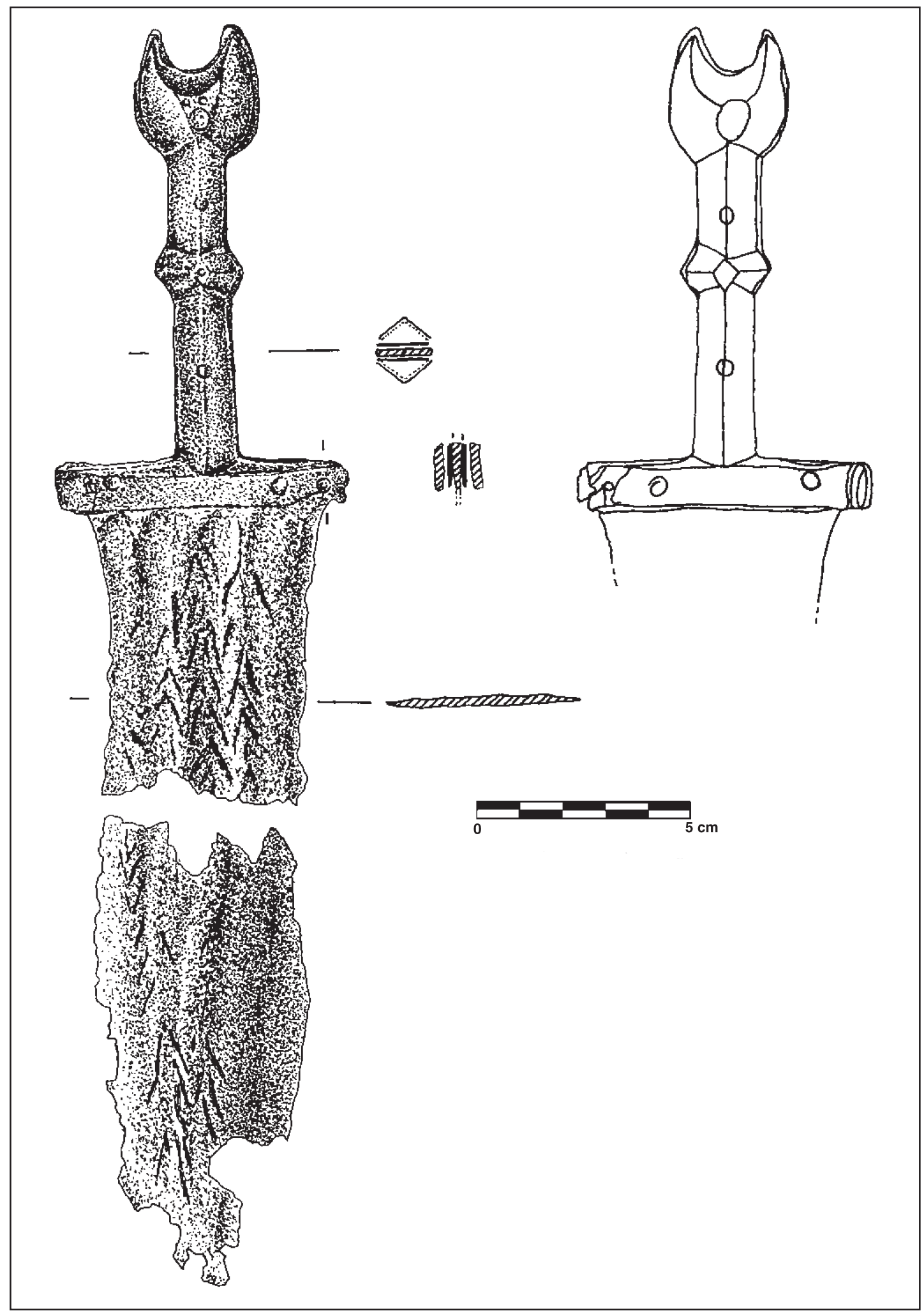

Figura 38. Daga de Sotopalacios (Burgos). 


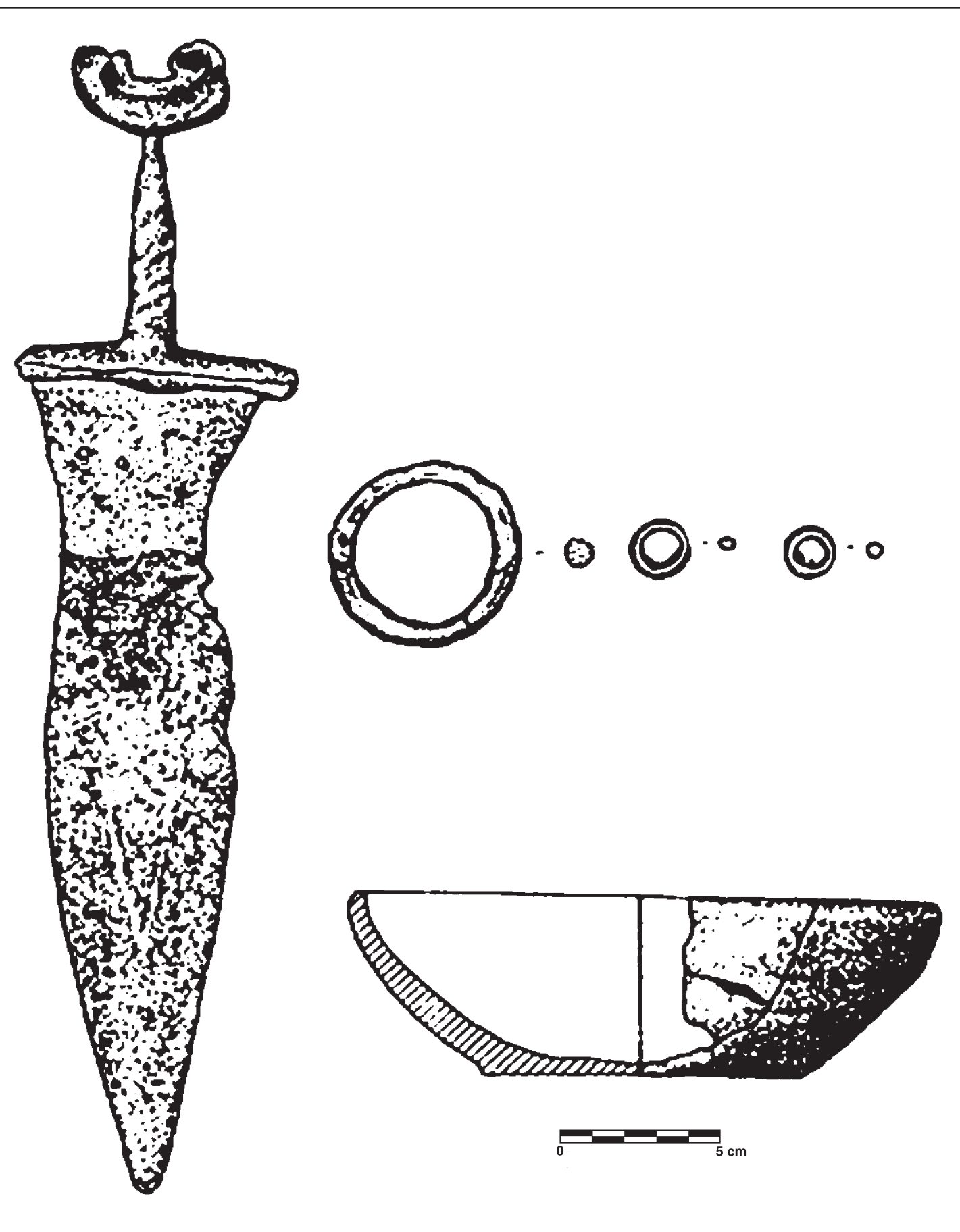

Figura 39. Ajuar visigodo de Sta. M. a de Brozas (Cáceres) (sg. González). 

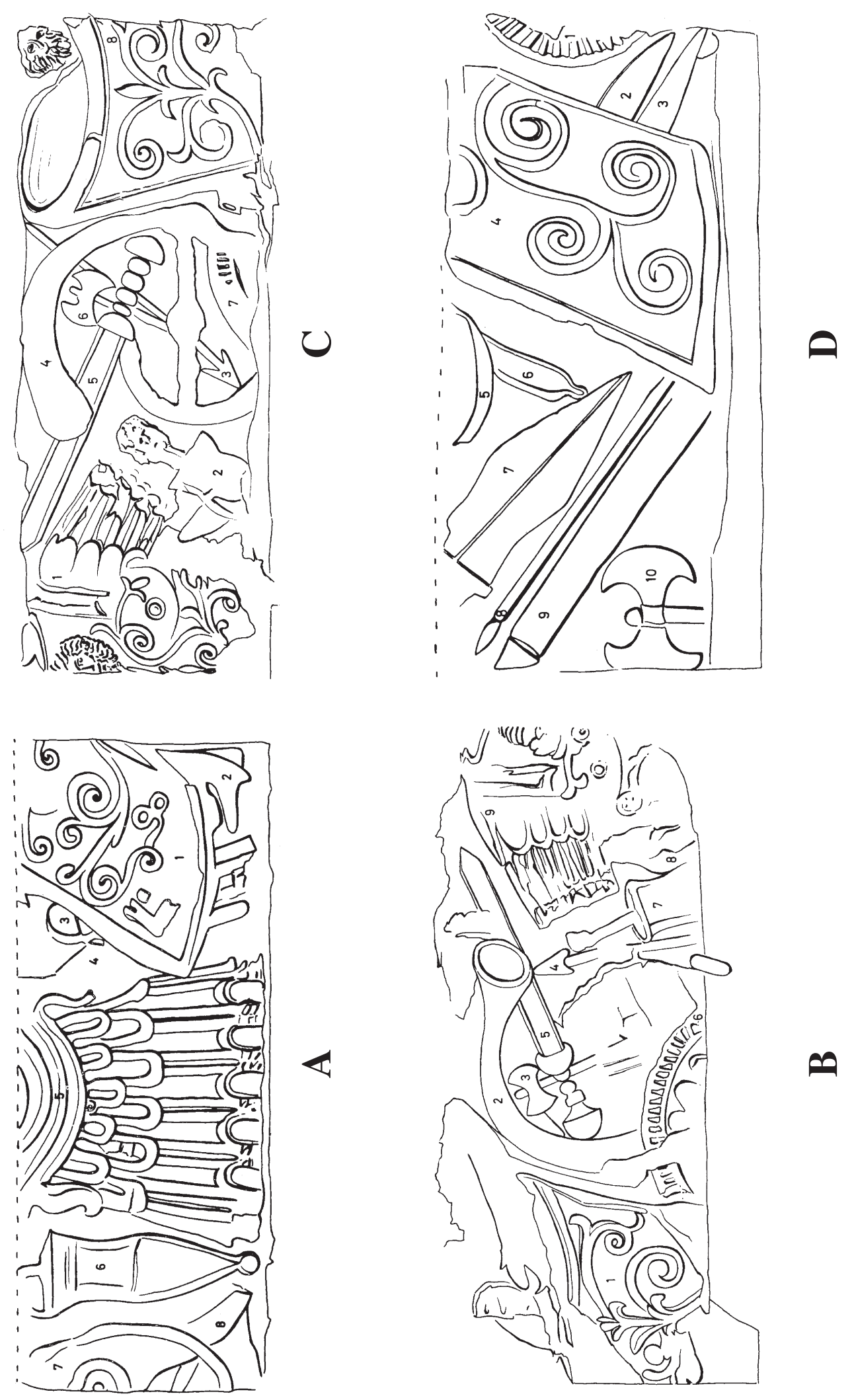

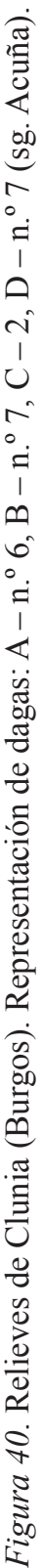



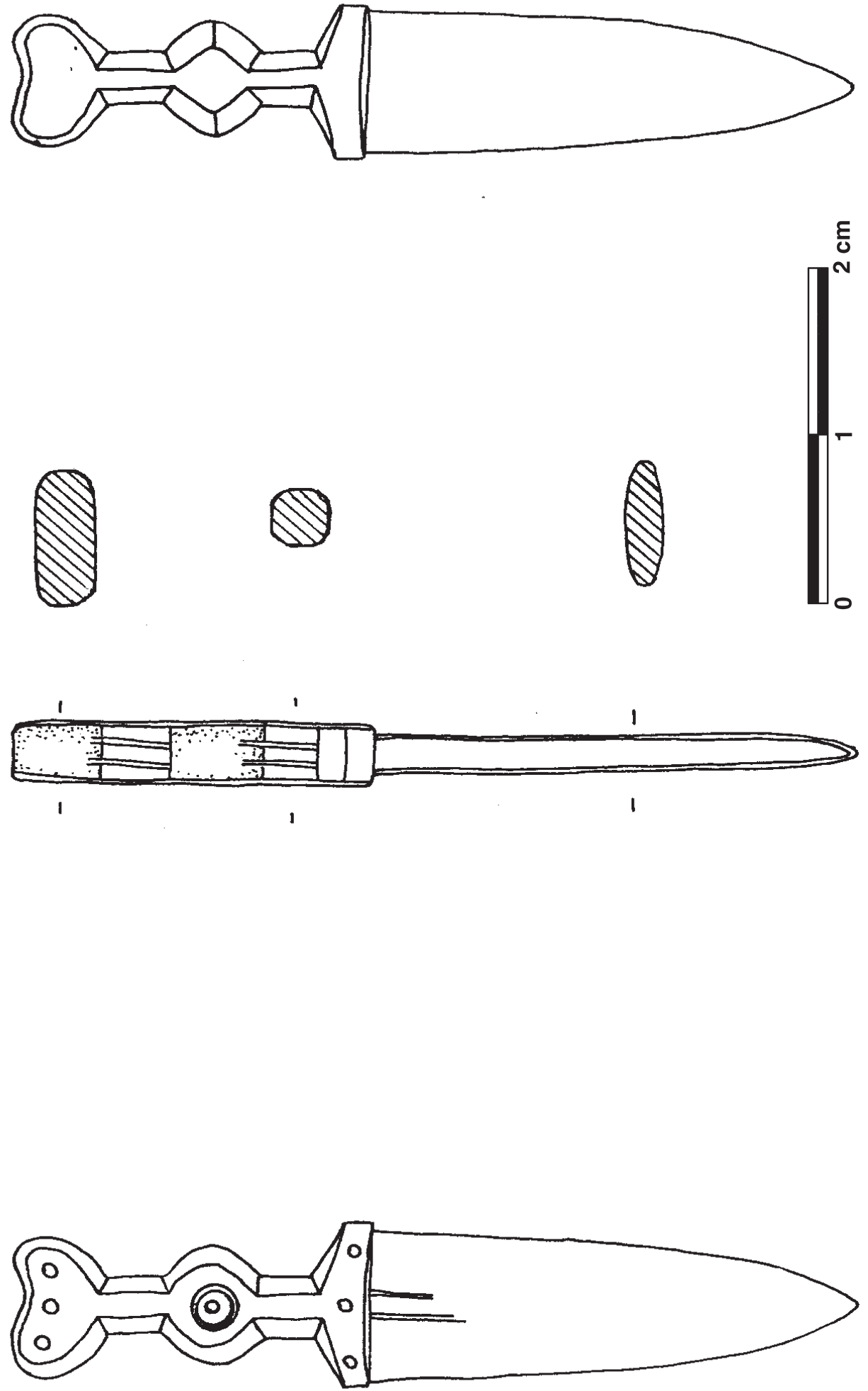

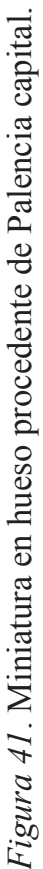




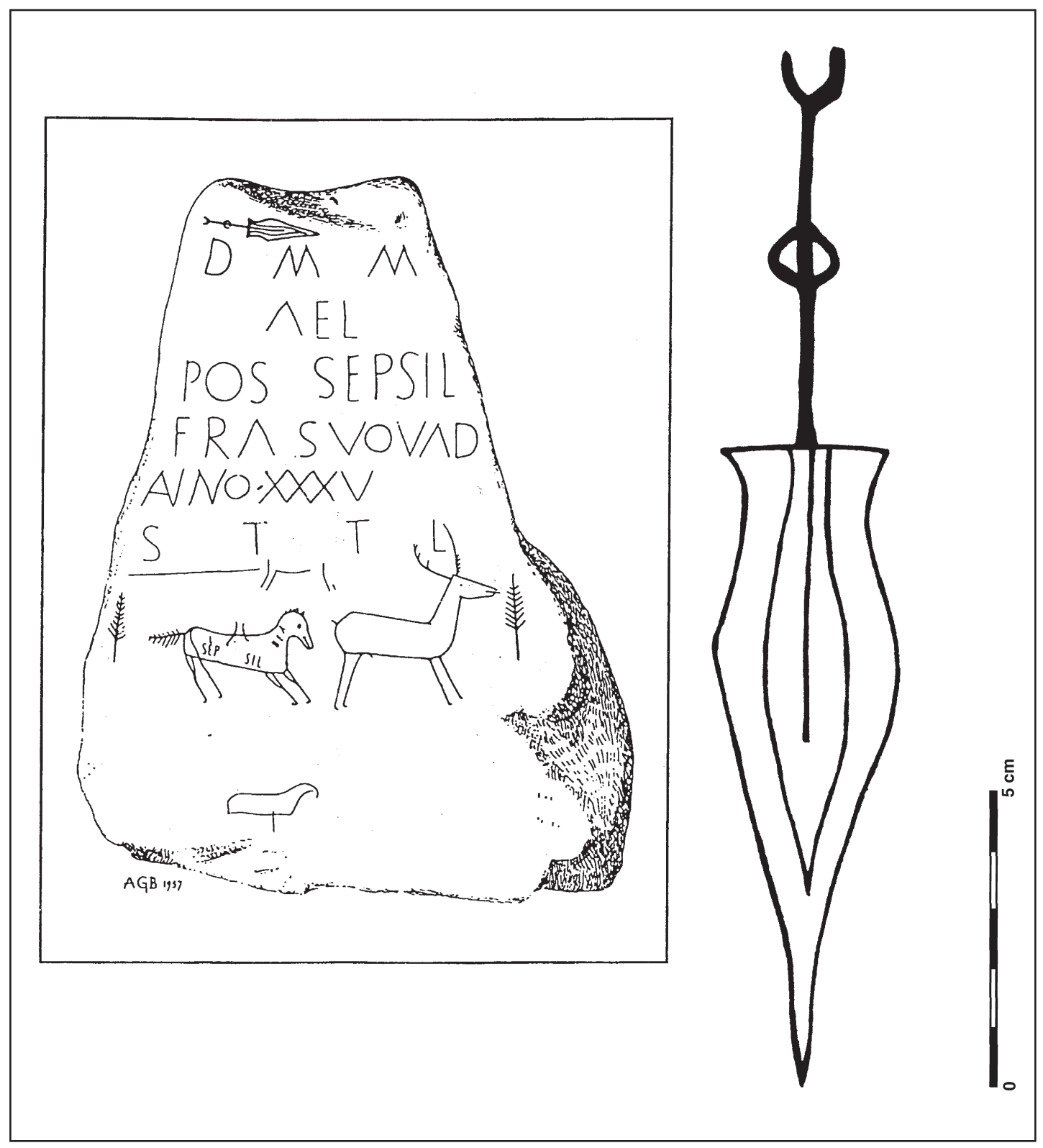

Figura 42. Estela de Beleño (Asturias) (sg. García y Bellido), y ampliación de la daga grabada (sg. Maya). 


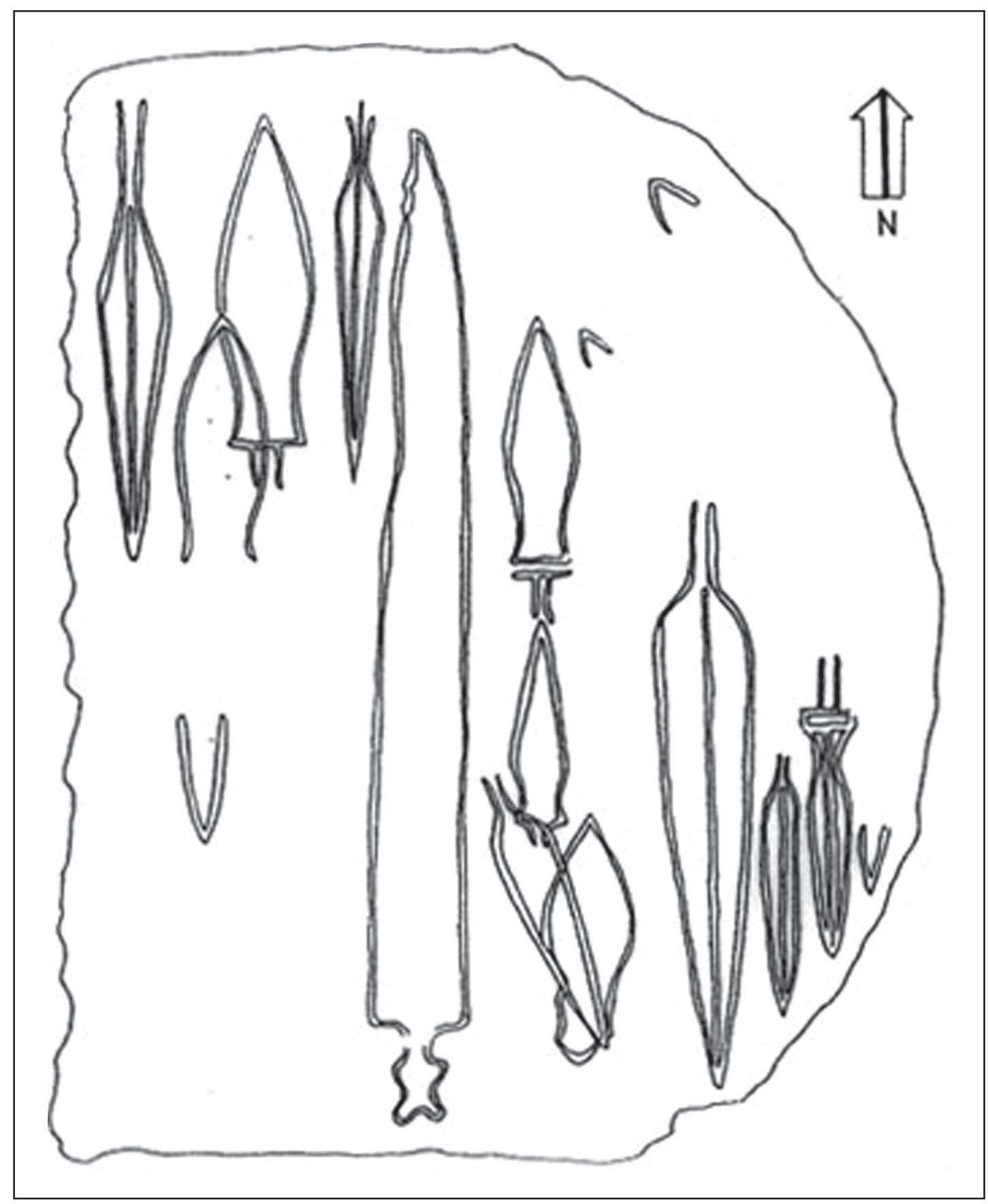

Figura 43. Representaciones de armas — dagas y espadas - en el Collado de las Chivas (Torrecilla de los Ángeles, Cáceres) (sg. González). 


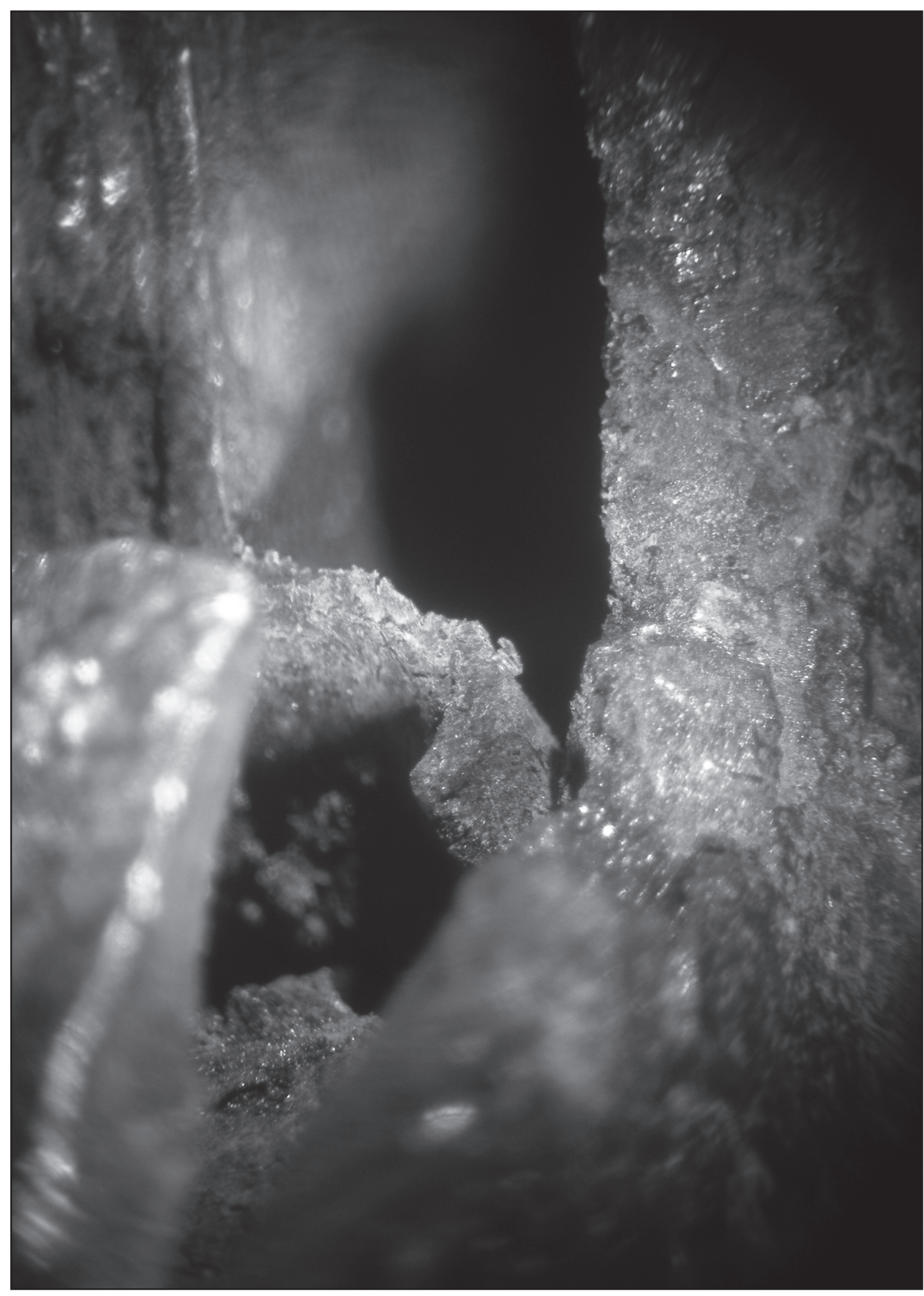

Lámina I. Microfotografía de la estructura que soporta el refuerzo del pomo en la daga dobleglobular de Palencia capital. 


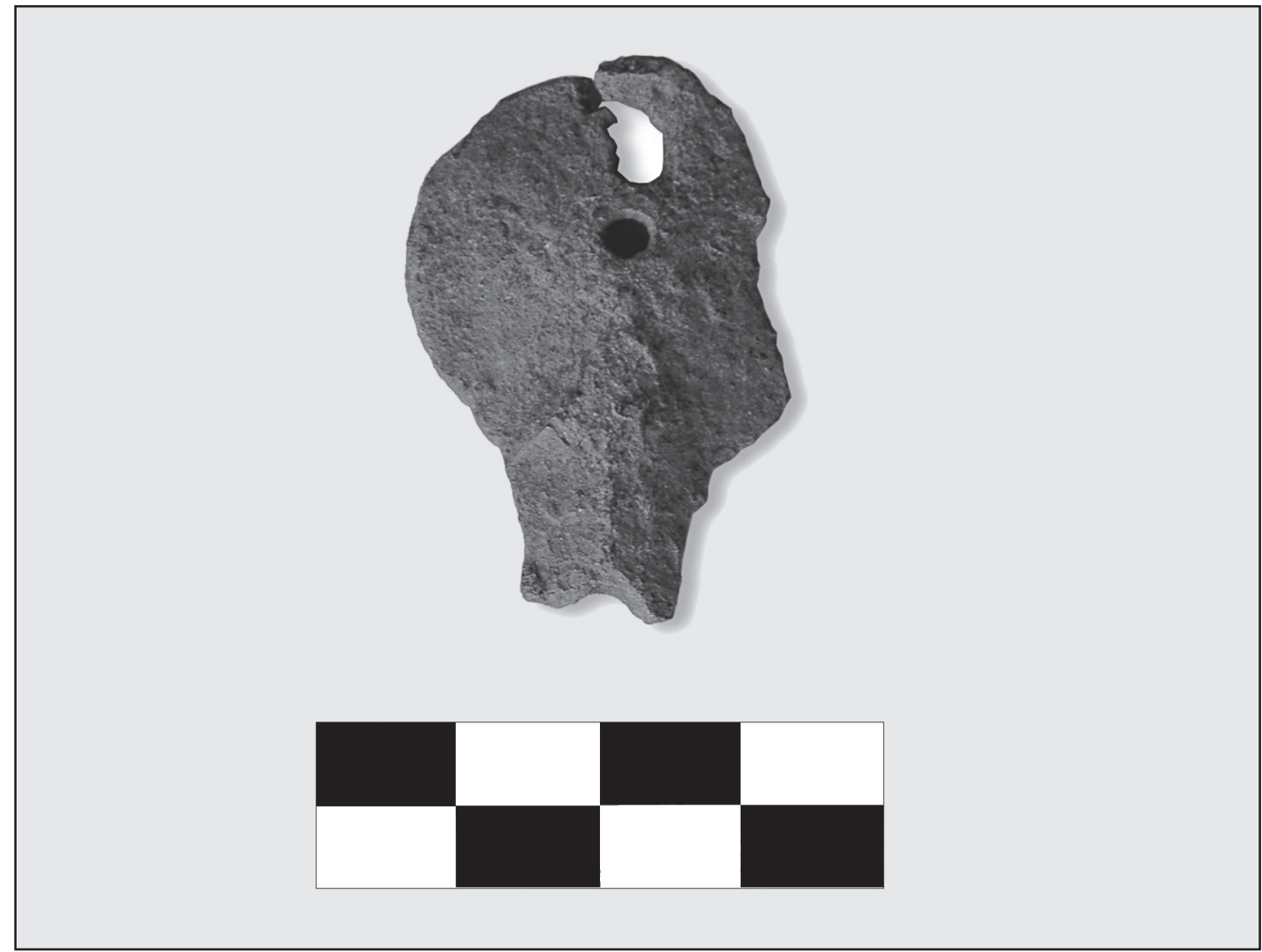

Lámina II. Fragmento de pomo. La Loma (Palencia) (Fot. E. Peralta). 


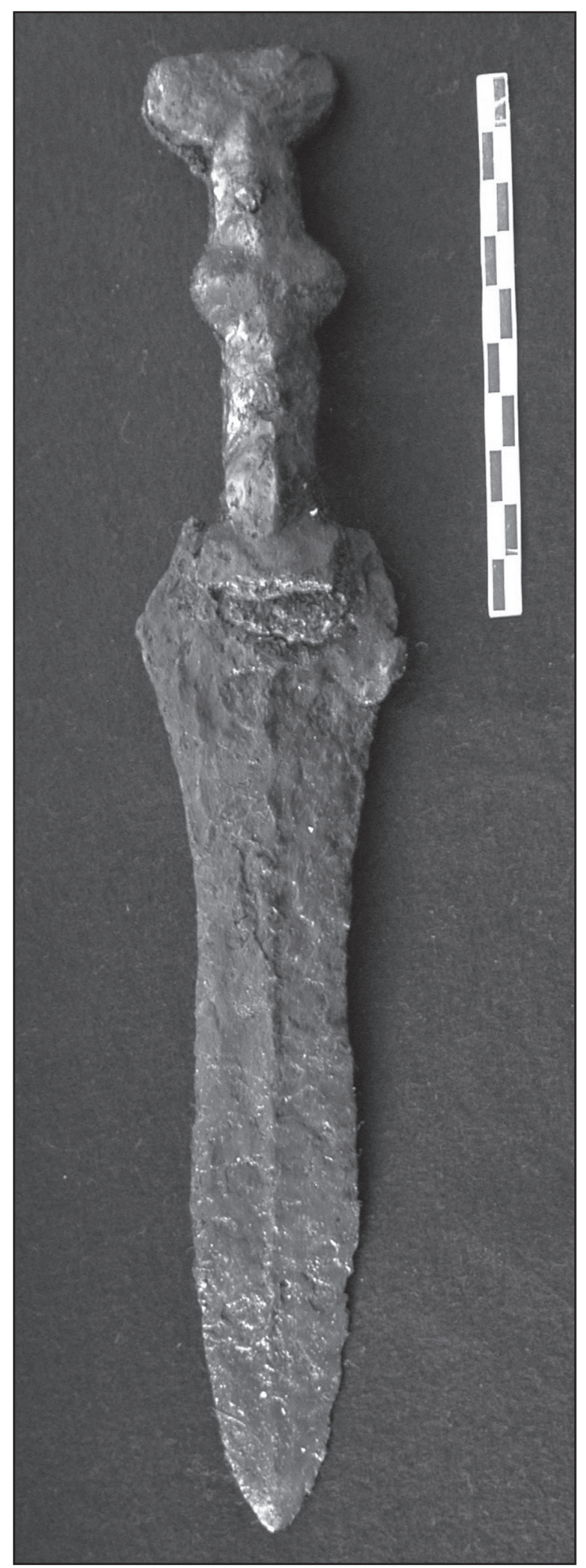

Lámina III. Daga de Monte Castrelo (Asturias) (Fot. Ángel Villa). 


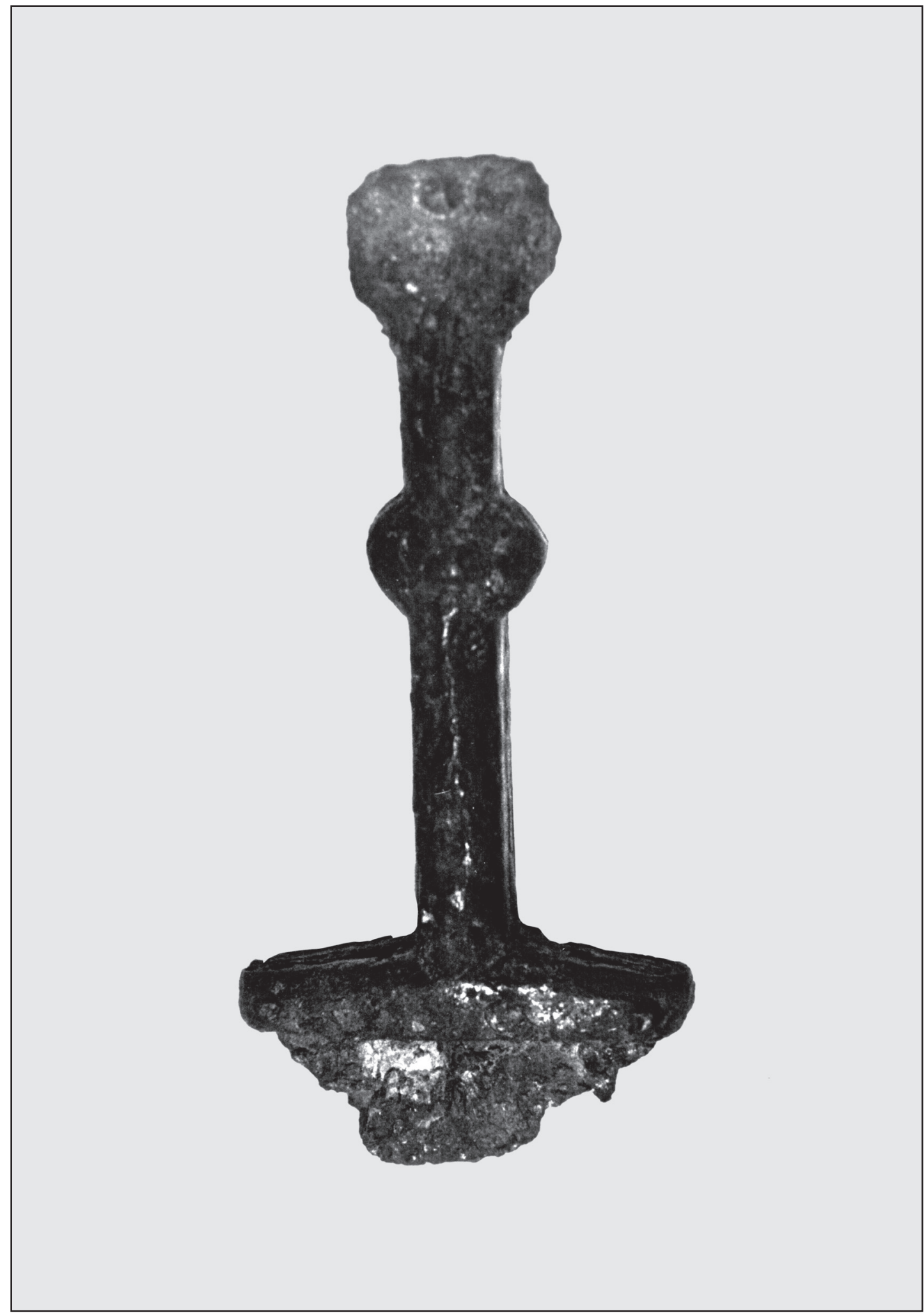

Lámina IV. Daga de La Armedilla (Valladolid), vista frontal (Fot. Museo de Valladolid). 


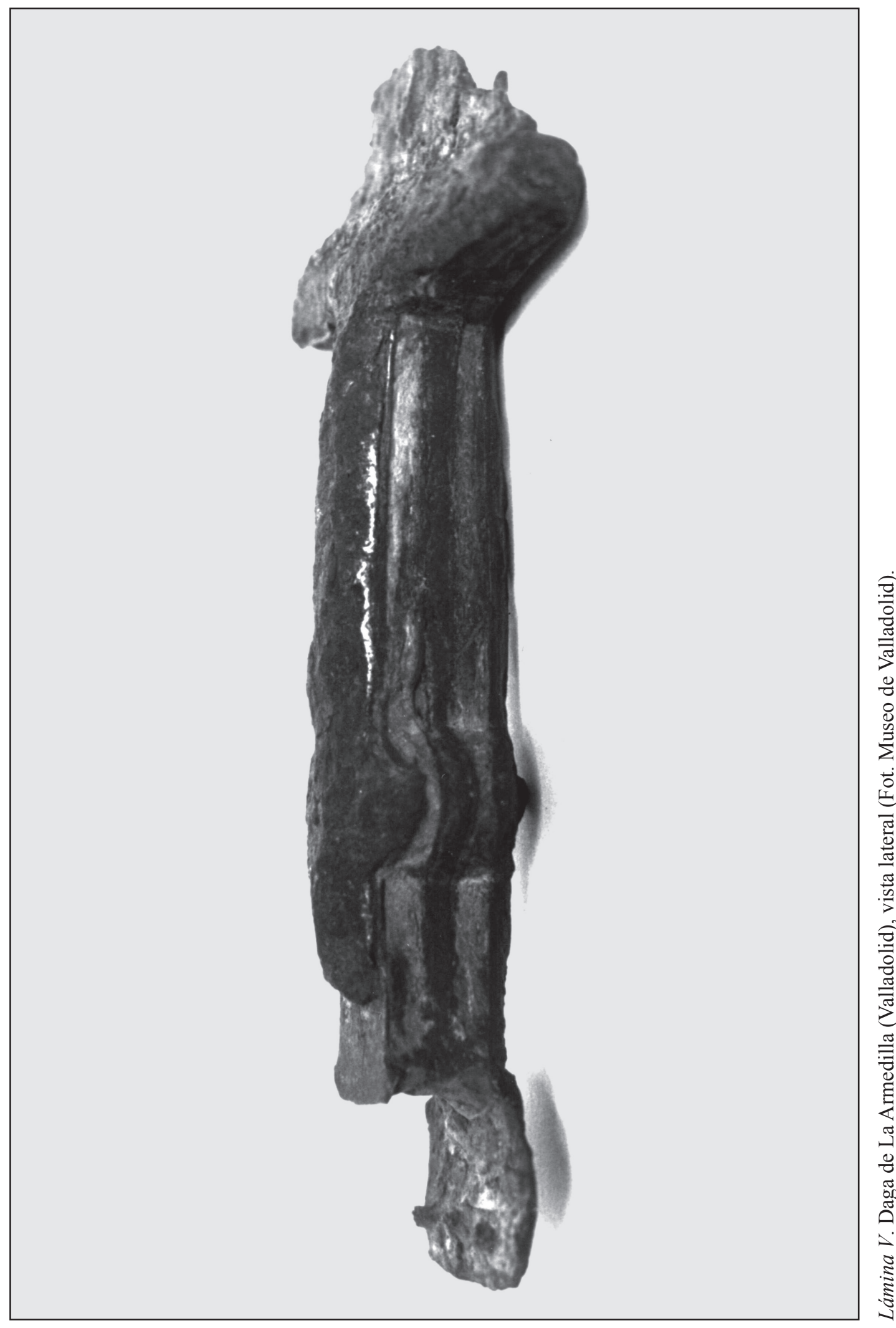

Gladius, XXVIII (2008), pp. 87-175. ISSN: 0436-029X 


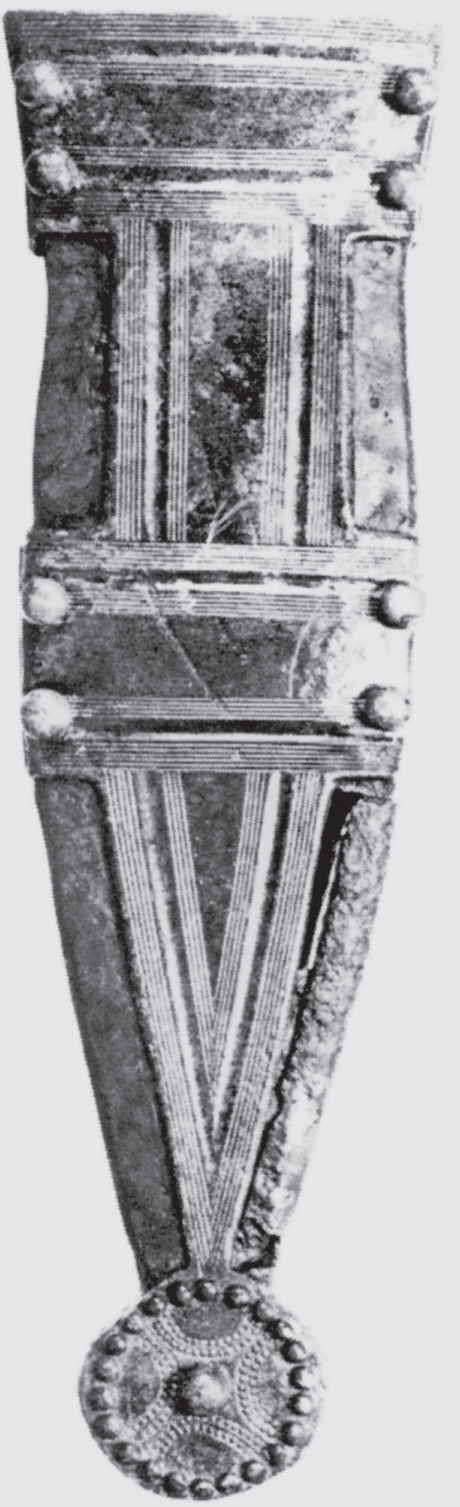

Lámina VI. Funda que figura como hallada en España pero sin procedencia conocida, que se custodia en el Museo de Mainz (Fot. J. Obmann). 


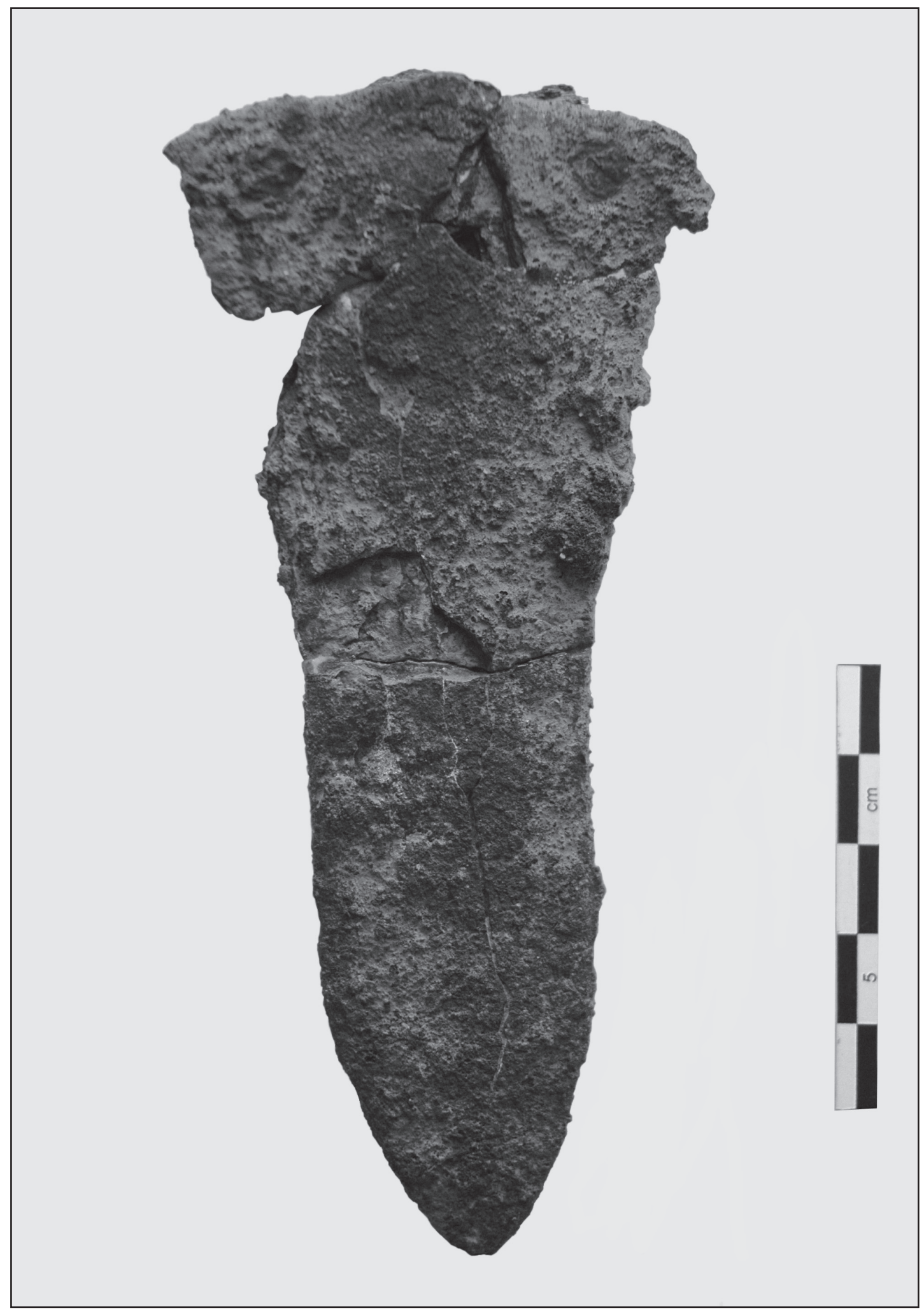

Lámina VII. Daga de la villa de Tolegassos (Girona) (Fot. Museo de Girona). 